\title{
Rehabilitation Strategies: The Case of Vancouver Downtown Eastside
}

Glory Wang

$=$

A thesis submitted to the Faculty of Graduate Studies and Research in partial fulfillment of the requirements for the degree of Master of Architecture

Thesis Supervisor:

Lucie Fontein

Carleton University

Ottawa, Ontario

December, 2004

(C) 2004, Glory Wang 
Library and

Archives Canada

Published Heritage

Branch

395 Wellington Street Ottawa ON K1A ON4 Canada
Bibliothèque et

Archives Canada

Direction du

Patrimoine de l'édition

395, rue Wellington

Ottawa ON K1A ON4

Canada
NOTICE:

The author has granted a nonexclusive license allowing Library and Archives Canada to reproduce, publish, archive, preserve, conserve, communicate to the public by telecommunication or on the Internet, loan, distribute and sell theses worldwide, for commercial or noncommercial purposes, in microform, paper, electronic and/or any other formats.

The author retains copyright ownership and moral rights in this thesis. Neither the thesis nor substantial extracts from it may be printed or otherwise reproduced without the author's permission.
AVIS:

L'auteur a accordé une licence non exclusive permettant à la Bibliothèque et Archives Canada de reproduire, publier, archiver, sauvegarder, conserver, transmettre au public par télécommunication ou par l'Internet, prêter, distribuer et vendre des thèses partout dans le monde, à des fins commerciales ou autres, sur support microforme, papier, électronique et/ou autres formats.

L'auteur conserve la propriété du droit d'auteur et des droits moraux qui protège cette thèse. $\mathrm{Ni}$ la thèse ni des extraits substantiels de celle-ci ne doivent être imprimés ou autrement reproduits sans son autorisation.
In compliance with the Canadian Privacy Act some supporting forms may have been removed from this thesis.

While these forms may be included in the document page count, their removal does not represent any loss of content from the thesis.

\section{Canadä}

Conformément à la loi canadienne sur la protection de la vie privée, quelques formulaires secondaires ont été enlevés de cette thèse.

Bien que ces formulaires aient inclus dans la pagination, il n'y aura aucun contenu manquant. 


\section{Abstract}

Models of treatment in drug addictions vary across cultures and disciplines. In most cases, the healing process in these treatment models is to rehabilitate a substance user by restoring his/her physical and psychological states to a level from which the individual is able to re-establish connections with society through a lifestyle change. This healing process does not impose a new identity onto the individual but reinstates his/her former positive qualities and allows these to transform over time and through new experiences. This thesis tests the appropriateness of forming an analogy between a person who suffers from a drug addiction and a neighbourhood that suffers from urban decay by following a drug rehabilitation treatment strategy as an architectural design methodology for the renewal of a deteriorating urban condition in Vancouver's Downtown Eastside. 


\section{Acknowledgements}

I would like to extend my appreciation to my supervisor, Prof. Lucie Fontein, for her tremendous support, guidance, and encouragement in exploring and developing my ideas.

A special thanks to Eric Archambault for his endless assistance and helpful advice in this project and Prof. Michael Jemtrud for theoretical clarification.

I would like to thank Mya McKay for her editorial assistance.

Thanks to all friends and fellow students at the University of Manitoba and Carleton University.

Lastly, a big thanks to my parents, my brothers, and sisters for their continuous support and their faith in me. 


\section{Table of Contents}

Abstract III

Acknowledgements IV

Table of Contents $\quad$ V

List of Illustrations _ VII

List of Appendices IX IX

Introduction 1

1.0 Context

1.1 History of Vancouver Downtown Eastside $\quad 7$

$\begin{array}{lr}1.2 \text { Research Precedents } & 14\end{array}$

$\begin{array}{ll}\text { 1.2.1 Gastown, Vancouver } & 14\end{array}$

$\begin{array}{lll}\text { 1.2.2 Yaletown, Vancouver } & 17\end{array}$

$\begin{array}{ll}\text { 1.2.3 King's Cross, London } & 19\end{array}$

$\begin{array}{ll}1.3 \text { Thesis Objectives } & 22\end{array}$

2.0 Rehabilitation Treatment

2.1 Rehabilitation treatment as a model for urban renewal 24

2.2 Rehabilitation Treatment Model: General Site Intervention 27

2.3 Rehabilitation Treatment Model: Proposed Program for the B.C.

Electric and Railway Company Building $\quad 40$

2.4 Rehabilitation treatment model: Building Intervention 44

2.4.1 Rock Climbing wall $\quad 45$

2.4.2 Circulation and Level Changes 47

2.4.3 Building Structure - Old and New 48

2.4.4 Interior and Exterior Courtyards 49 
Bibliography

Appendices 


\section{List of Illustrations}

Figure 1: Aerial photo of Hastings Street 2

Figure 2: 100 Block West Hastings Street 3

$\begin{array}{lll}\text { Figure 3: } & \text { Hastings Mill } 1865 & 7\end{array}$

Figure 4: Carnegie Library, now known as Carnegie Community Centre 8

Figure 5: 100 Block East Hastings Street in mid 1980's 9

Figure 6: A night view of 100 West Hastings in 1955

Figure 7: The Woodward's building after its closure in 1993

Figure 8: $\quad$ "Tent City" squatters' camp at the Woodward's building in November 200213

Figure 9: Tourists oriented restaurants and shops in Gastown 15

Figure 10: Heritage buildings are conserved and reused as offices and shops 16

Figure 11: Warehouses became vacant as local industries began to move away from the city

Figure 12: The extended loading bays of warehouses in Yaletown have become an architectural feature unique in the area

$\begin{array}{ll}\text { Figure 13: Loading bays are reused as sidewalk cafes } & 18\end{array}$

Figure 14: Old warehouses have become stylish lofts 18

Figure 15: New residential developments around the False Creek area 19

$\begin{array}{ll}\text { Figure 16: Site plan } & 20\end{array}$

Figure 17: A view of the residential block before restoration 20

Figure 18: A view of the residential block after restoration 21

Figure 19: Ramps are added for easy access 21

Figure 20: Additional architectural elements are added to improve building qualities 21

$\begin{array}{ll}\text { Figure 21: Hastings Street } & 28\end{array}$ 
Figure 22: Scaffolding options

Figure 23: Additional lightings in alleys

Figure 24: Homeless people protested around the Woodward's building, demanding for more affordable housing in the City

Figure 25: View from Carrall Street 32

Figure 26: Carnegie Community Centre 32

Figure 27: Locations of each "acupuncture" points 34

Figure 28: Schematic intervention proposed for Woodward's 35

Figure 29: Carnegie Community Centre community play 36

Figure 30: Proposed adjacent building to be renovated for additional living units 38

Figure 31: B.C. Electric and Railway Building proposed interventions 44

Figure 32: A view of atrium $\quad 46$

$\begin{array}{ll}\text { Figure 33: } & \text { Theatrical entrance }\end{array}$

Figure 34: $\quad$ Existing and proposed structures $\quad 49$

Figure 35: View of open space and atrium $\quad 50$

Figure 36: Interior courtyard 51

Figure 37: Exterior façade opens up to Carrall Street 52

Figure 38: People in atrium overlook the open space will provide a sense of safety to the users in the outdoor area 53

Figure 39: View from northeast 54 


\section{List of Appendices}

Appendix A: Drawings and Images

Appendix B: Economic Models for Urban Redevelopment

Appendix C: Street Front Land Use of 100 block West Hastings to 100 block East 80 Hastings from 1970's to 2001 


\section{Introduction}

A neighbourhood and its community have an interdependent relationship. The influences they have on each other determine their shared characters and qualities. In the case of Vancouver Downtown Eastside, parallel conditions are found between the deteriorating neighbourhood and the large population of substance users who reside in the area. Both have become isolated and marginalized from the rest of the city and society. However, neither a neighbourhood nor a person can function alone. Both need to establish connections to other neighbourhoods and people in order for a healthy condition to develop. A neighbourhood's vitality is dependent on the possibility of a range of interactions occurring simultaneously. As the connections begin to disappear, the health of the neighbourhood is jeopardized. When it is forced to continue in isolation, the neighbourhood experiences stresses. In the case of Vancouver Downtown Eastside, this has resulted in increased drug use by the population and a steady degradation of the urban fabric, to the point where many of the buildings are boarded up and are no longer safe to occupy. Both the population and the urban environment have become dysfunctional.

Much research supported by case study evidence has been done regarding the effectiveness of drug rehabilitation treatments for people suffering from drug addictions. It is my contention that as architects we can benefit from lessons learned in the field of addiction research by exploring the possibility of applying drug rehabilitation strategies to the dysfunctional urban fabric.

To begin, the identification of the possible reasons for frequent drug use of the population may also help to identify the areas where the neighbourhood is most stressed. Once these factors have been identified, an appropriate treatment strategy can be adopted for the rehabilitation of the city 
fabric. Through a process of analogy, these methods of drug rehabilitative treatments will establish the framework for the architectural interventions on the site, with the intention of restoring and transforming the area to a condition that allows dynamic and viable activities. In contrast to alternative solutions such as urban renewal or gentrification, this thesis proposes a form of urban rehabilitation that responds in ways that are more sensitive and less destructive to the needs of the local residents and the city.

The eight city blocks of Hastings Street between Cambie and Main Streets comprise a significant part of the Vancouver Downtown Eastside neighbourhood.

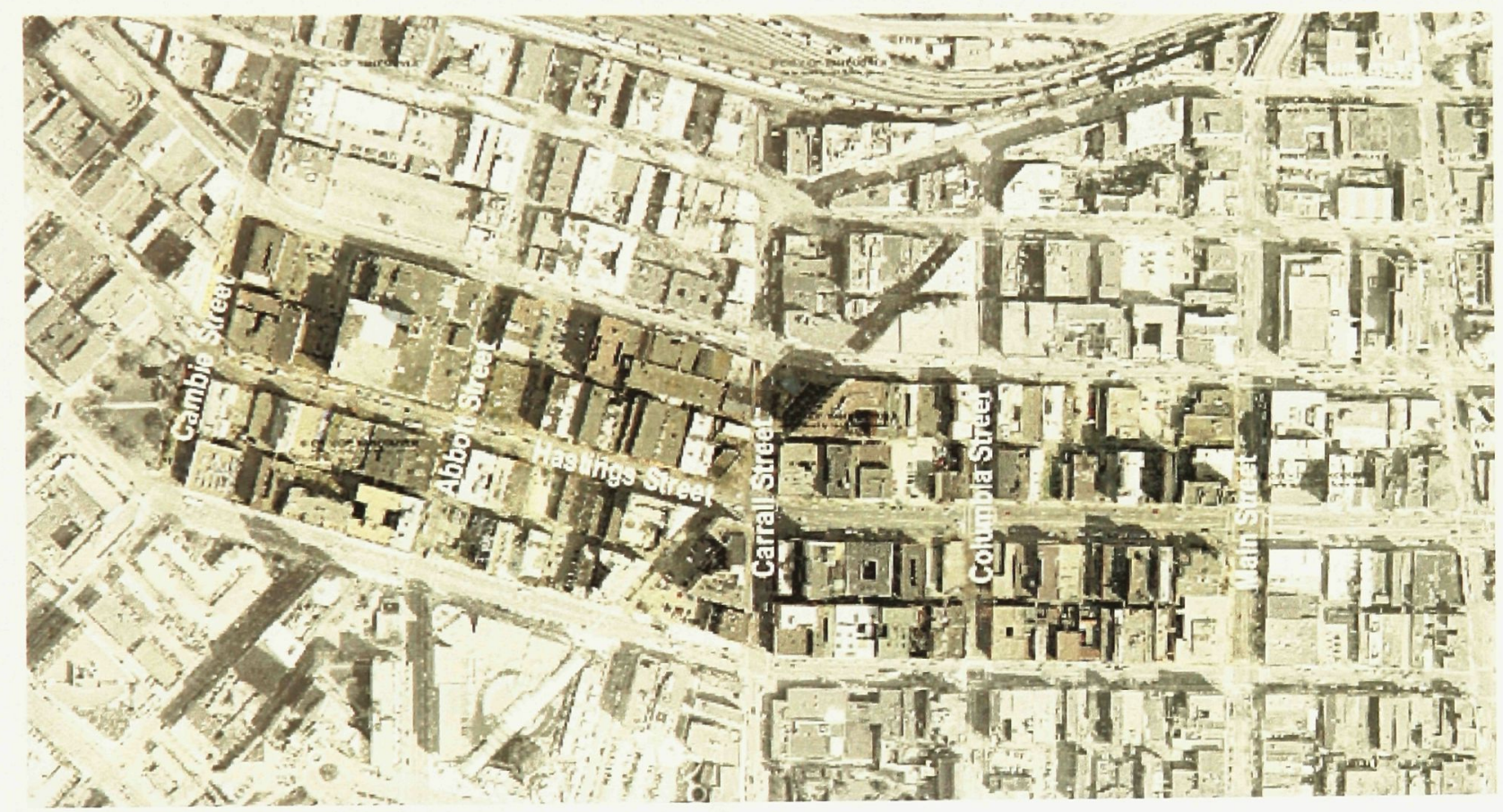

Figure 1. Aerial photo of Hastings Street.

City of Vancouver: VanMap Public Version, 2004.

This is one of the first urban developments in the city, however it is now mostly known for drug trafficking, the casual use of drugs and alcohol on streets, high rate of crime, vandalism, poverty, filth, and the deterioration of its building stock. Even with its long established history and significant contribution to the construction of Vancouver's identity in the early years, these blocks of Hastings 
Street have now become a black spot, an urban blight, that many Vancouverites avoid and pretend does not exist.

Numerous businesses that once existed in this neighbourhood have been driven out because of the current situation. Without a stable population in the area to maintain diverse activities, many building owners have lost interest in providing proper maintenance to the buildings. The vacant buildings are simply boarded up, and it is not

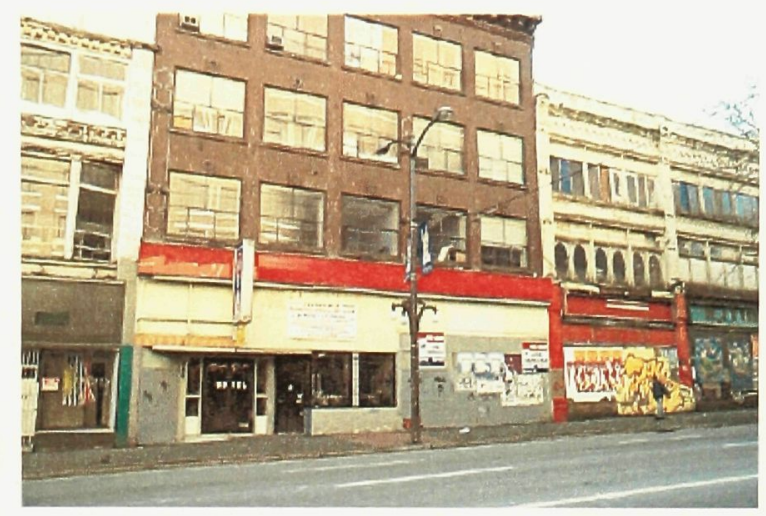

Figure 2. 100 Block West Hastings Street. Photo by Author, 2004. uncommon to find windows left broken and building facades that are covered with layers of graffiti.

Even with the advantages of being in close proximity to downtown Vancouver and tourist attractions such as Gastown and Chinatown, these blocks of Hastings Street remain completely isolated and have become disconnected and disengaged from the rest of the city; an area in limbo, waiting in the hope that someone will find a solution to its problems. On one hand, land developers are waiting for the City to "clean up" the area before any major redevelopments will occur. On the other hand, the City is intentionally keeping the substance users and the related problems of drug use within these blocks of Hastings Street, with the intention of reducing the impact on neighbouring communities (Shier 2002). The lack of concern from the City by allowing these drug related problems to flourish has created an atmosphere that suggests that casual use of drugs and associated crimes are permissible in the area. This passive aggressive environment significantly reduces the options for those who wish to recover from addiction and increases the possibility that others may become addicted. 
Clearly this is an area in crisis. To the author, it would appear that it needs the same kind of care that a person in crisis would need. Hence the proposal to test the appropriateness of loosely following a drug rehabilitation treatment strategy as an architectural design methodology for the renewal of this neighbourhood.

Rehabilitation is a healing method that can help an addicted person to have a better chance of recovery from his/her addiction. Through a series of treatments, an addicted individual can learn how to adapt to a new life situation by reducing the negative qualities that hinder his/her constructive development and by enhancing the positive qualities that promote the development of a healthy life.

The main objective of rehabilitative treatments was identified by Rinaldi et al. in Delphi Survey study in 1988 as an "application of planned procedures to identify and change patterns of behaviour that are maladaptive, destructive, or health injuring; or to restore appropriate levels of physical, psychological, or social functioning." rehabilitation, it is necessary to develop an appropriate treatment model that is both sensitive and effective for a substance user. Studies have shown that an identical treatment for addiction with the same procedures can have different results on different individuals (Kasl 1992). Not only is the type of addiction treatment proposed crucial to the success of one's recovery, but the individual's personality, social, economic, and environmental circumstances before and during treatment are also extremely influential to the success of recovery for the substance abuser. The planned procedures targeted to identify and change the negative patterns of addict's behaviour have to be

\footnotetext{
1 Gerald J. Connors, Dennis M. Donovan, and Carlo C. DiClemente. Substance Abuse Treatment and the Stages of Change: Selecting and Planning Interventions (New York: Guilford, 2001) 4.
} 
derived from a careful and complete survey of the addict's personal history: family background, past experiences of trauma, and the areas that are causing stresses on the person. A sensitive rehabilitation strategy then considers all aspects of life that are critical to the individual to determine the most appropriate method, hence, maximizing the chance of success. Identifying the areas of the addict's life that hinder a healthy development and those that encourage recovery from his / her addiction is the initial phase of treatment. It is necessary throughout the treatment process that these qualities are revisited periodically because these qualities may change over time as the treatment process continues to develop. The advantage of this strategy is that it allows the individual to recover his/her positive qualities from before the addiction. The rehabilitation process does not demand that the individual find a new character for him/herself through treatment but sustains and builds upon the essential nature of the person. It is a process that works with the person rather than on the person to make change.

Treatment modalities are effective processes not only for recovering from drug and alcohol addictions but also for promoting abstinence (Stimmel 2002). Types of treatments in rehabilitations vary across cultures and disciplines in order to respond to different needs. A general framework of treatments in rehabilitation can be developed into a specific treatment program that responds to the user's personal background, history and psychological state, identifying the areas where most stresses occur (Wallace 1992). Rehabilitation is a long-term process of treatment that integrates the drug abuser into society so that he/she can cope without drugs and can be restored to the best possible level of functioning. ${ }^{2}$

${ }^{2}$ Hamid Ghodse, Drugs and Addictive Behaviour: A Guide to Treatment, $3^{\text {rd }}$ ed. (Cambridge: Cambridge, 2002) 41. 
These are precisely the objectives that the author has for Vancouver's Downtown Eastside. The existing urban fabric is essentially sound and holds enormous potential for recovery. The challenge is to enable this recovery without imposing a complete personality transformation; the focus being on rehabilitation rather than gentrification. 


\subsection{Context}

\subsection{History of Vancouver Downtown Eastside}

The four blocks of Hastings Street between Cambie and Main Streets is a location of filth, corruption, disease, danger, and isolation, but it is also the same area where the city of Vancouver first developed. Vancouver Downtown Eastside was never intended to be developed for the

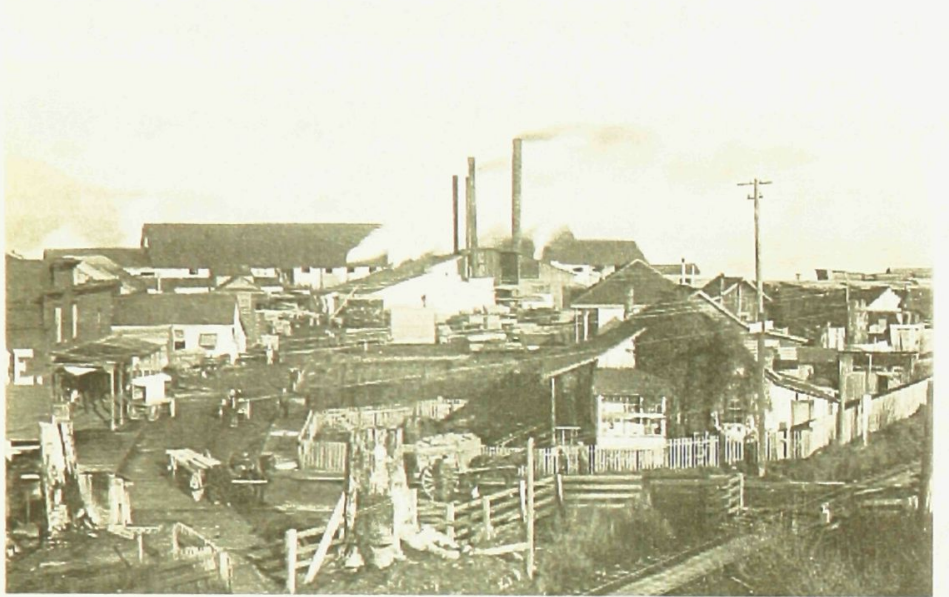

Figure 3. Hastings Mill 1865.

Carnegie Community Centre Website, 2004. affluent; it began as a neighbourhood of the working class. The natural physical qualities of this site formed an industrial waterfront where lumber was transported to the first large-scale sawmill, the Hastings Mill, in 1860's. Workers from all over the world with different backgrounds began to gather around the

area. Cultural, social, and economic activities were vibrant; it was a place where people lived, shopped and met with friends, and communities were formed naturally. In 1882, at least two local societies were established: the Hastings Literary Institute and the Ancient Order of United Workmen. ${ }^{3}$

Vancouver Downtown Eastside is where one of the earliest settlements in the city developed: "The shore of the site was sandy and accessible by canoe (central harbour). It became a camp site for the Musqueam and Squamish nations."4 This area was called Luck-luck-ee by the First Nations and known as Gastown or the Granville Townsite by other settlers (Footprints Community Art

\footnotetext{
${ }^{3}$ The Working Lives Collectives, Working Lives - Vancouver 1886-1986 (Vancouver: New Star, 1985) 10.

${ }^{4}$ Footprint Community Art Project, Old Vancouver Townsite Waking Tour - Powell Street, Strathcona, Chinatown, and Victory Square, ed. John Atkins (Vancouver, 2001) 6.
} 
Project 2001). (Gastown is the adjacent area to the Downtown Eastside which has been gentrified, now a tourist area with high end shops and restaurants.) In 1865, Stamp's Mill was constructed; later on it was sold to Admiral George Fowler Hastings and the mill has since been renamed to Hastings Mill (Davis 1976). Hastings Mill had a significant influence on this site because it was the largest-scale steamed-powered sawmilling operations on the west coast and was the focus of Vancouver's worker-community during the years $1866-1886$. Hastings Street was known as the "Skid Road" because a part of the street was used to skid the timber logs to the mill; however, the term Skid Road bore a much different meaning to the neighbourhood later on (Shier 2002).

The mill workers exemplified the ethnic and social mix that would be a hallmark of the future city, including "native Indians and half-breeds, Chinese immigrants, Scandinavian deserters from the sailing ships and busted refugees from the gold mines." ${ }^{5}$ There was a mix of permanent and transient populations related to the proximity to the port of Vancouver and terminus of the Canadian Pacific Railway. Slowly bars, hotels and bordellos sprang up near logging camps and mills to service their workers. ${ }^{6}$ The neighbourhood was a rough place so fist fights and stabbings were a regular occurrence; the violence did not die down until many of the workers began to marry and settle with their families. Since then, schools, social groups, and

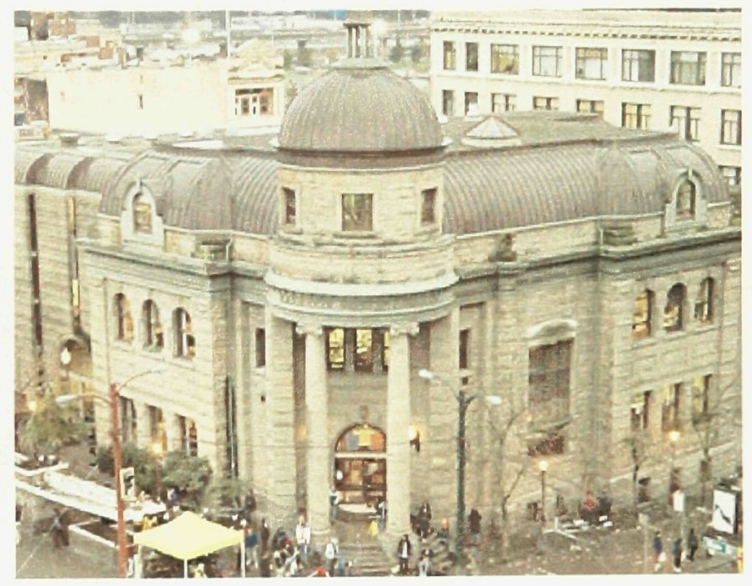

Figure 4. Carnegie Library, now known as Carnegie Community Centre.

City of Vancouver Community Services Website, 2004

\footnotetext{
5 The Working Lives Collectives, Working Lives - Vancouver 1886-1986 (Vancouver: New Star, 1985) 9. ${ }^{6}$ Reid Shier, ed., Stan Douglas: Every Building on 100 West Hastings (Vancouver: Contemporary Art Gallery, 2002) 30.
} 
communities began to establish themselves within the area (Footprint Community Art Project 2001). In 1901, with the donation by philanthropist Andrew Carnegie, the Carnegie Library was constructed at the southwest corner of Hastings and Westminster (now known as Main) Streets to serve the growing population of the neighbourhood. ${ }^{7}$

People spread along the False Creek area as the population began to increase. The Vancouver Electric Railway and Light Company, now known as B.C. Hydro, proposed to establish a transportation system within the city (Footprint Community Art Project 2001). In 1890, North America's first interurban electric streetcar line was opened. ${ }^{8}$ The success of the interurban line led to a further development of an electric railway, connecting the downtown core area to other new development areas such as New Westminster. The housing market was booming due to the development of this railway system (Footprint Community Project 2001). In 1911, the Vancouver Electric Railway and Light Company built its own company headquarters along with a depot at the southwest corner of Hastings and Carrall Streets. "By the time the B.C. Electric Railway Company built this depot, the company's interurban system was the largest in Canada, reaching sixty miles up the Fraser Valley to Chilliwack. Streetcars entered this building,

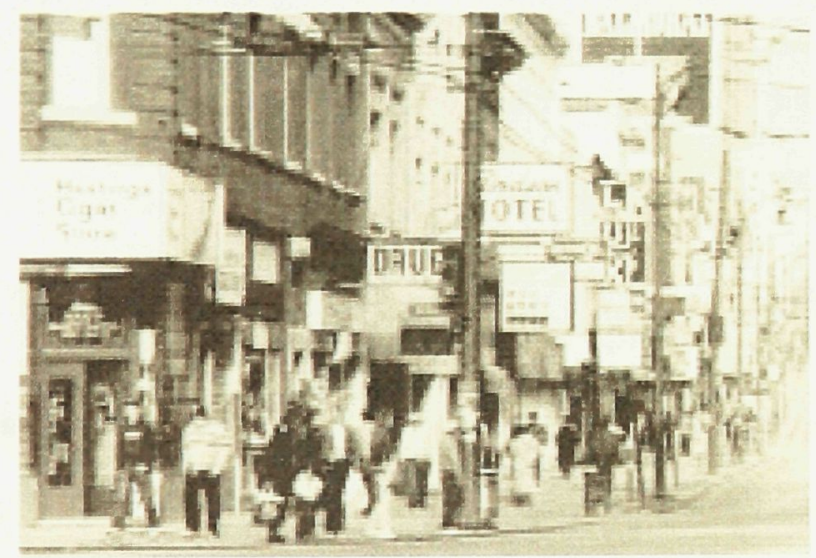

Figure 5. 100 Block East Hastings Street in mid 1980 's.

Carnegie Community Action Project, 2001: 4.

\footnotetext{
${ }^{7}$ Chuck Davis, Marilyn Sacks, and Daniel Wood, ed., The Vancouver Book (Vancouver: J.J. Douglas, 1976) 422.

${ }^{8}$ Footprint Community Art Project, Old Vancouver Townsite Walking Tour - Powell Street, Strathcona, Chinatown, and Victory Square, ed. John Atkins (Vancouver, 2001) 38.
} 
and the Canadian Pacific Railway spur line passed by its side."9 "This building was the terminus for many lines and from here throngs of people set off for work on foot. Hastings Street became a blur of motion as shoppers and commuters raced through daily life. The downtown area was alive with people, electric with neon signs and the Interurban building was the hub. Restaurants, nightclubs, theatres, coffee shops all did great trade in servicing the transit riders."10

By the end of World War II, "a slow decline began in the neighbourhood as its central role in

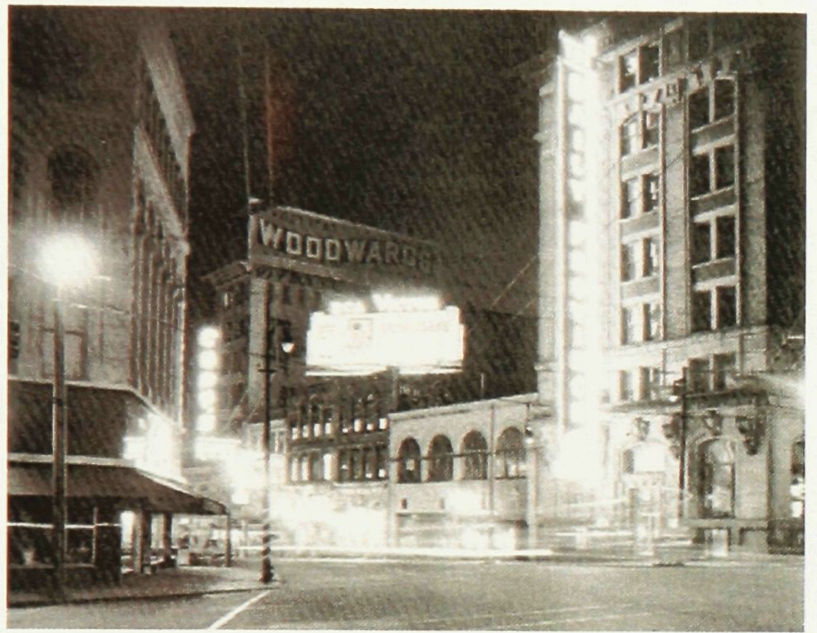

Figure 6. A night view of 100 West Hastings in 1955.

Shier, 2002: 43 .

warehousing, transportation, and a host of manufacturing operations that relied on or supported hinterland resource extraction began diminish. Also, the demand for migrant workers who lived in the neighbourhood around the downtown waterfront reduced because of a shift in the structure of the labour market. The situation worsened when the waterfront industries began to relocate to cheaper land far from the downtown core. ${ }^{11}$ At the same time, the demand for public transportation dramatically decreased because of the increasing use of the personal automobile. Also, buses were slowly replacing the trams of the interurban rails (Footprint Community Project). By 1955, every tram and

\footnotetext{
9 Harold D. Kalman, Exploring Vancouver 2: Ten Tours of the City and Its Buildings (Vancouver: University of British Columbia, 1978) 42.

${ }^{10}$ Footprint Community Project. p. Footprint Community Art Project, Old Vancouver Townsite Waking Tour - Powell Street, Strathcona, Chinatown, and Victory Square, ed. John Atkins (Vancouver, 2001) 39.

${ }^{11}$ Reid Shier, ed., Stan Douglas: Every Building on 100 West Hastings (Vancouver: Contemporary Art Gallery, 2002) 31.
} 
train line that travelled on Hastings Street was closed. ${ }^{12}$ In the same year, the B.C. Electric Rail Company headquarters was moved to Burrard Street, in the current downtown area (Kalman 1978). "The restructuring of the waterfront industrial area propelled the ebbing of the subculture that had formed around it. Increasingly, this neighbourhood was no longer identified through work, but rather in terms of the morally dubious nature of other activities that took place in the area such as gambling, and especially drinking." 13

Small businesses in the downtown started to decline. By the early 1990's, some businesses were still active along Hastings Street; however, since the closure of Woodward's Department Store, the

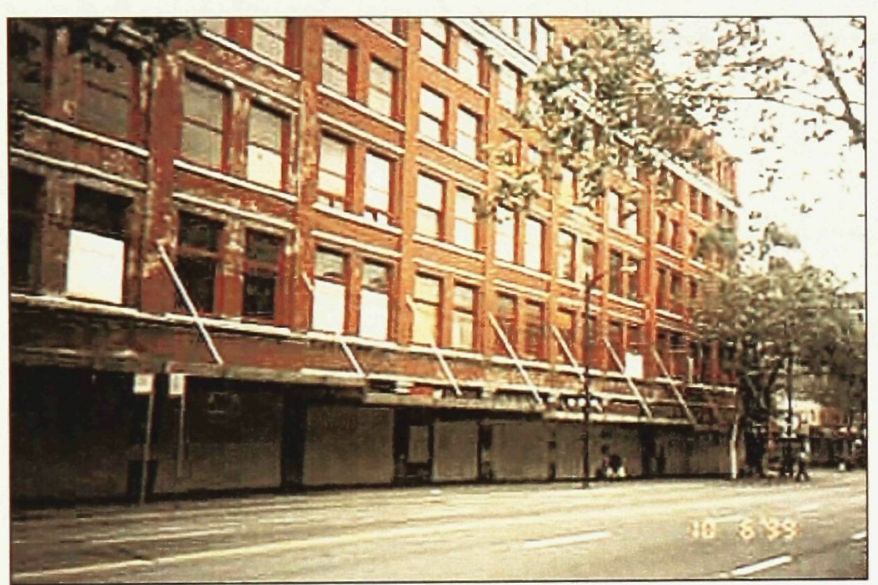

Figure 7. The Woodward's building after its closure in 1993.

City of Vancouver: DTES Revitalization Community History, 2003. area began to deteriorate at a rapid rate until the end of the decade (Shier 2002). "Its [Woodward's] closure ripped a hole in Hastings Street. The repercussive effects the closure had on the neighbourhood's dependent shops and businesses, and a once-thriving commercial area, were immediately felt. Into this retail vacuum a drug economy took over. Not coincidentally,

this was also when crack entered Vancouver's street culture. Ventures like the restaurants and galleries which rented space on the street are gone."14

\footnotetext{
12 Footprint Community Project. p. Footprint Community Art Project, Old Vancouver Townsite Waking Tour - Powell Street, Strathcona, Chinatown, and Victory Square, ed. John Atkins (Vancouver, 2001) 39.

${ }_{13}$ Reid Shier, ed., Stan Douglas: Every Building on 100 West Hastings (Vancouver: Contemporary Art Gallery, 2002) 33.

14 Reid Shier, ed., Stan Douglas: Every Building on 100 West Hastings (Vancouver: Contemporary Art Gallery, 2002) $11-12$.
} 
The use of drugs is now a common association with this area. Used needles are often found on these blocks since injection drugs such as cocaine and heroine became popular and "affordable" to many users (Alexander 2001). Activities of drug trafficking and consumption are openly found in the back alleys and on the streets at any time of the day or night. Break-in's, shoplifting, and vandalism are common crimes along these blocks, crimes which are confirmed by the existence of numerous pawn shops (Shier 2002).

The 1996 Census indicates that the average income of the people in this neighbourhood is onethird that of the average Vancouverite. Many living in this area are those who cannot afford to live in other parts of the city. The unwillingness of building owners to maintain their buildings has led to the sacrifice of adequate living conditions for low-income individuals in this area. For these people, the transformed motel-like single room units are their only choice. Many of these units do not meet the standards set by the current building code; their conditions being described as unimaginably awful (Shier 2002).

To add to the real problems of the area is the biased reporting of the various media with respect to the Vancouver Eastside Downtown. The local media and authorities associate the consistent drug use and the frequent occurrence of crime with low-income, mentally-handicapped and homeless individuals and by focusing on the addict population have portrayed a very negative image of this area (Shier 2002). Even with the advantages of being in close proximity to downtown Vancouver and tourist attractions such as Gastown and Chinatown, these blocks of Hastings Street remain completely isolated and have become "the worst block in Vancouver"15 that people avoid at all cost.

${ }^{15}$ Reid Shier, ed., Stan Douglas: Every Building on 100 West Hastings (Vancouver: Contemporary Art Gallery, 2002) 18. 
In the face of such urban deterioration, and for fear that it might spread to adjacent neighbourhoods, the City of Vancouverhas adopted a strategy of containment. Keeping drug use and trades within the few blocks of Hastings Street could prevent the withdrawal of vibrant activities in the surrounding gentrified areas of Gastown and False Creek. "Cars troll the street, and cruise past police officers who have long since given up hope of stopping trade. For the police, success is measured in how

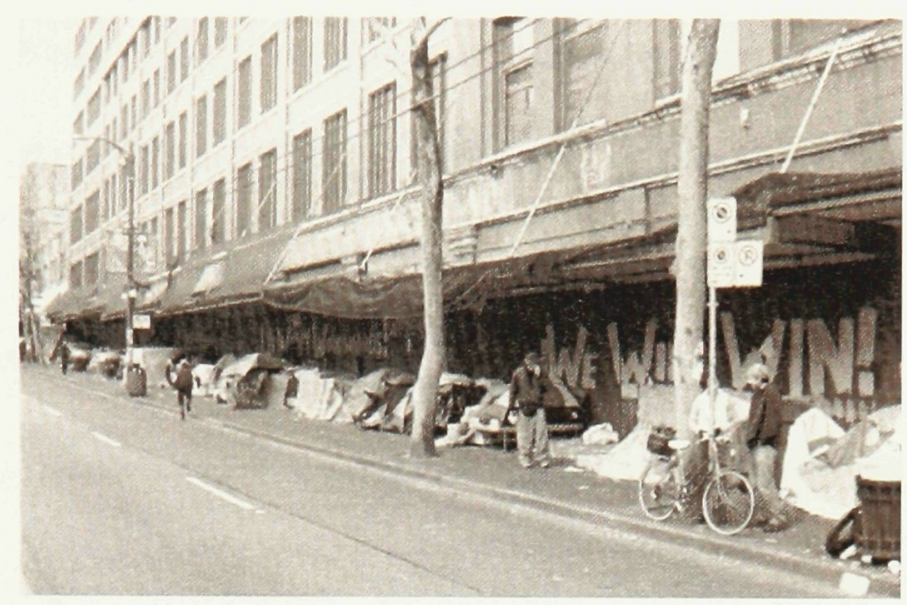

Figure 8. "Tent City" squatters' camp at the Woodward's building in November 2002.

Shier, 2002: 85. well the drugs are kept corralled on Hastings between Cambie and Main, where they can expect the fewest complaints."16 The closure of Woodward's Department Store in 1993 has ultimately changed the entire atmosphere of the neighbourhood. The last symbolic structure of the neighbourhood's golden times has lost its battle to reality. Since then, the Vancouver Downtown Eastside has moved deeper into the environment of drug use and addiction, allowing the neighbourhood to become further disconnected and isolated from the rest of the city.

${ }^{16}$ Reid Shier, ed., Stan Douglas: Every Building on 100 West Hastings (Vancouver: Contemporary Art Gallery, 2002) 14. 


\subsection{Precedents of Urban Renewal: Gastown and Yaletown of Vancouver; King's}

Cross, London.

Neighbourhoods and cities have life cycles. A neighbourhood's life span is determined by different aspects such as demographic changes in the population, social standard changes, economic changes, and the changes in the quality of buildings. A neighbourhood must continually adapt to the changes in these aspects; if not the neighbourhood is at risk of becoming obsolete or rundown. Urban renewal is therefore an unavoidable phase of city development because cities naturally evolve. With the intention of adapting a neighbourhood to the new conditions, urban renewal strategies are often too focused on accommodating the needs in specific areas. In many cases, economic benefits are the main drivers behind these projects.

A number of urban renewal projects have been studied as precedents. Gastown and Yaletown of Vancouver are selected for their similarities to the site and social contexts before their renewal when compared to the current conditions of Hastings Street. In both cases, the renewal strategy adopted was mainly determined by the economic benefits. The case study of King's Cross, London demonstrates a more sensitive strategy to the new conditions of the local residents; however, this project did not respond to the issues which arose due to drug uses in the neighbourhood.

\subsubsection{Urban Renewal Case Study One: Gastown, Vancouver}

Immediately adjacent to the 100 block of West Hastings is the district known as Gastown. Gastown is one of the oldest areas developed in the city; settlements in this area date back to 1867, before the City of Vancouver was formed (Gastown Business Improvement Society 2004). 
Before Gastown was formally included as part of the City of Vancouver in 1886, the area was known as Granville (Davis 1976). Being the first waterfront industrial site developed in Vancouver, the area has an established history in social, community, economic and building development. Gastown was the city center where the majority of businesses and industrial activities took place. These energetic activities were reflected through the buildings in the area, built mostly between 1886 and 1914, after the Great Fire in 1886 (Storyeum Website 2004). Since the 1920's, due to a number of various reasons such as global economic downturn, a shift in the location of downtown Vancouver, a switch in Vancouver's primary industry development in the urban area, and the World Wars, Gastown began experiencing similar conditions to those of Hastings Street, until a series of new redevelopments took place in the 1970's.

Before Gastown was identified as one of the premier heritage districts by the City of Vancouver in 1971, the area experienced deteriorating conditions where the buildings lacked the proper maintenance and care. Once the provincial government declared Gastown as a historical site,

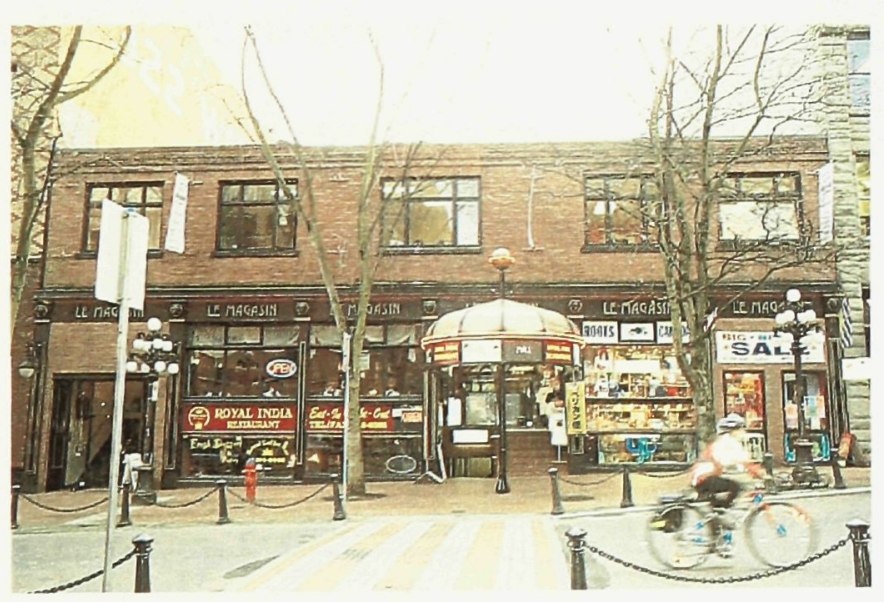

Figure 9. Tourists oriented restaurants and shops in Gastown.

Photo by author, 2004. protecting the heritage buildings from being demolished, local authorities began working with local businesses to promote economic revitalization (Storyeum Website 2004). New businesses were introduced into the area, transforming the heritage buildings into restaurants, offices, art galleries, shops, and studios. The transformation of Gastown is dramatically changed from a rundown area to a tourist attraction. This is the new atmosphere of 
the area that is being promoted: "Today: Gastown is a refreshing mix of old and new, downhome and upscale, a place for tourists, Vancouver residents and office workers alike. Various shops have the streets buzzing during the day. A host of restaurants and nightspots keeps the area humming into the wee hours. And, more and more, Gastown is becoming home to permanent residents...just like in the old days."17

There is no doubt that the gentrification strategies adopted in the case of Gastown have introduced new businesses and different social classes to this area. However, this strategy drove out the lower working class, the local residents, who used to reside in this district. The changes of Gastown to an upscale, tourist-oriented district created a neighbourhood that is unfamiliar to those who dwelt here for decades. They became alienated and displaced by the new changes. Their needs were neglected and their sense of belonging to this community vanished. They had no

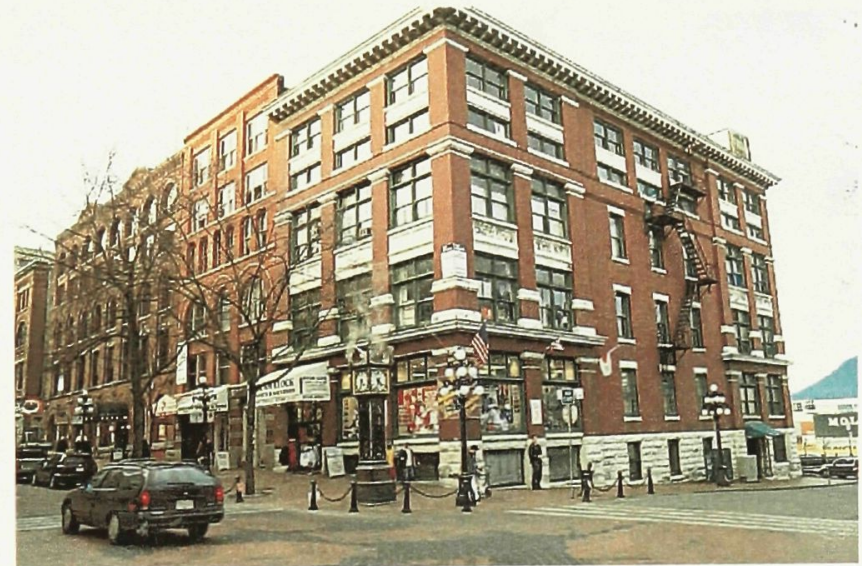

Figure 10. Heritage buildings are conserved and reused as offices and shops.

Photo by author, 2004. choice but to move to more affordable neighbourhoods, replaced by an upper middle class population that could afford the trendy old lofts now commonly found in the neighbourhood.

\footnotetext{
17 Gastown Business Improvement Society, "Gastown History," Gastown Website, 2004 $<$ <ttp://www.gastown.org/history/index.html>.
} 


\subsubsection{Urban Renewal Case Study Two: Yaletown, Vancouver}

Yaletown is another older district in Vancouver that was developed to accommodate the needs of

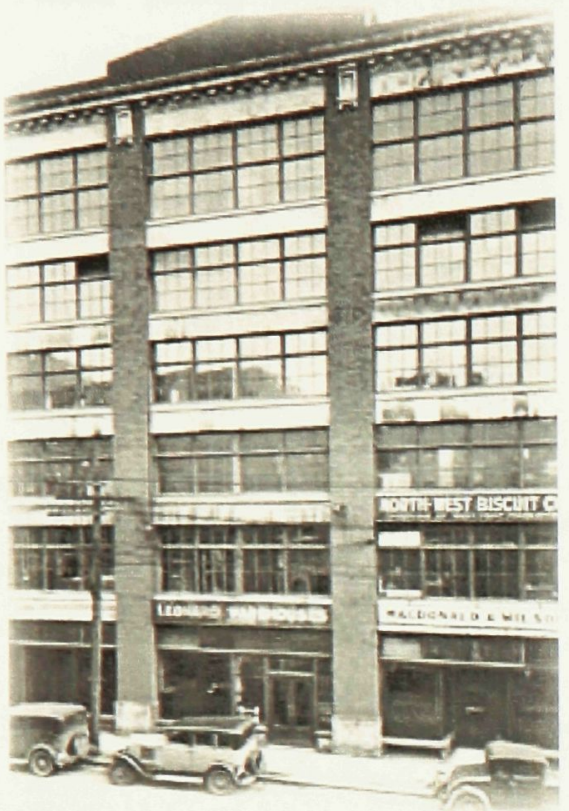

Figure 11. Warehouses became vacant as local industries began to move away from the city.

City of Vancouver Community Services Online Walking Tour: Yaletown, 2003.

the industries developing in the city during the 1880's when the Canadian Pacific Railway began to run. Vancouver was becoming the center for sawmills and lumber products in Western Canada; Yaletown became the warehouse area for storage, packaging, and processing goods as a result of the advantages of its geographical location. Situated just north of False Creek and approximately one kilometre away from the Canadian Pacific Railway terminus, Yaletown became the home of many local blue-collar workers and the warehouse industry.

Gastown and Yaletown were heavily dependent on

the sawmills, the lumber industry and the transportation of these goods, so when these industries began moving to the industrial sites in the east and away from the urban areas, both districts suffered much from this loss economically and socially. Similar to the situation of Gastown, Yaletown began to deteriorate during mid $20^{\text {th }}$ Century. Many of the warehouses were left vacant and rundown, with only a few remaining as packaging and storage buildings for garments (Duncan 2004). The conditions of Yaletown did not improve

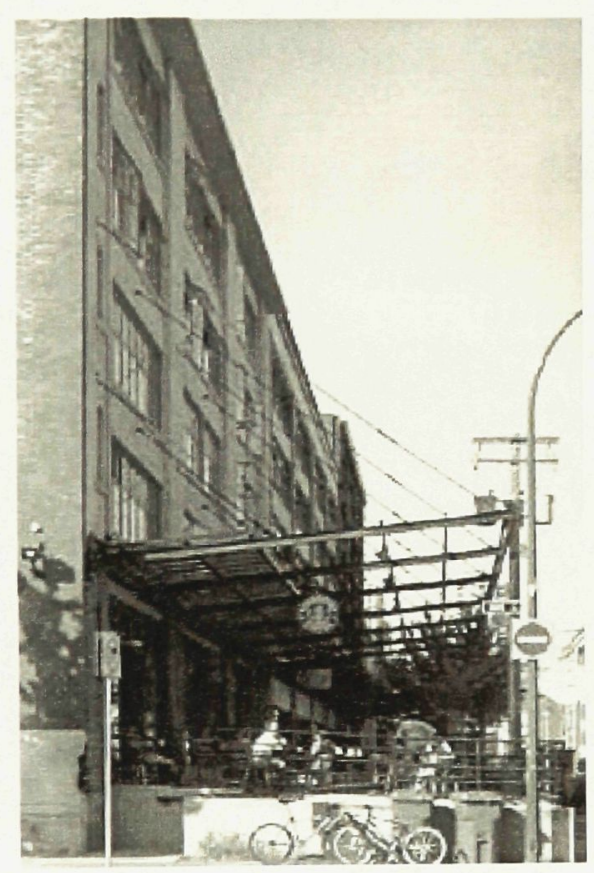

Figure 12. The extended loading bays of warehouses in Yaletown have become an architectural feature unique in the area.

City of Vancouver Community Senvices Online Walking Tour: Yaletown, 2003. 
until late 1970's when Yaletown was discovered by some local designers and young professionals and appropriated for their homes and/or offices (City of Vancouver - Community Webpages 2001). These young professionals were attracted by the area's close proximity to downtown, the affordable rents and the spacious units. The alterations of warehouses to offices and loft style homes were at first relatively minor in this neighbourhood. It was not until the late 1980's, after Expo '86, that major revitalization projects began in Yaletown. This happened when the City of Vancouver sold most of the Expo '86 site (a portion of which site lay within Yaletown) to an international land development company for major redevelopment.

In the past decade, Yaletown has been identified as the most stylish area in Vancouver; this is

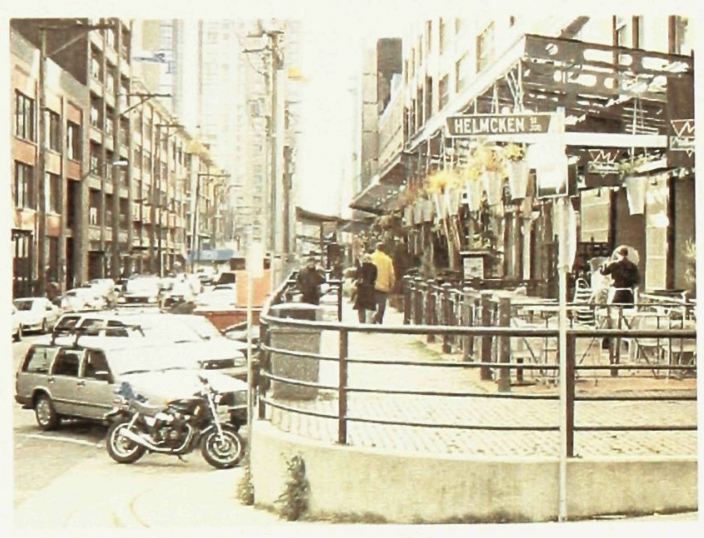

Figure 13. Loading bays are reused as sidewalk cafes.

walkvancouver.com, 2001.

where young trendy middle-class professionals live and work. Yaletown is now described as "a trendy urban community comprising a mix of residential, office, restaurants, boutiques, cafes, and more...added to this mix are: high-end restaurants, microbreweries, high tech companies, home furnishings, galleries, BMW's Mini Cooper showroom, \& hotel Opus: a contemporary boutique inn."18 Added to the warehouses are many 'Vancouver style' condominiums along the waterfront of False Creek,

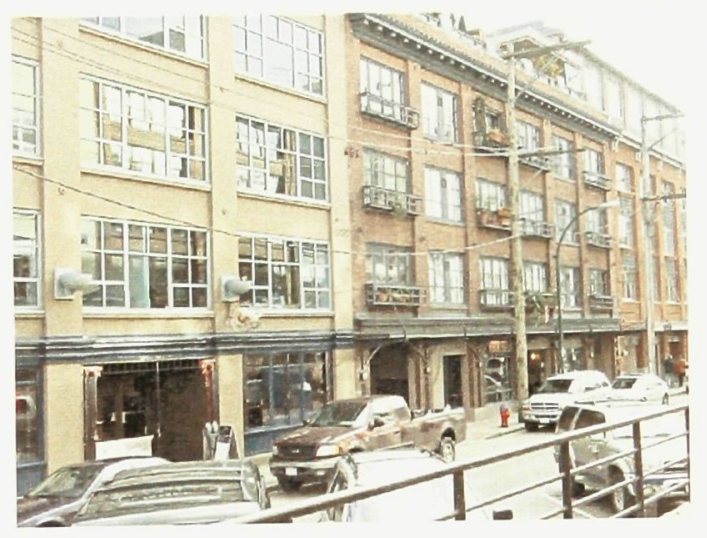

Figure 14. Old warehouses have become stylish lofts.

walkvancouver.com, 2001.

\footnotetext{
18 William Duncan, "The Rebirth of Vancouver's Yaletown," History of Yaletown Webpage, 2004 <http://www.mylocation.ca/articles2/yaletownhistory.html>.
} 
dominating the skyline of downtown Vancouver from the south. Being one of the most popular areas in the city, the prices of residential homes are affordable only to the affluent.

The case of Yaletown has demonstrated another "success" of economic revitalization in an urban area. The land developers have strategically introduced a new type of lifestyle to a deteriorating neighbourhood, a strategy that is widely accepted by many land redevelopment project companies because of the rate of economic success. However, the gentrification of Yaletown has exclusively accommodated this area to those who are more privileged, the upper and middle classes. Again, the industrial workers who once resided in this neighbourhood with the advantages of living in the urban area were driven out to other places that were more affordable. A community was forced to break up and disperse to different parts

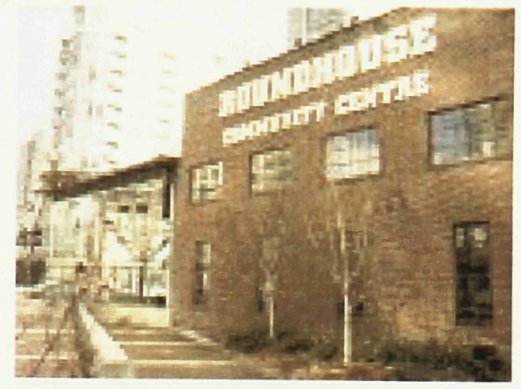

Figure 15. New residential developments around the False Creek area.

walkvancouver.com, 2001. of the city.

\subsubsection{Urban Renewal Case Study Three: King's Cross, London}

King's Cross is a residential neighbourhood in London that was experiencing similar conditions to the four block of Hastings Street before the area was slated to undergo a series of renewal processes. Unlike Hastings Street, King's Cross is solely a residential neighbourhood that was built between the 1950's and 60's. Similar to Hastings Street, the residential units in King's Cross were mainly affordable housing that served the lower working class. Initiations of renewal began when the neighbourhood conditions were no longer acceptable to the local residents. There were 
two major concerns to the local residents in King's Cross: one was the extremely poor conditions of the residential buildings and the other was the increasing crime rate in the neighbourhood (Allen 1998). Drug use and other related activities were becoming frequent in the neighbourhood.

The local residents no longer felt secure in

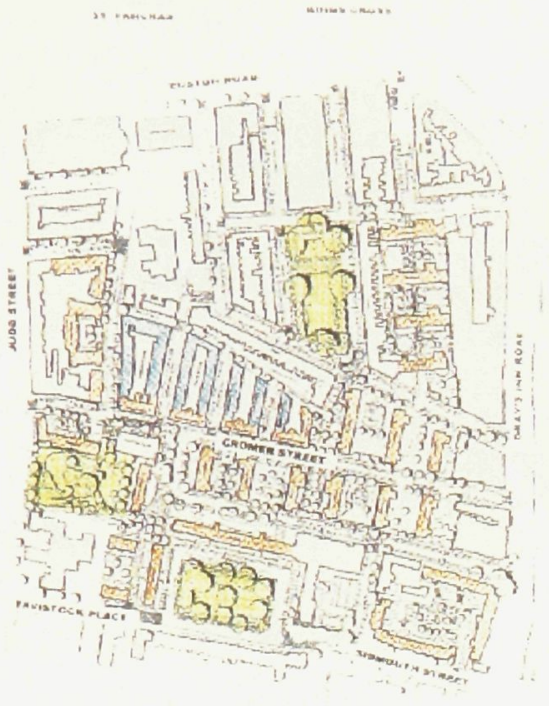

Figure 16. Site plan. Allen, 1998: 33.

the area. The residents of King's Cross felt strongly that their living conditions had to improve, so a revitalization project team, King's Cross/Brunswick Neighbourhood Association, was formed. Representatives from the local residents, government authorities, and designers formed this collaboration as the client (Allen 1998).

The revitalization project at King's Cross focused mainly on three issues: to improve the building conditions of the residential blocks, to address the increasing crime rate in the area, and to improve the quality of public space in the neighbourhood (Allen 1998). The design team proposed a few design

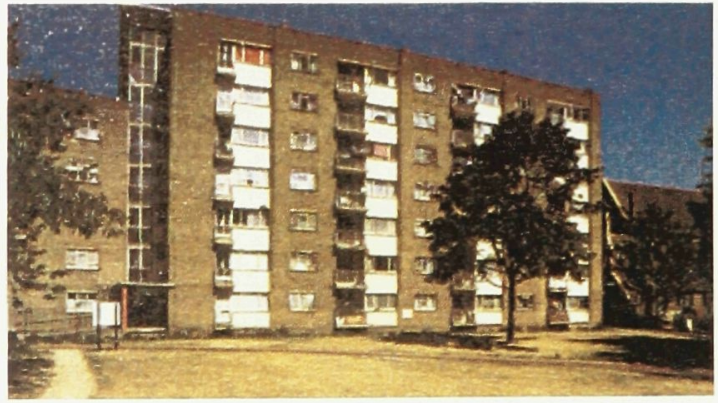

Figure 17. A view of the residential block before restoration.

Allen, 1998: 34. interventions in response to these concerns, however, in the end, this revitalization project did not deal with the problems of drug uses and other crimes in the area because police evidence suggested that those who participated in these activities were people from outside King's Cross 
and not residents from this neighbourhood. Nevertheless, for the residential blocks, the exterior facades were re-clad, new windows were installed, insulations were repaired, and the electrical and mechanical systems of the living units were upgraded. For the improvement works in the public areas, surveillance cameras were installed, additional lighting was added, and new street furniture was included in the public parks (Allen 1998).

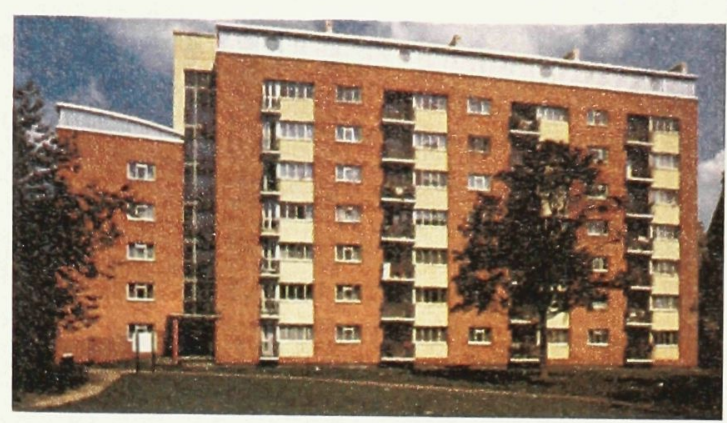

Figure 18. A view of the residential block after restoration.

Allen, 1998: 34 .

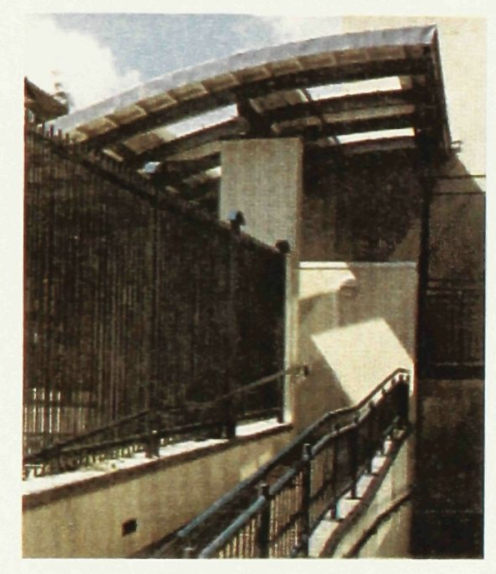

Figure 19. Ramps are added for easy access.

Allen, 1998: 36.

Unlike the previous two case studies, which were mostly driven by the economic benefits of the private developers, the King's Cross neighbourhood renewal project responded to most of the local residents' concerns. As an example of a private/public partnership redevelopment, the interventions involved the local residents in the decision making process. Design solutions did not result only from the private investors' economic decisions. After the intervention, the local residents felt more safe and secure; their living conditions in the units were improved. However, the drug related activities that the residents were much concerned with were not really addressed in this revitalization project. (Refer to the Appendix for Economic Models for Urban Redevelopment.)

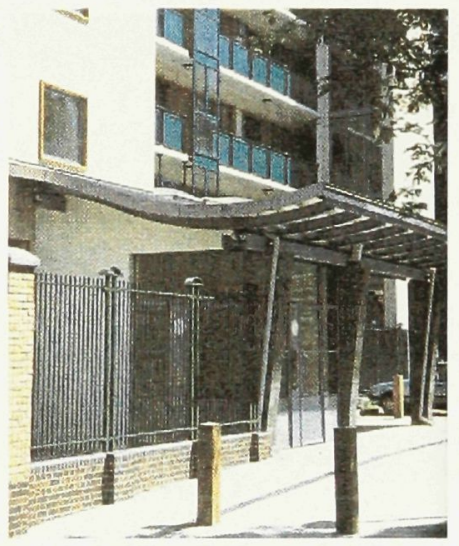

Figure 20. Additional architectural elements are added to improve building qualities.

Allen, 1998: 36. 


\subsection{Thesis Objectives}

The case studies of Gastown and Yaletown have demonstrated the most prevalent strategy in recent global urban renewal projects, that of gentrification. Gentrification has become a popular strategy approved by local authorities because, in general, governments are less willing to be involved in urban projects and prefer to introduce private investments as much as possible, as demonstrated in the case of Yaletown (Shier 2002). Although gentrification is a more economical and efficient strategy in terms of time and resource investments, the cost of allowing economic benefits as the main factor to dictate an urban renewal project is the social upheaval that results. Since a deteriorating neighbourhood is usually the home to many lower class residents because of the more affordable rents, once it is transformed into an upscale, affluent neighbourhood without a detailed plan to accommodate the existing residents, many social issues may arise from population displacement.

The intention of the King's Cross revitalization project is more in keeping with the concerns of this author. Rather than gentrifying the neighbourhood, King's Cross took a more sensitive approach to revitalize the area. However, the neighbourhood's desire to reduce drug related activities was not addressed at its roots.

The objective of this thesis is to explore an alternative strategy to urban renewal that is more sensitive to the needs of the existing population. Specifically, it looks to rehabilitate the eight city blocks of Hastings Street with the intention of creating a healthy neighbourhood so that the area can once again accommodate diverse activities. This proposed strategy appropriates drug rehabilitation techniques and therapies and reinterprets them into a design methodology to be used 
in the redevelopment of the Vancouver Downtown Eastside blocks. In contrast to a gentrification project, the renewal of the area is considered not as an end product, but rather as an on-going process that allows the neighbourhood to continually adapt to the changing needs of the existing population, ensuring that the area does not become white washed and exclude certain social groups. The intention of this thesis is to offer a plan which revitalizes the area so it can again accommodate diverse activities and a new economic base for the lower working class as an alternative to the drug trade and other drug related activities. At the same time, the area should provide an environment where both inhabitants and visitors will feel safe. 


\subsection{Rehabilitation Treatment}

\subsection{Rehabilitation treatment as a model for urban renewal}

This thesis has selected drug rehabilitation model as a possible strategy to revitalize an urban area. This strategy comes as a result of the observations of the current conditions of the site as well as detailed research on the area's history and the identification of the significant changes of the city and the area. Different urban renewal models have been considered, but the author feels that developing a design methodology that draws upon the analogy of a drug rehabilitation model applying to this situation of Hastings has enormous potential to answer the different needs of the city when compared to other urban renewal strategies. The treatment models in drug rehabilitation are selected and examined as processes of treatment for urban decay because the objectives in rehabilitation and in a sensitive urban renewal proposal are similar. The objective of rehabilitation is first to help the drug user to identify the behaviours that are most vulnerable to the drug use and addiction. Then through a series of planned procedures, these behaviours that are most susceptible are slowly altered. Moreover, the positive behaviours of the user are emphasized and promoted. Through the rehabilitation, the treatment models are periodically revised to adapt to the current conditions.

There are no specific factors that will directly cause a person to become addicted to drugs, however a number of common scenarios have been identified that are found to be fairly consistent in such situations. These conditions are also apparent in Vancouver's Downtown Eastside. They can be divided into three main areas: the availability of drugs, the predisposition of the individual, and societal influences (Ghodse 2002). 
The continual availability of drugs and the easy access to such substances is a known secret in the area. The geographical advantages of Vancouver being a major gateway to Canada and an important seaport have also created a consistent supply of affordable hard drugs, especially cocaine and heroine. Being the first stop of trade, "rocks [cocaine] are sold for as little as five dollars."19 The availability of drugs alone cannot be considered as a reason for a person's addiction; however, consistent supplies of cheap drugs that are easily accessible have encouraged such behaviour to develop in this neighbourhood.

Studies in psychology have indicated that individuals who have experienced personality disorders are more vulnerable to drug abuse. The chance of becoming addicted to drugs is directly proportional to the number of these past disorder experiences. The term "personality disorders" describes a number of features such as low self-esteem and confidence, rebelliousness, and the difficulty in forming stable relationships. ${ }^{20}$ The data from the 1996 Census indicates that the average size of a household in the area is 1.2 and over $85 \%$ of the dwelling units are one-person households. ${ }^{21}$ With the majority of residents being single, without having the necessary stable personal relationships to structure their lives, these residents are more vulnerable to regular use of drugs than those in more family oriented neighbourhoods.

Finally, there are societal conditions that end up supporting (through neglect) the use of drugs in this neighbourhood. As adjacent districts are being redeveloped into tourist oriented and upscale neighbourhoods, local authorities and city police are limiting drug related activities to remain within

${ }^{19}$ Reid Shier, ed., Stan Douglas: Every Building on 100 West Hastings (Vancouver: Contemporary Art Gallery, 2002) 11.

20 Hamid Ghodse, Drugs and Addictive Behaviour: A Guide to Treatment, 3rd ed. (Cambridge: Cambridge, 2002) 15.

${ }^{21}$ Community WebPages, "Community Statistics," City of Vancouver, 1996

$<$ http://www.city.vancouver.bc.ca/community_profiles/downtown_eastside/statistics.htm>. 
these four blocks of Hastings Street. With this strategy, all problems that are associated with drug use are contained within the area, minimizing the possibilities of spreading related crimes and vandalism to the newly redeveloped areas (Shier 2002).

When aligning these factors together, the problems of drug use and addiction have not only become deeply rooted in this area along Hastings Street, but both the neighbourhood and the residents have also become very isolated and disconnected from the rest of the city.

Applying typical gentrification strategies to revitalize this area may not be appropriate in this situation because the drug-dependent population would continue to exist; gentrification of this area would only disperse this population into other neighbouring areas.

In order to improve the current urban situation of Hastings Street, then, it is necessary to help the current community members break away from the use of drugs by re-establishing connections from this neighbourhood to the rest of the city. Using the analogy of rehabilitation treatment, a series of healing strategies are proposed to sensitively alter some conditions of the neighbourhood. As opposed to gentrification, whereby a new atmosphere or character is often imposed onto a neighbourhood, a rehabilitation model is gentle; the intention is not to create a new character through rehabilitation, but to modify the existing to become better connected and more suited to the new situation. Through a process of healing in the neighbourhood, this thesis proposes a neighbourhood that can accommodate the new changes of the city while creating an environment that does not exclude certain social groups. A healthy neighbourhood that has vibrant and diverse activities is also a place where different social groups feel safe and comfortable. 


\subsection{Rehabilitation Treatment Model: General Site Intervention}

Before any healing treatment is applied, the initial step of rehabilitation is to identify the areas of the neighbourhood that are the most vulnerable, where healing is most needed. This involves thorough research into the site's background information, with identification of the site's social, economic, demographic, and community changes throughout different periods. A holistic approach to rehabilitation addresses the recovery of a person in three areas: individual (physical), socio/cultural (community), and interpersonal/spiritual (psychological/mind) (Krestan 2000). Taking the analogy of drug rehabilitation treatment as a strategy for dealing with urban decay, this thesis has selected a number of strategies in rehabilitation for different phases of treatment that deal with all three aspects of healing. The rehabilitation treatment for the current urban decay conditions of Hastings Street also addresses the recovery of the neighbourhood in the same areas: physical, non-physical, and community.

\section{Detoxification: Person}

Detoxification is the first step of treatment, rehabilitation, and recovery from drug and alcohol abuse.22 The detoxification process is intended to eliminate any chemical toxins or residuals accumulated in the abuser's body resulting from prolonged drug or alcohol use. Prescribed medications may also be given to the client to reduce the effects of the withdrawal symptoms (Detox 5 2002). Symptoms of withdrawal vary between different drugs. For example, sudden termination in an amphetamine will result in drowsiness, apathy, and depression, while discontinuing barbiturates will cause hallucinations and convulsions (Ghodse 2002). Nevertheless,

22 Addiction Information Center, "Detox," Alcohol and Drug Abuse Informational Website. $<$ http://www.addictioncareoptions.com/detox.htm>. 
any kind of "sudden drug withdrawal is intensely stressful for a physically dependent individual; all the body's responses to stress are called into play." ${ }^{23}$ The detoxification process varies from five days (Detox 5 2002) to 28 days (Stimmel 2002) or even longer, depending on the program and the users' physical and psychological states. During the detoxification process, a therapeutic plan will be developed to commence rehabilitation. This is also the opportunity for the drug user to learn "to diminish his/her need to engage in antisocial behaviour."24 The substance user's biological, psychological, environmental (social) factors will be identified. By considering all these factors, a specific therapy and counselling program will be constructed to amplify the positive qualities and to change the negative aspects to prevent relapse (Ghodse 2002).

\section{Detoxification: Hastings Street}

Detoxification of the neighbourhood begins by eliminating the residuals accumulated in the physical environment. More than half of the buildings along these blocks are vacant, boarded up, or

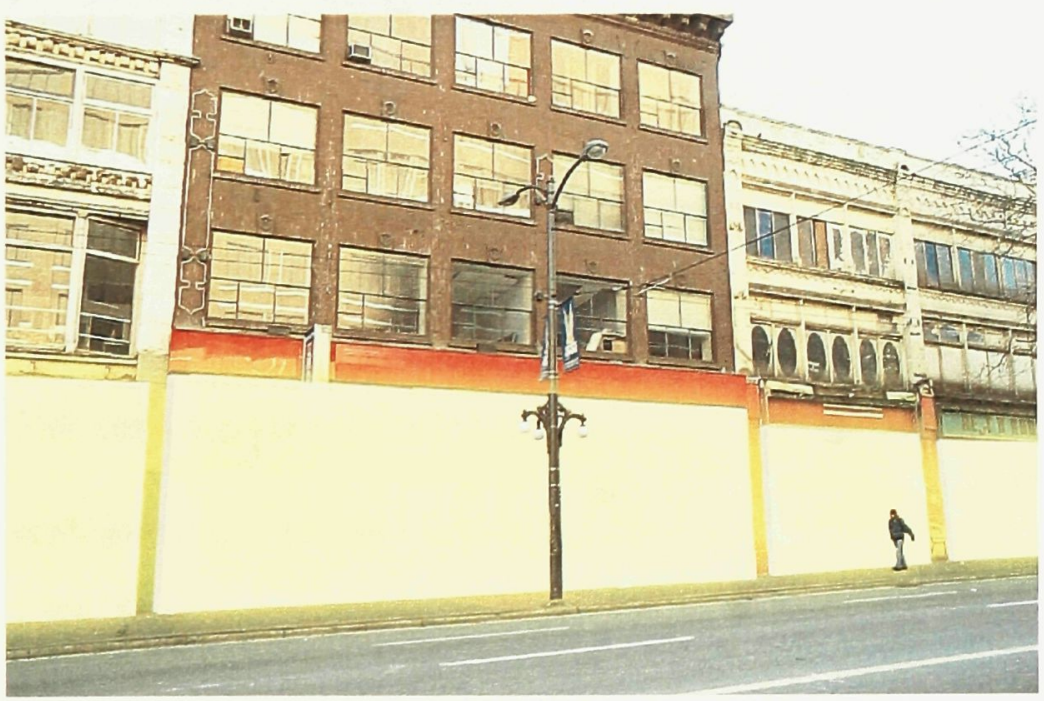

Figure 21. Hastings Street.

Sketch by author, 2004. vandalized. For the shops and restaurants that are still in business, the shop fronts are often characterized by layers of steel fences to prevent break-in's and merchandise losses. Most buildings, nevertheless, are still

${ }^{23}$ Hamid Ghodse, Drugs and Addictive Behaviour: A Guide to Treatment, $3^{\text {rd }}$ ed. (Cambridge: Cambridge, 2002) 5 . ${ }^{24}$ Barry Stimmel, Alcoholism, Drug Addiction and the Road to Recovery: Life on the Edge (New York: Haworth, 2002) 61. 
structurally sound. The first step of treatment is to "clean up" the vacant buildings, starting at the ground level. Missing or broken windows and doors will be replaced, building exterior walls will be washed, steel bars and fences will be removed, and garbage will be picked up. Additional lighting will be installed inside the buildings at ground level, creating a continuous band of white light along the street level - a gesture to demonstrate to others that the beginning of treatment has commenced. For the buildings that have structural instabilities, additional structures or scaffolding will be erected to provide the necessary support. At this phase, the history, qualities, and background information of the site and of particular buildings are collected and analyzed to determine where and when other treatments will take place. From this background information,
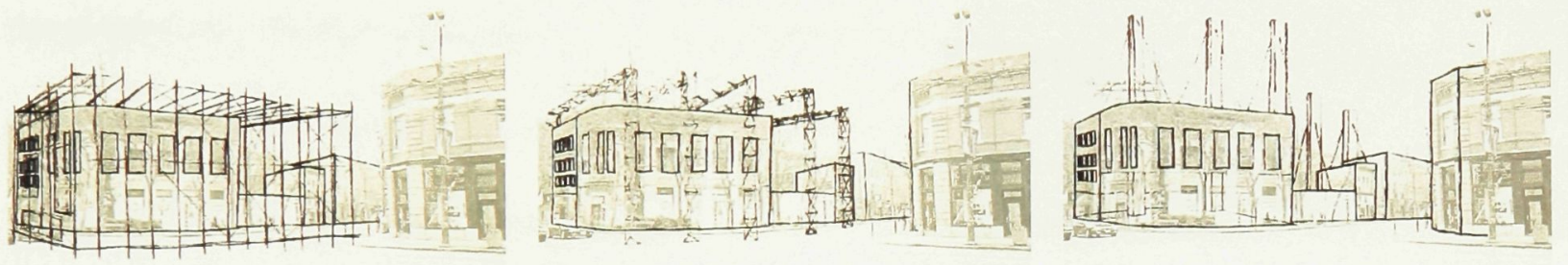

Figure 22. Scaffolding options.

Sketches by author, 2004.

building programs that respond to the needs of the local residents will also be determined to develop the positive qualities and the potentials of particular buildings in the site.

This very first step of treatment is critical; detoxification in this area will not improve the health and environmental qualities in the area, but by simply installing additional lighting to the hauntedlooking vacant buildings along these blocks, the impressions other people have of this area can be changed. This is a gesture to demonstrate to the local community and to others that there is a willingness to make a change in this neighbourhood. Reducing the amount of garbage, eliminating the smell of urine and waste, and installing additional lighting in the buildings are simple actions 
that can greatly increase the sense of safety for people going through the area. This will also raise awareness outside this area, and act as an initial step in the re-establishment of connections between this neighbourhood and the rest of the city. The announcement of a willingness to change in a rehabilitation treatment is one of the crucial factors that influences the success of the treatment.

\section{Acupuncture: Person}

Acupuncture is an alternative treatment in rehabilitation developed in recent decades. In an acupuncture treatment, needles are inserted into specific acupuncture points to reduce the "withdrawal symptoms, promoting general relaxation, and enhancing the ability to remain drug free."25 In traditional Chinese medical theories,

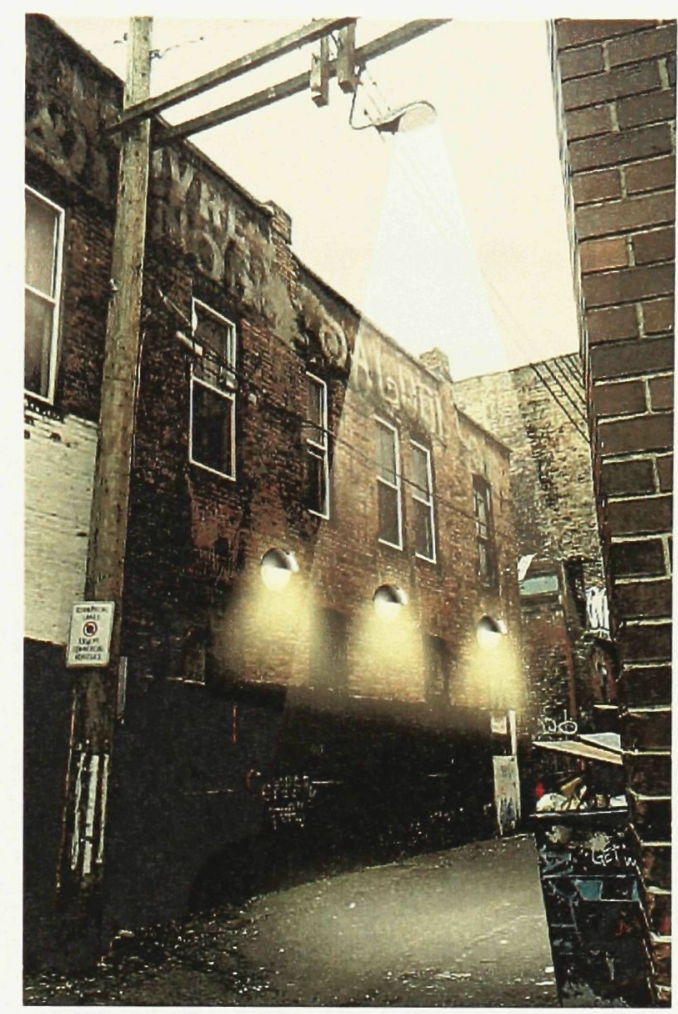

Figure 23. Additional lightings in alleys.

Sketch by author, 2004 acupuncture is believed to help in releasing the energy flow (also known as chi) inside one's body that might have been blocked because of prolonged drug use (Ghodse 2002). Recently, studies have shown that the insertions of acupuncture needles into specific body points help stimulate the release of endorphins (Stimmel 2002) and "raise the concentrations of an endogenous opiate metenkephalin in the cerebrospinal fluid."26 Acupuncture remains as an alternative method of treatment because currently this treatment model still lacks a well-developed scientific testing structure to support the results. However, with a well-planned approach to this treatment model,

${ }^{25}$ Barry Stimmel, Alcoholism, Drug Addiction and the Road to Recovery: Life on the Edge (New York: Haworth, 2002) 65.

${ }^{26}$ Hamid Ghodse, Drugs and Addictive Behaviour: A Guide to Treatment, $3^{\text {rd }}$ ed. (Cambridge: Cambridge, 2002) 251. 
acupuncture appears to be quite useful as one of the treatment models in a drug rehabilitation program, with very little or no side effects (Ghodse 2002).

\section{Acupuncture: Hastings Street}

Three sites have been identified as acupuncture points along the four blocks of Hastings Street. The Woodward's building is on the west side of the site, at the corner of Hastings and Abbot Streets. Woodward's was one of the largest department stores in Western Canada when it was first built in 1903 (Kalman 1978). Woodward's became significant to the neighbourhood, and eventually the city as well, because for many Vancouverites it was the main shopping destination adjacent to the transportation hub. Woodward's was the place where both local residents and suburban commuters could shop, eat, and get their

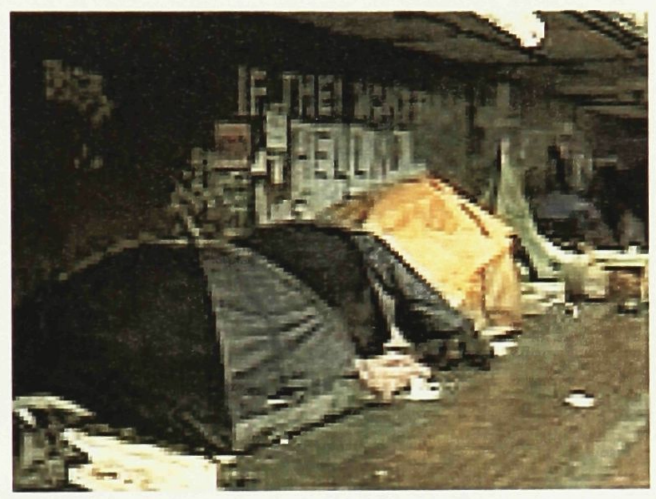

Figure 24. Homeless people protested around the Woodward's building, demanding for more affordable housing in the City.

Canadian Press Online, 2003. groceries. Later the building expanded, occupying half of a city block, and the Woodward's building became the litmus test for healthy activity in the neighbourhood. Its closure in 1993 was devastating and it remains vacant to this day. In November 1996, the Woodward's building was designated as a historical building (City of Vancouver 2004). In recent years, the Woodward's building has become a battlefield between those who demand more social housing and major land developers in the area. It has become a rallying symbol for Vancouver's lower working class.

A second acupuncture point is the B.C. Electric Railway Company (now known as the B.C. Hydro) building, located at the corner of Hastings and Carrall Streets, and in the center of the four blocks 
of Hastings Street, between Cambie and Main Streets. This building was built between 1911 and 1912 as the main terminal for the interurban rail that linked the downtown area of the time to the suburban areas and as the company headquarters (Kalman 1978). Being the transportation hub during the early $20^{\text {th }}$ century, as many as 10000 commuters travelled through this part of Hastings Street everyday (City of Vancouver 2004), creating a lively and diverse neighbourhood at the time. The termination of the

interurban rail in 1955 took away the opportunities for this area to develop further.

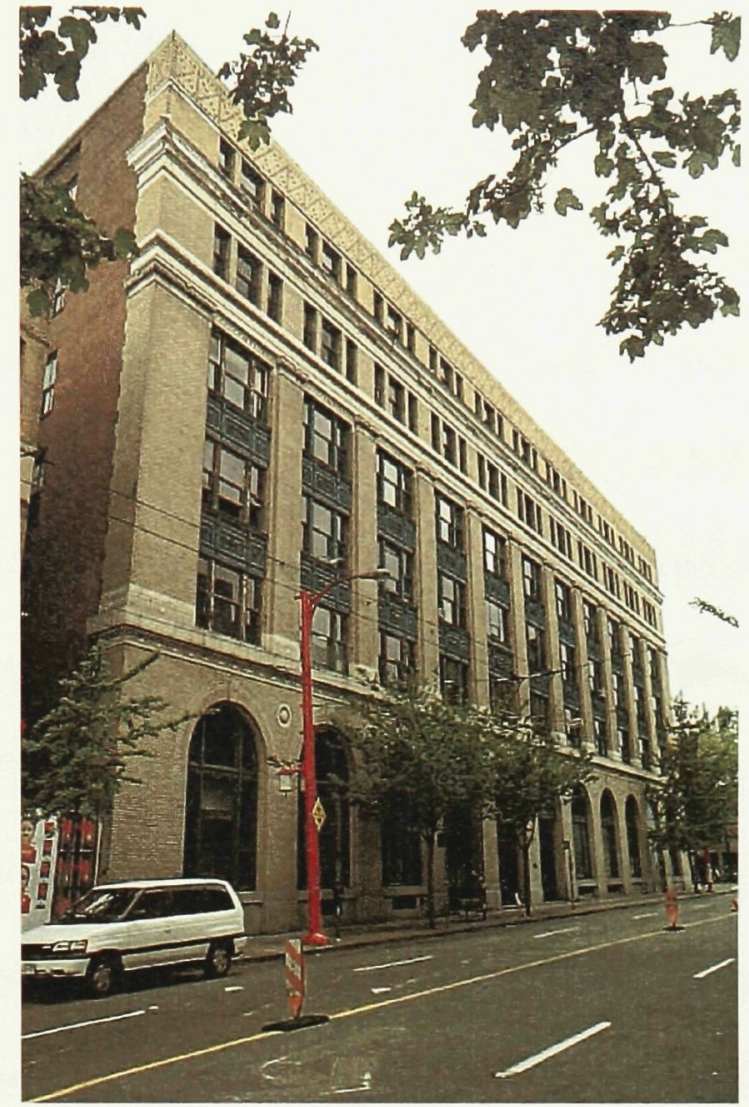

Figure 25. View from Carrall Street. Photo by author, 2004.

Finally, the third acupuncture point is considered to be the Carnegie Library (now known as the Carnegie Community Center), located at the corner of Hastings and Main Streets, on the east side of the site. This was the first library built in the neighbourhood to serve the needs of new immigrants at the time (Footprint Community Project 2001). The Carnegie Library was built between 1902 and 1903. In the early 1980's the Carnegie Library was renovated to serve as a community center, providing to the residents amenities such as a gymnasium, arts and games

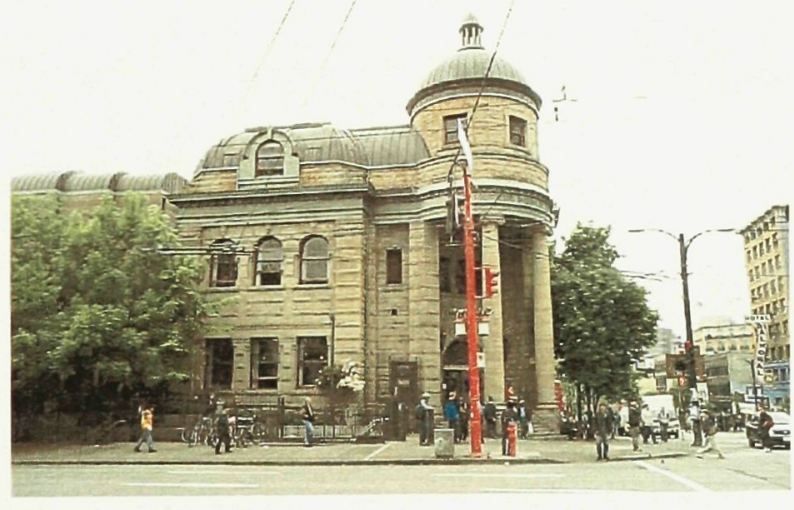

Figure 26. Carnegie Community Centre.

Photo by author, 2004. 
room, child care facilities, cafeteria, and a small library (Kalman 1978).

Many buildings are unique and have contributed to the rich history of Hastings Street, but these three particular buildings have become energy points in this area, not only because of their strategic physical locations in the focus area along Hastings, but also the history of each building has contributed to the character development of Hastings Street, from the beginning tothe present. These buildings are likely to be able to offer continuity into the future. The Woodward's building and the Carnegie Community Centre act as entry points on the east and west sides of the site. The enormous size of the vacant Woodward's building and the police cars that are stationed daily at the corner of Main and Hastings Streets establish a visual and psychological border that suggests one should not cross the line into the dangerous neighbourhood. The B.C. Electric \& Railway building, located in the heart of this area, once was a major transportation hub, but its significance has been ignored since the interurban rail was terminated. The possibility of reactivating the rail yards and corridor as a connection to the rest of the city makes it an obvious third entry point into this neighbourhood.

These three acupuncture points/buildings are considered together as addressing the recovery of the person/urban fabric in the three recognized areas of treatment: individual (physical), socio/cultural (community), and interpersonal/spiritual (psychological/mind) (Krestan 2000). Treatment at these three energy points includes healing strategies that deal with all three aspects of rehabilitation but at each site, one aspect will be emphasized in particular. After research on the history of these buildings and their architectural significance and the current building conditions in the neighbourhood, the Woodward's building has been identified as the site with interventions that would emphasize the non-physical aspect of the healing process. The interventions on the B.C. 


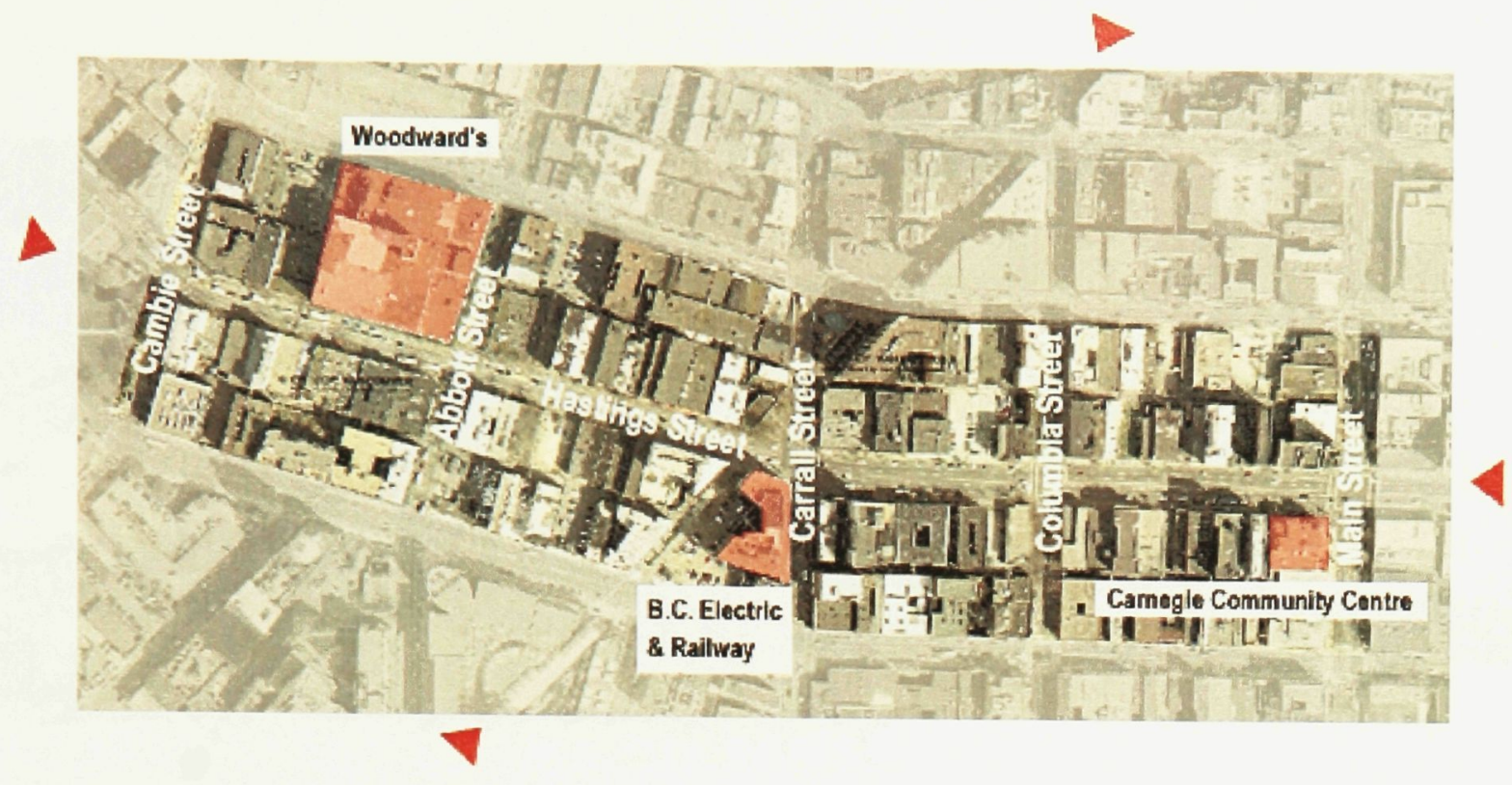

Figure 27. Locations of each "acupuncture" points.

City of Vancouver: VanMap Public Version, 2004.

Electric Railway Company building emphasize the physical aspect of the healing process. And the Carnegie Community Center is seen to underline the community aspect of the healing process. Though each site has been designated to focus on a particular aspect of the healing process, all three aspects are considered in each of the building site. The particular importance of each building site is reflected in the new building programs proposed.

The building program proposed for the currently vacant Woodward's building is intended to accommodate different uses such as living units for low-income groups, both individuals and families of different sizes. The different sizes of residential units are mixed together, to create a more diverse local population that can support the development of different local business opportunities. The living environment is intended to introduce a strong sense of community by providing a large communal eating area, laundry facilities, leisure and activities areas, and shared open spaces. In addition, a retreat for religious groups is proposed, the design of which would 
encourage interactions between the permanent residents and the people on the retreat. Design

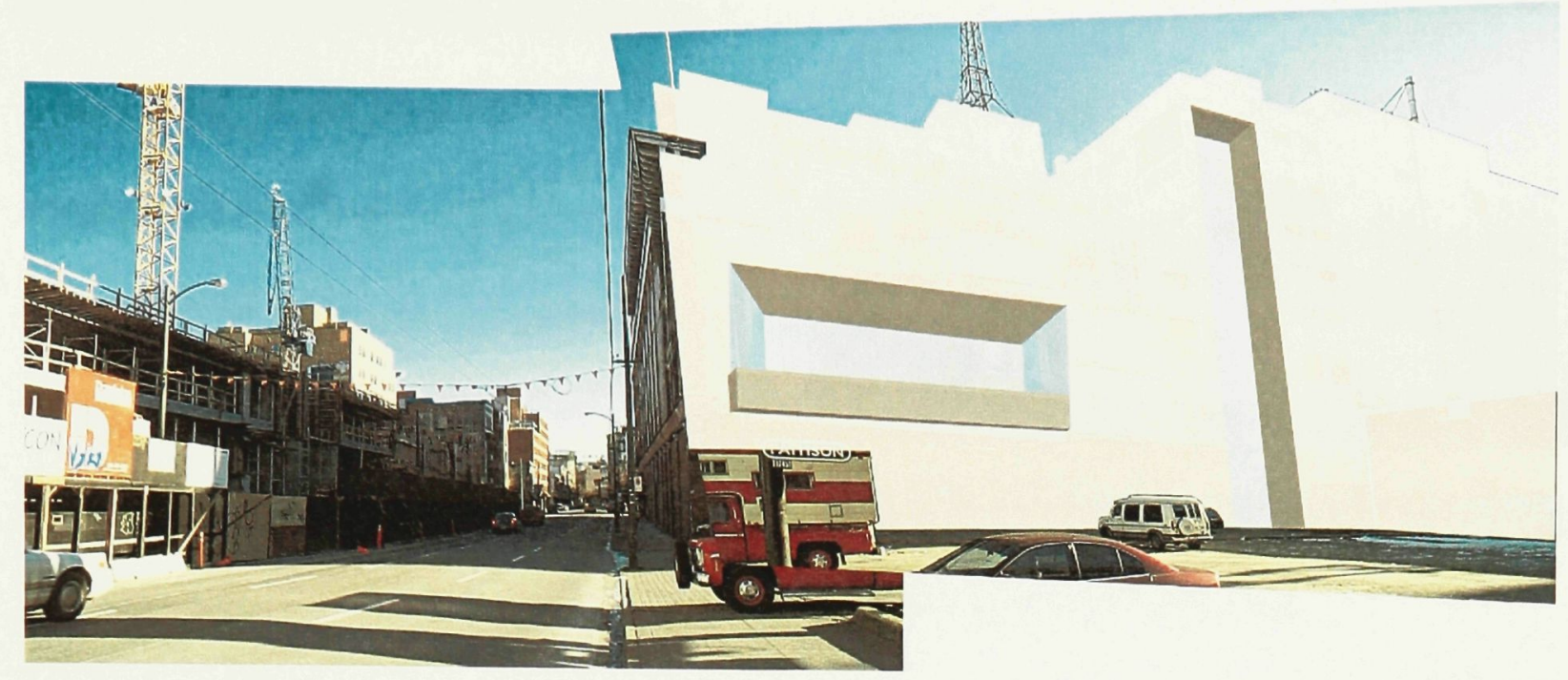

Figure 28. Schematic intervention proposed for Woodward's.

Sketch by author, 2004.

emphasis would be placed on the public spaces such as the communal eating areas (which would also act as the cafeteria during a retreat), open spaces, activities rooms, and multi-purpose rooms. With these new programs, not only the demand for quality affordable housing would be addressed, but the building would also provide affordable price opportunities for people from outside this community to experience the area from a different perspective, on a personal level. This would provide a chance for the neighbourhood, through interactions in the building, to speak for itself, to express its true character in contrast to the negative image projected by the media.

The Carnegie Community Centre is currently an active community center serving the residents of the Vancouver Downtown Eastside. The center has provided social, educational, cultural and recreational activities to the local community since 1983; the doors of Carnegie are open 14 hours a day, 7 days a week, with facilities that include the most utilized public library/reading room in the 
city, as well as ongoing writing, theatre and music programs. ${ }^{27}$ Since the Carnegie Community Centre offers a safe, drug and alcohol free environment, it is often described as the community's living room - a place where people can come to participate in programs or to simply relax and socialize with others. ${ }^{28}$ Resources and services that are available at this center include a reading room, a seniors'

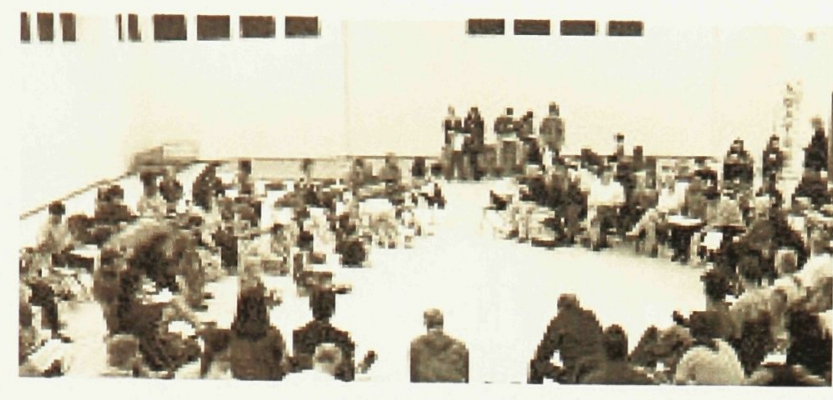

Figure 29. Carnegie Community Centre community play.

Carnegie Community Centre, 2004.

center, a weight room, a learning/literacy centre, a kitchen that offers three daily meals and snacks to the public at low cost, an art gallery, an auditorium and gym, and a dark room \& pottery area.

A technique adopted in cognitive intervention is to identify which behaviour promotes and which discourages the use of drugs; those behaviours that promote drug use are slowly changed through therapies. The other behaviours that promote a healthy lifestyle will be reinforced and even magnified by the therapist, indicating to the user his/her positive potential (Ghodse 2002). Similarly, in this neighbourhood, the Carnegie Community Centre is one of the rare places that is in a healthy condition and is free from drug use. It is a place where the local population can meet and strengthen the development of the community. In terms of the scope of this thesis, the proposed changes to the Carnegie Community Centre are therefore very minimal. It is suggested that only normal building maintenance work needs to be done to keep the building in a satisfactory condition to continue serving the neighbourhood.

\footnotetext{
${ }^{27}$ Carnegie Community Centre, "DTES Community Play," Carnegie Community Centre Website <http://www.carnegie.vcn.bc.ca/index.pl/whoweare2>.

${ }^{28}$ Community Services, "Carnegie Centre: The Downtown Eastside's Livingroom," City of Vancouver Website, 2004 $<$ http://www.city.vancouver.bc.ca/commsvcs/CARNEGIECENTRE/>.
} 
A new Vocational School is proposed as the program for the existing B.C. Electric and Railway Company building, the emphasis being on the physical aspect of treatment. Alterations to the existing building are proposed in order to accommodate the different needs of the building program and to re-establish connections between this building and the rest of the neighbourhood. As the site for a vocational school, services offered are not only limited to those who are willing to learn certain skills, but this is also where people can get certain services provided by the students at an affordable price. To create a stronger sense of community in the site, the vocation school also includes 25 different sized living units for the enrolled students (and their families as appropriate). Once again, this building provides opportunities to serve as a meeting place where the local residents and others can interact. Communications between this area and the rest of Vancouver are initiated through the interactions in the building. These constructive communications let other people recognize that this area no longer exists only as a drug-related neighbourhood. The daily influx of students from the greater Vancouver area, along with the public events related to the vocational programs (theatre productions, beauty and cosmetic treatments, massage therapies etc.) will enhance the role of this building as a catalyst for better interactions with the rest of Vancouver in the future. Also, the services provided by the students that are offered in this school will bring revenues to this area, so the neighbourhood is no longer solely dependent on drugs and drug-related economic activities for its economic base. This area begins rehabilitation through this building (along with the other two energy points) by establishing positive connections between the area and the City, and by building up alternative means of income through healthy activities. 
The proposed new building program and interventions for the B.C. Electric and Railway Company building is one of the initial steps to the rehabilitation of the area. At this stage, the B.C. Electric and Railway Company building is proposed to accommodate most of
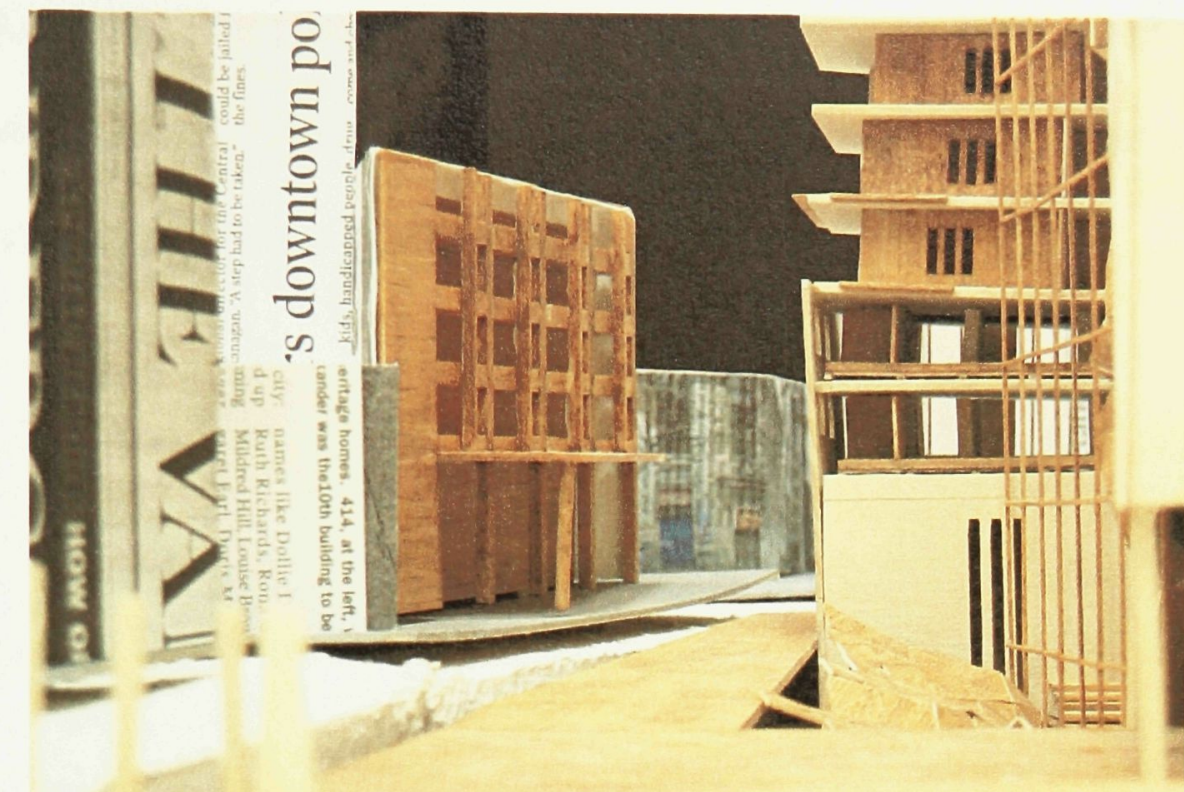

the programs of the school (with limited Figure 30. Proposed adjacent building to be renovated for additional living units.

Photo by author, 2004.

number of enrolments).

However, it is intended that as the demand for enrolments to this school increase, other vacant buildings in this area will accommodate this need, through renovations and additions to the existing buildings. As demonstrated in this proposed design, additional living units are provided by renovating the adjacent vacant buildings when demand for student residence space increases.

Interventions at these three particular sites together compose a holistic approach to the general site interventions. With the particular treatment focus at each location, all three aspects (physical, non-physical, and community) are considered at each energy point. When the interventions on each particular building are considered together, they create an impact on the overall site. The building interventions on Woodward's and Carnegie Community Centre are intended to re-establish the long lost connections between these blocks of Hastings Street to the adjacent areas. The B.C. 
Electric and Railway Company building is selected for further exploration and investigation architecturally because it speaks to the possibility of rehabilitative actions at the very core of the patient. The interventions proposed for this building are intended to act as a beach-head and catalyst for continued treatment of the rest of the very neighbourhood. 


\subsection{Rehabilitation Treatment Model: Proposed Program for the B.C. Electric and Railway Company Building}

A vocational school provides opportunities to those people who wish to learn new skills and to make changes to improve their current situations. There are no restrictions to the qualifications of applicants to enroll in such a school. This school is targeted to serve the lower working class individual who may be out of work or the new immigrant who needs to obtain new skills to have better job opportunities in the area.

\section{Vocational School Program}

The vocational training programs offered by the school have been derived by reinterpreting a number of rehabilitative treatment models and their intended objectives. Training programs have been selected to help people to develop and practice particular skills so the students can use these to expand their job opportunities. ${ }^{29}$ By taking the different objectives of rehabilitation and drawing parallels to these intentions, specific life skill training programs have been developed:

Rehabilitative intervention objective one: Some treatments are directed at the underlying causes which may have initiated drug-taking and/or are contributing to its continuation. ${ }^{30}$

- "To develop a treatment plan that meets the needs of the patient, and this in turn relies heavily on the findings of the assessment procedure. The key to successful intervention is

\footnotetext{
29 Vancouver Community College Website, 2004. <http://www.vcc.bc.ca/>.

30 Hamid Ghodse, Drugs and Addictive Behaviour: A Guide to Treatment, $3^{\text {rd }}$ ed. (Cambridge: Cambridge, 2002) 212.
} 
to bring about change, and before that can be done, it is essential to know as much as possible about the existing situation." 31

- Personal trainer program and Food \& nutrition program - as consultants for dieting / weight control programs. A personal trainer and a nutritionist will work as a team to prepare a personalized program. The team has to identify the client's background information such as age, weight, height, eating habits, family medical history and personal lifestyle to develop a suitable program. The client's program is periodically revisited to adapt to the physiological, psychological, mental, and lifestyles changes.

Rehabilitative intervention objective two: Some help to resolve the problems associated with or consequent upon drug-taking. ${ }^{32}$

- "Pharmacotherapies to treat drug dependency are used for detoxification to prevent withdrawal, for maintenance, to block the effects of specific mood-altering drugs, to prevent drug craving, and to treat coexisting psychiatric conditions. '33

- Cosmetology program - includes cosmetic, hair styling, and personal styling. Instead of identifying the causes of the client's current conditions, beautification improves the existing physical conditions of the client that may also increase his/her confidence (psychological improvement).

Rehabilitative intervention objective three: Some deal more directly with the drug-taking behaviour itself, aiming to reduce or stop drug-taking, regardless of other problems or circumstances. ${ }^{34}$

\footnotetext{
${ }^{31}$ Hamid Ghodse, Drugs and Addictive Behaviour: A Guide to Treatment, $3^{\text {rd }}$ ed. (Cambridge: Cambridge, 2002) 213. 32 Hamid Ghodse, Drugs and Addictive Behaviour: A Guide to Treatment, $3^{\text {rd }}$ ed. (Cambridge: Cambridge, 2002) 212. ${ }^{33}$ Barry Stimmel, Alcoholism, Drug Addiction and the Road to Recovery: Life on the Edge (New York: Haworth, 2002) 61.
} 
- "Behavioural therapies are based on the belief that dependence on mood-altering drugs is a learned behaviour, maintained and reinforced by conditioning caused by the drugs and independent of other psychosocial conditions. It teaches the user to understand the relationship between the thought process that initiates the intent to use and the actual use. Therapy is directed toward developing behaviours that are incompatible with drug use and avoiding situations associated with a high risk of recidivism. ${ }^{35}$

- Martial arts program - Many physical (and psychological) illnesses are believed to be caused by an imbalance of the belly (body) and the head (mind). To minimize the chances of getting these illnesses, one must learn how to achieve the integrated state of mind and body. The program teaches people how to achieve this integrated state, which is "a new dimension, a new kind of energy, and a new principle; symbolized by the 'Centre'.' (Payne 1981) By practicing and learning the philosophy of martial arts, it will help the client to "regain the central Heart principle and restore balance." This practice of martial art and its philosophies will eventually cause a physical and behavioural change of the person.

Rehabilitative intervention objective four: Some treatments may be directed at helping the client's motivation for change, rather than directly changing the behaviour. ${ }^{36}$

- "In a motivational enhancement therapy, the therapist selects the patient's certain comments and through summarizing, affirming, reframing, and questioning techniques, increases dissonance which is the vehicle for motivating change. The therapy also helps

${ }^{34}$ Hamid Ghodse, Drugs and Addictive Behaviour: A Guide to Treatment, 3 rd ed. (Cambridge: Cambridge, 2002) 212 35 Barry Stimmel, Alcoholism, Drug Addiction and the Road to Recovery: Life on the Edge (New York: Haworth, 2002) 66.

${ }^{36}$ Hamid Ghodse, Drugs and Addictive Behaviour: A Guide to Treatment, $3^{\text {rd }}$ ed. (Cambridge: Cambridge, 2002) 212. 
raise the client's self-esteem, self-efficacy, and awareness of problems. It attributes responsibility to the client."37

- Community theatre - includes a drama school and stage production program (lighting, stage design, sounds \& acoustics, props). Through training and performances, performers can develop their self-esteem and self-confidence. The community theatre is a medium to raise awareness for local problems and concerns.

Rehabilitative intervention objective five: Some treatments are aimed at helping prevent relapse in those who have achieved change. ${ }^{38}$

- 'The therapist can help the client to identify and analyze 'high-risk' situations and develop ways of dealing with them in future - by avoiding or preventing high-risk situations, or by structured problem-solving techniques."39

- Massage therapy - certain massage therapies, such as craniosacral therapy and shiatsu, when done in a regular basis, can prevent build-up of physical stresses in our bodies; hence, promoting good health and enhance resistance to disease. Most massage therapies can greatly reduce the development of painful muscular patterning, if employed early enough after accidents involving trauma and injury.40

The new vocational school provides residence space for those who need accommodations in the area. Living units of different sizes, from studio to two bedrooms, accommodate students with different needs. These residential units are intended to cater to a mixed group of people with

\footnotetext{
${ }^{37}$ Hamid Ghodse, Drugs and Addictive Behaviour: A Guide to Treatment, $3^{\text {rd }}$ ed. (Cambridge: Cambridge, 2002) 219220.

${ }^{38}$ Hamid Ghodse, Drugs and Addictive Behaviour: A Guide to Treatment, 3rd ed. (Cambridge: Cambridge, 2002) 212.

${ }^{39}$ Hamid Ghodse, Drugs and Addictive Behaviour: A Guide to Treatment, 3rd ed. (Cambridge: Cambridge, 2002) 222

${ }^{40}$ Massage Network website. "What is Massage Therapy?" <http://massagenetwork.com/massage_therapy.html>.
} 
different family conditions: from singles to small families. The units have individual bathrooms and kitchens. Common dinning area, multi-purpose rooms, laundry facilities, and a children's day-care (and other shared facilities) are also provided for the residents. Spaces are organized to encourage interactions with others when possible; creating a small but strong community between the students and those outside this neighbourhood.

\subsection{Rehabilitation treatment model: building intervention}

Rehabilitation is a long-term process of changes rather than a result of transformation. A series of

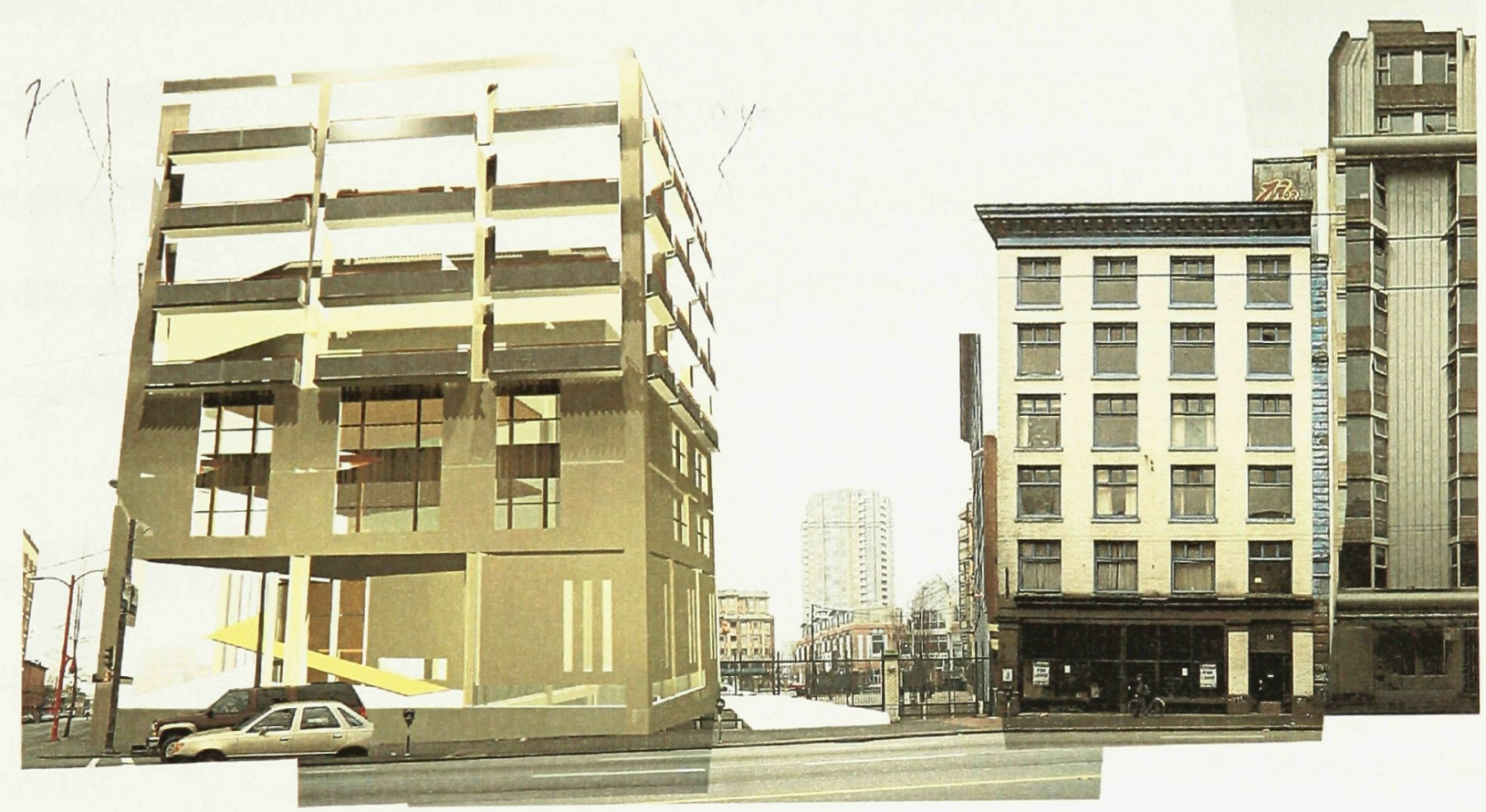

Figure 31. B.C. Electric and Railway Building proposed interventions.

Image by author, 2004.

interventions are proposed to rehabilitate the existing B.C. Electric and Railway building so that it can re-establish connections to the neighbourhood. The interventions are intended to rehabilitate both the building inside and its relation to the site. As an on-going process, the area is rehabilitated starting at this particular site, as well as the other two acupuncture points mentioned, 
by creating desirable connections. Strategies adopted for the interventions are based on the principles of treatment: to change the destructive qualities and to maximize the positive qualities so the building is at an appropriate level of functioning (Connors 2001). New programs and functions of the building are proposed with the intention of increasing the opportunities for different people to interact. Design interventions are targeted to connect the building to the adjacent streets and open space in a micro scale. In the urban scale, the building interventions are a series of processes to encourage connections between these eight blocks of Hastings and the rest of the City. The proposed school targets not only the people in the local community but also those from other areas of the city. Like the Carnegie Library, the B.C. Electric and Railway building is designed to provide a safe and drug free environment. The building interventions proposed are not radical changes to the building and the site, but stand as the first step towards resumption of a healthy lifestyle. Since rehabilitation is an on-going process rather then a one-time treatment, subtle design moves that gradually change the area are likely to be more acceptable and effective as a response to the local community.

\subsubsection{Rock Climbing Wall}

As part of the personal trainer program, a rock-climbing wall is proposed for skills and strength training. This climbing wall is located in the most central public area of the school for two purposes: first, this wall is open for users outside the school, and second, the wall spans over the entire building height; it is visible from most parts of the building. The climbing wall can be extended along the south exterior wall to the adjacent open space later on as the area is further in the rehabilitation process. The extension of this climbing wall from the open courtyard can be then 
used as an element to test the effectiveness of rehabilitation, whether any dangerous acts will occur after this exterior portion of the climbing wall is installed.

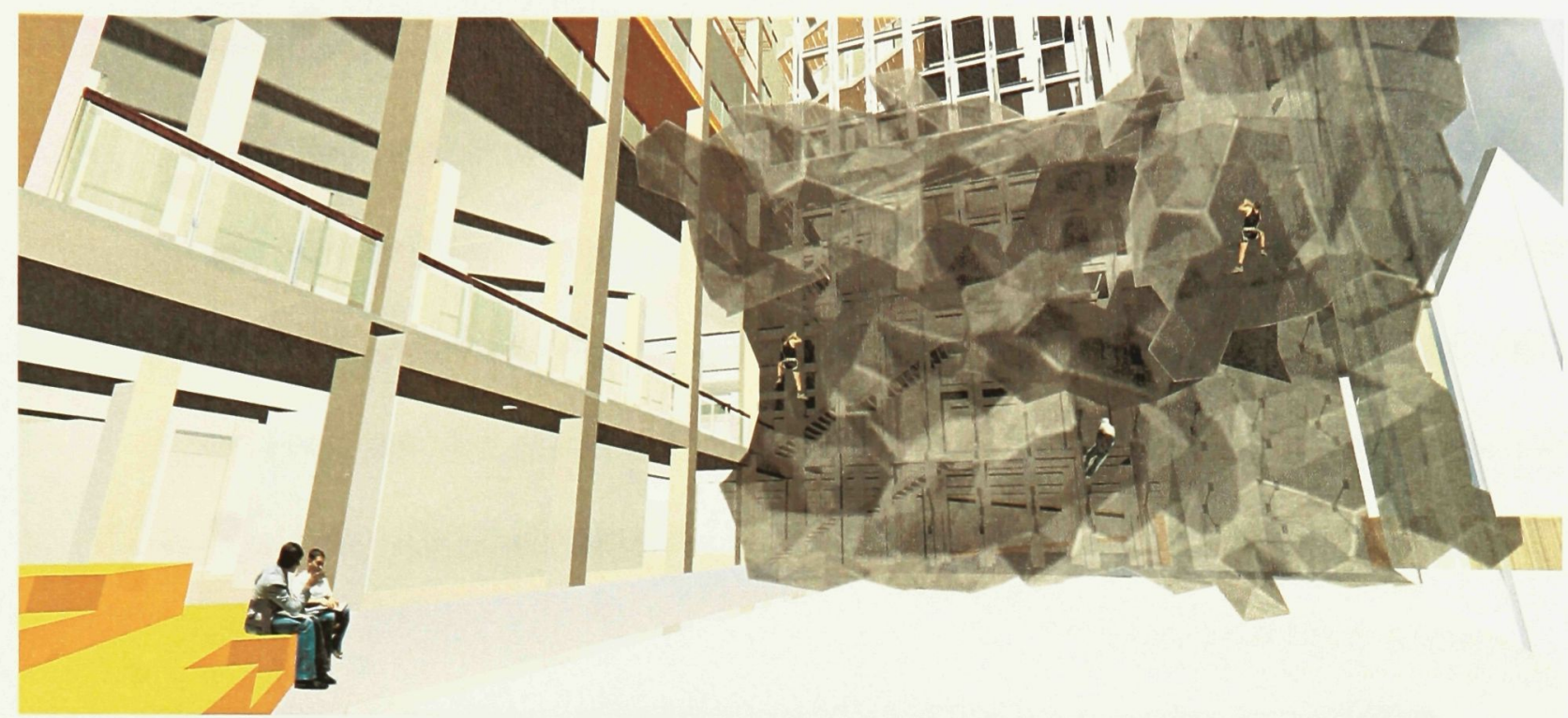

Figure 32. A view of atrium.

Image by author, 2004.

Experiences of the climbing wall are not only limited to visual contacts, but through physical experience as well; at moments, individuals can become part of the wall. Experience of the wall occurs at different participatory levels: climber, observer, or supporter; nevertheless, this climbing wall is able to "bring back into awareness, at least retrospectively, the large part that intrinsic reward can play in getting us through the day." 41 Each climb is a metaphor for life. Even with careful planning and preparations before a climb, unexpected situations will occur whereby the

\footnotetext{
${ }^{41}$ Richard G. Mitchell, Jr. Mountain Experience: The Psychology and Sociology of Adventure. In the forward by Gerald Suttles, he sees that "ordinary daily experience is often so clouded with detail and distraction that it is difficult to find in it the skeletal outline of intrinsic purpose. Even the overriding importance of extrinsic rewards - their ultimate necessity - may distract us from what is intrinsically engrossing. Thus, to a large extent we must create occasions, games, or sports in which these distractions are temporarily held in abeyance. Mountain climbing may be one of the most demanding and purest examples of the intrinsically engrossing." (Chicago: University of Chicago, 1983) viii.
} 
climber may feel extremely stressed; yet, the climber must still be focused to find a constructive solution to complete the climb.

\subsubsection{Circulation and Level Changes}

- The recovery process of every substance user is different. There are no specific healing models that can guarantee a successful treatment. One may see rehabilitative treatment as an explorative process of self-discovery, with assistance and support from professionals, families and friends. Through treatment, life issues and past experiences are raised and addressed with different perspectives to be seen from different angles.

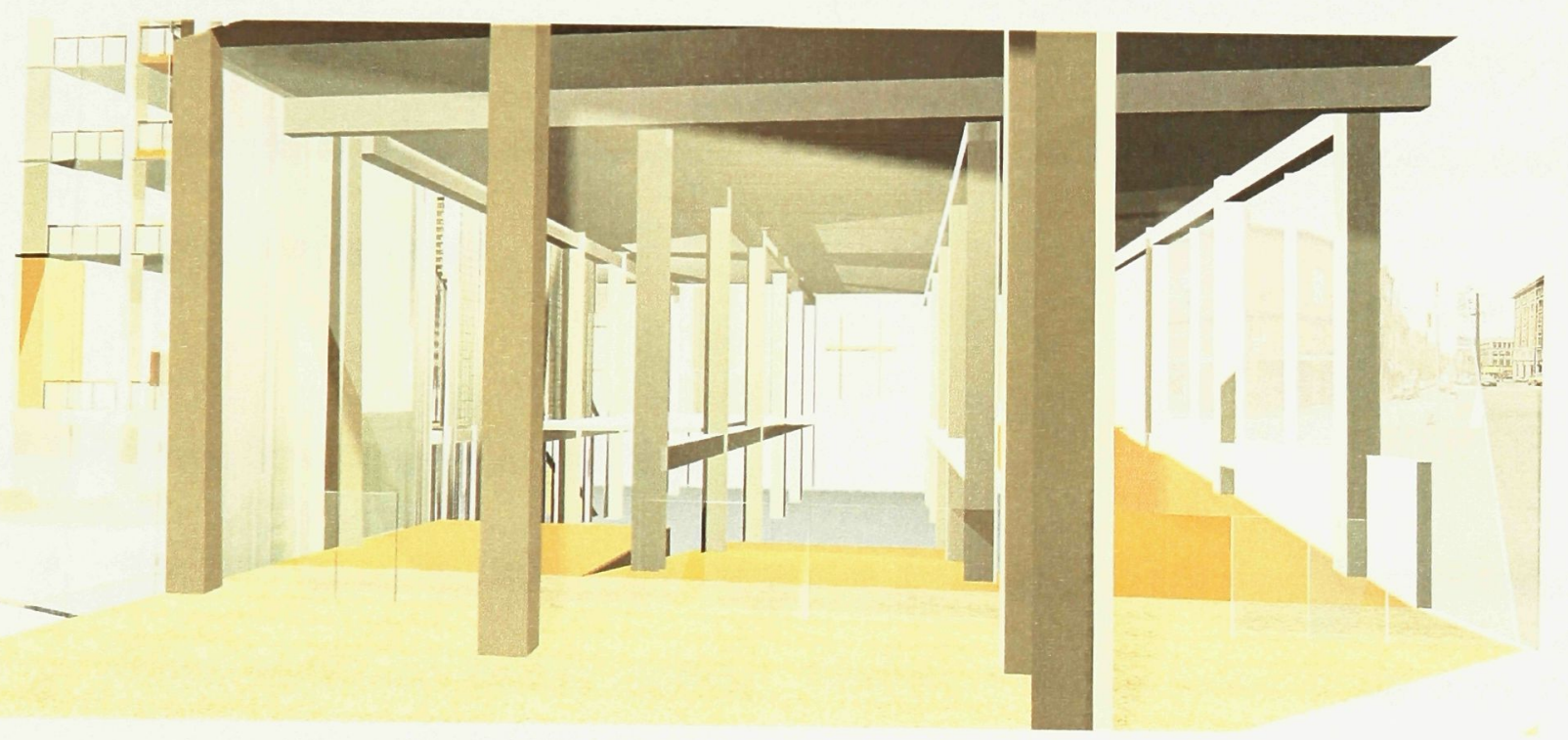

Figure 33. Theatrical entrance.

Image by author, 2004

- There are various accesses to this school, two on Hastings Street and one on Carrall Street, bringing different experiences of the building to the users. Circulation within the school is free and not complex. The users can get to each level by different means such as using the staircases, ramps, or the elevator, which offers a unique experience of the building; this allows the users to experience the building through a more functional, 
directed route or a more experiential route, reflecting the various pathways of recovery to every substance user.

- To increase the flexibility of the spatial utilization in this vocational school, classrooms and other learning spaces are defined by slight floor level changes. Rather than defining each classroom with solid walls and doors, the learning spaces in this school are defined with a slight rise in the floor, accessed by ramps and steps. Changes in the ceiling material and movable panels are also elements that further define the spaces and provide privacy when needed. When these learning spaces are not in use, the raised floor can be used as seating and meeting spaces, places where individuals can sit and not be disturbed or where discussions and casual conversations occur. These casual moments of contemplation or discussions may be the essence that determines the effectiveness of a rehabilitative treatment.

\subsubsection{Building Structure - Old and New}

- "Interpretation of the past by the therapist is assumed to break down client defences, provide insight, and facilitate recovery. However, it may be unwise to strip away the 'preferred defence structure'... Other methods must be developed before they [substance users] will give them up." ${ }^{\text {"2 }}$

- Though the existing building was built over 90 years ago, the building structure is still sound. The author proposes only minor alterations to the existing concrete frame building structure.

${ }^{42}$ John Jung, Psychology of Alcohol and Other Drugs: A Research Perspective (Thousand Oaks: Sage, 2001$) 425$. 


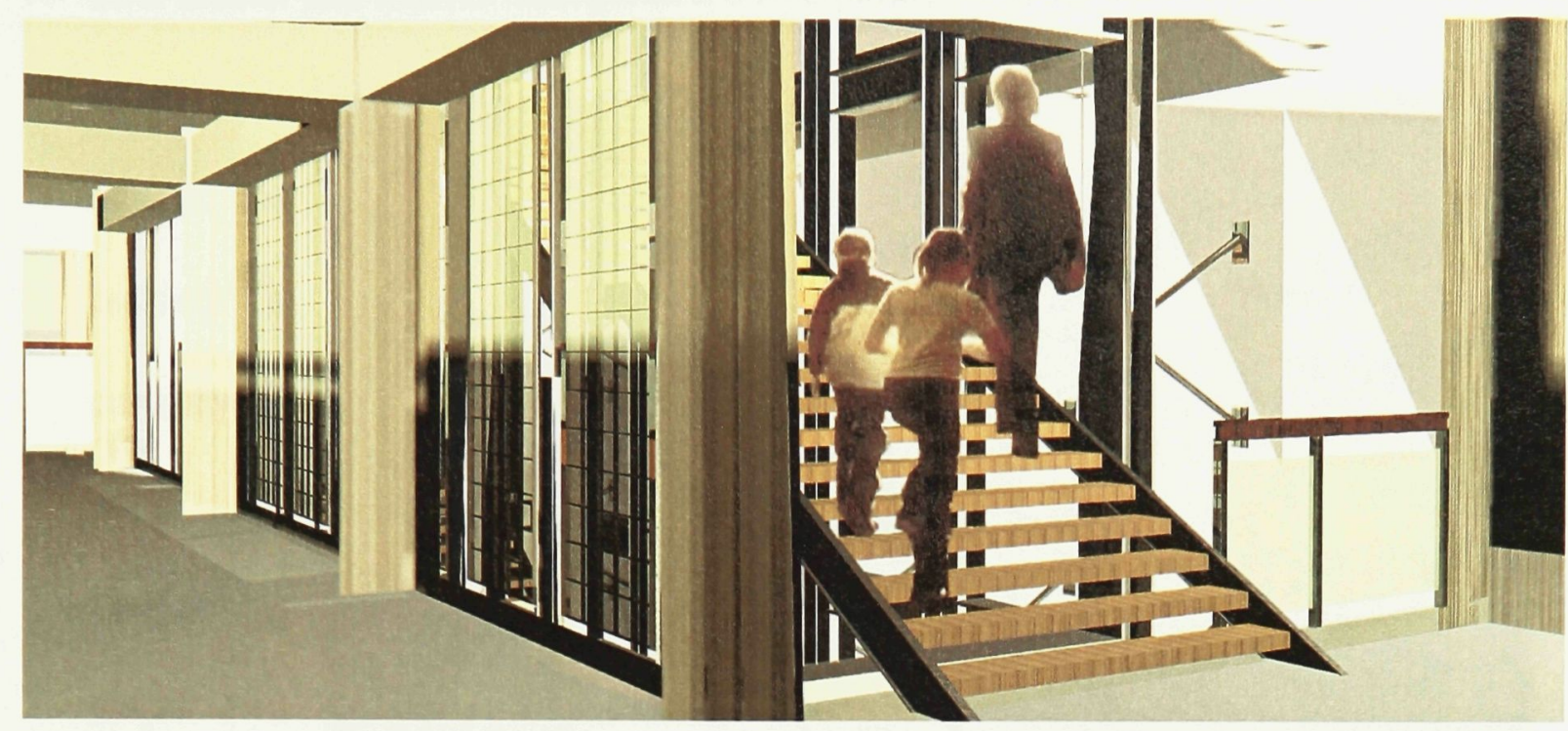

Figure 34. Existing and proposed structures.

Image by author, 2004.

Steel structure is proposed in areas where new structure is required, allowing for a different view to the existing building structure. In some cases the new structure will reinforce the existing structure, in other cases the existing structure will support the new. All the new raised floors are supported by light steel structure. Wood is proposed as the primary material for all new floors because it ages well, is resilient, and is not too delicate for rough use. It can also provide a sense of gentleness and calm. To balance the heavy concrete and stone blocks, a variety of glazing opacities is incorporated into the building to provide different levels of privacy.

\subsubsection{Interior and Exterior Courtyards}

- Providing moments for self-reflection, contemplation, or silence is beneficial in a rehabilitative treatment. These moments of thoughts or meditation allow an individual to quiet down and to find peace within him/herself. 
- Both interior and exterior courtyards are incorporated into the school design. The outdoor

space
around the
building is
currently
used as
parking
where it is
fenced off
from

Hastings

Street. To

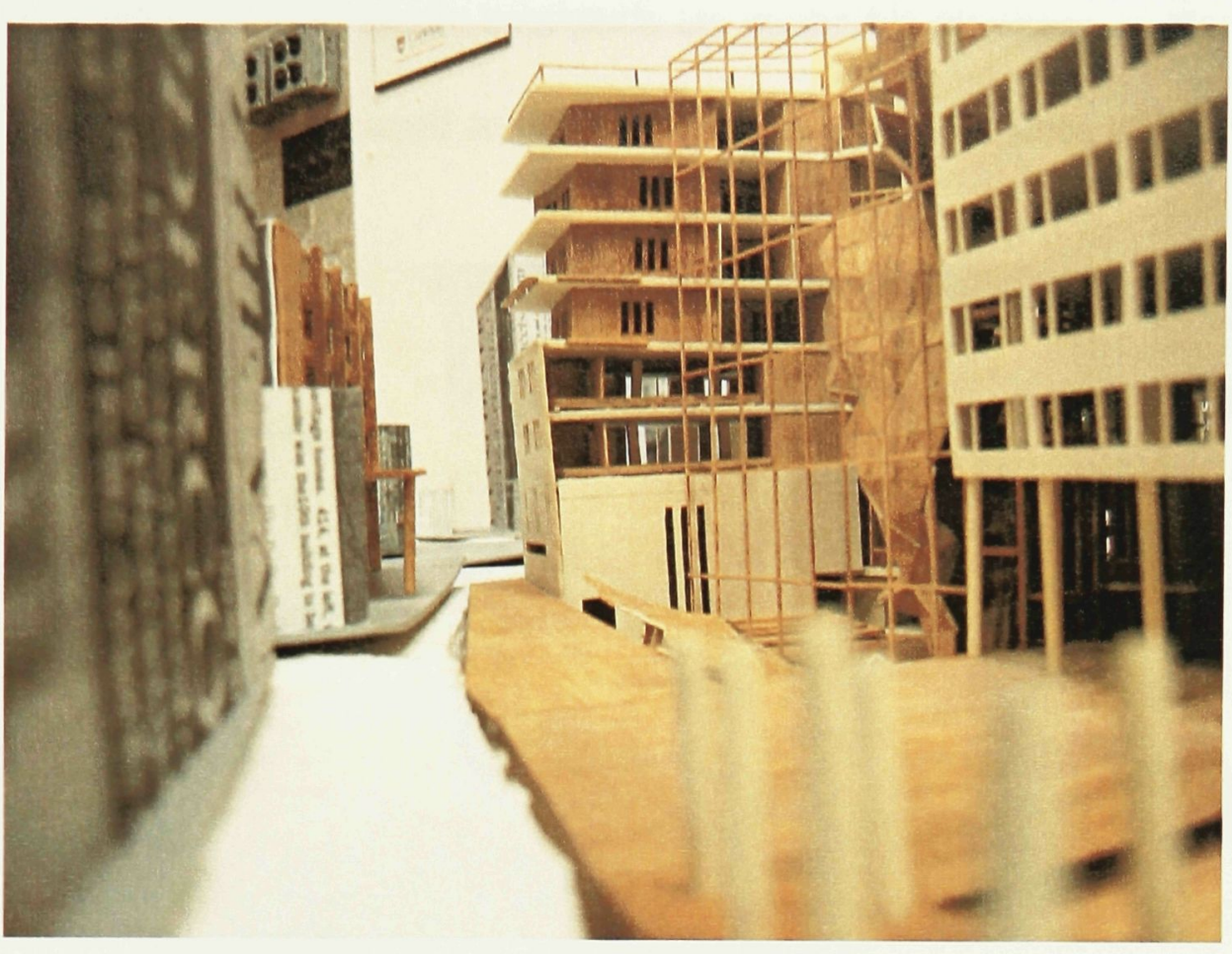

Figure 35. View of open space and atrium.

re-connect this site to the adjacent spaces, as one of the rehabilitative strategies, an exterior courtyard is proposed. The exterior courtyard is also the outdoor theatre and it is incorporated into one of the entrance routes from Hastings Street. This exterior courtyard has a relationship, both physically and visually, to the school atrium space, expanding the "stage" of the outdoor theatre when necessary. Allowing the atrium to overlook the open space will create a strong sense of safety for the users in the open space without having the presence of security guards or cameras. As the main circulation space is around the atrium, with a steady flow of people at all times, they will keep "eyes upon the street [public open space]... which will naturally provide safety to both residents and strangers." ${ }^{43}$

\footnotetext{
43 Jane Jacobs, The Death and Life of Great American Cities (New York: Random House, 1961) 35.
} 
- The interior courtyards are located at different levels, opening up to the roof level to allow daylight into the building. These interior courtyards are accessible physically at certain locations and at others, are mainly used as light wells and moments of silence within the

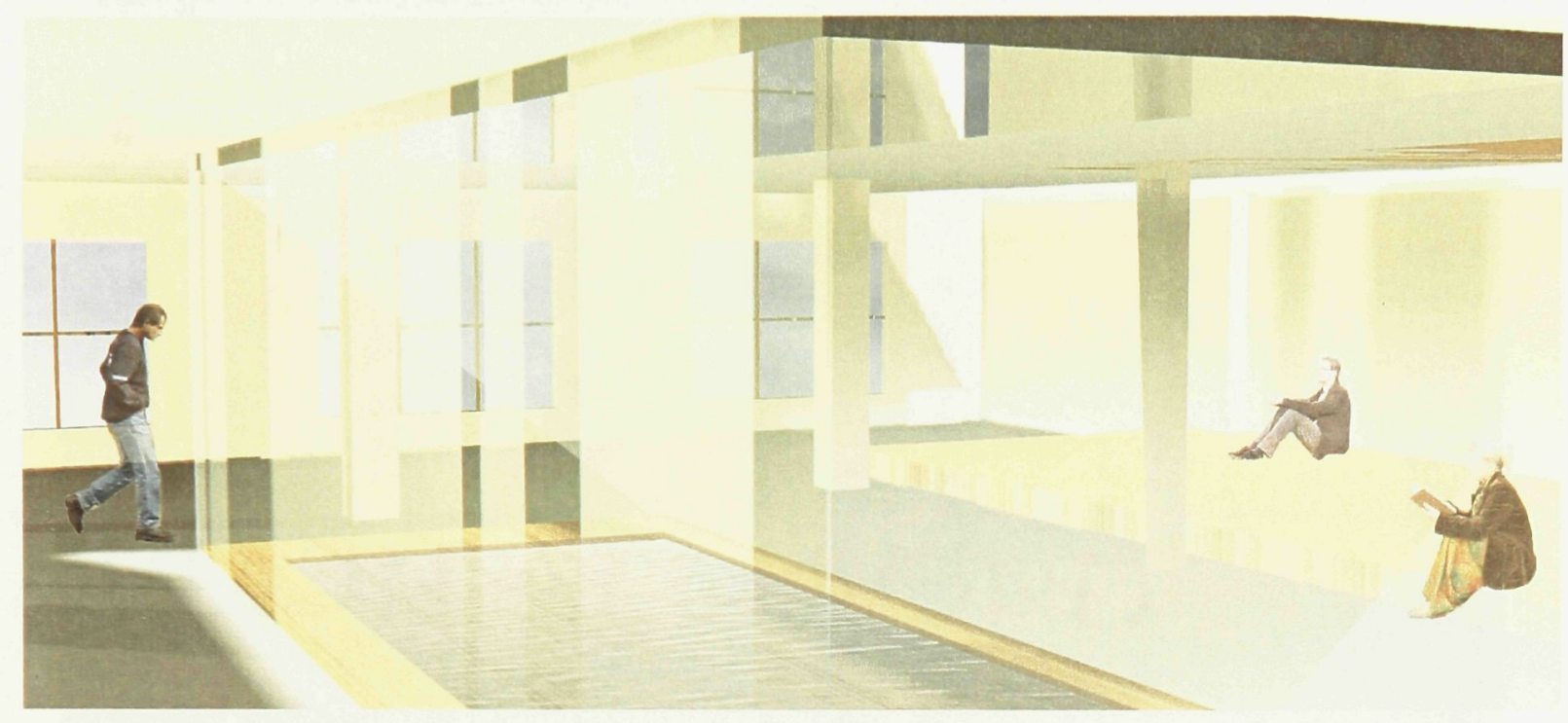

Figure 36. Interior courtyard.

Image by author, 2004.

building. Introducing natural light into the building not only increases the energy efficiency of the building, but also improves visual interest and comfort. It allows individuals to experience the building differently by expanding the boundaries of perceptions because "space and void that are structured by light and are in turn structure the viewer's perception. Light is the material of their realization in perception." ${ }^{44}$

${ }^{4}$ James Turrell, James Turrell: First Light and Catso White, contributors Josef Helfenstein and Christoph Schenker (Stuttgart: Edition Cantz, 1991) 13. 


\subsubsection{Building Façade}

- The objective of a rehabilitative treatment is not to completely change an individual's character and personality; rather, rehabilitation is intended to make a series of changes to strength the individual's positive characteristics so that changes to a recovered substance user may not be apparent from his/her appearance.

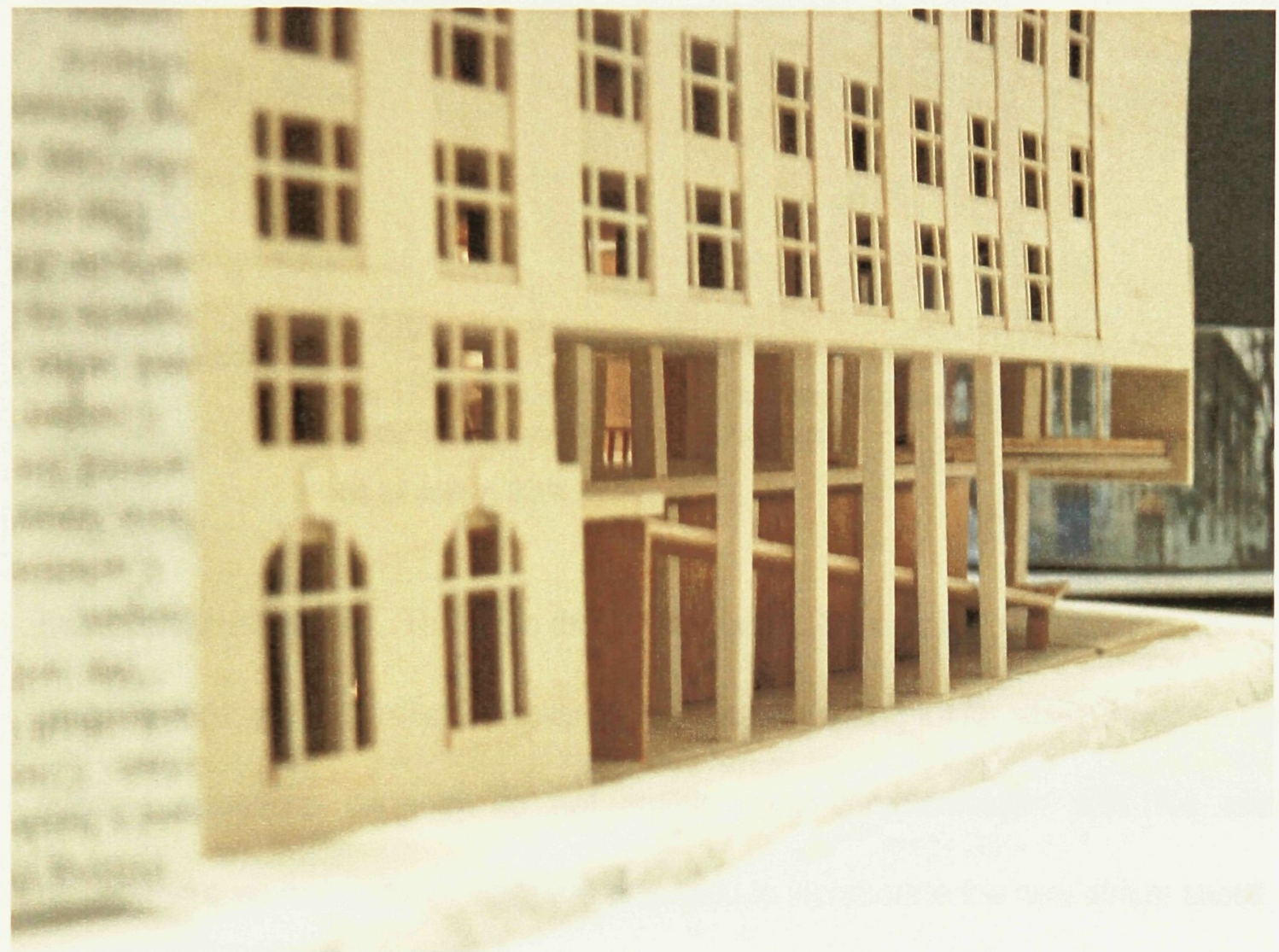

Figure 37. Exterior facade opens up to Carrall Street.

Photo by author, 2004.

- Changes or interventions to the exterior building façades along Hastings and Carrall Street of the B.C. Electric and Railway Company building are subtle at the upper floors, with the major changes taking place at ground level to make a better relationship between the building and the street. The existing stone façade along Carrall Street is partially removed, opening up the building to facilitate communications to the street. The users in the building 


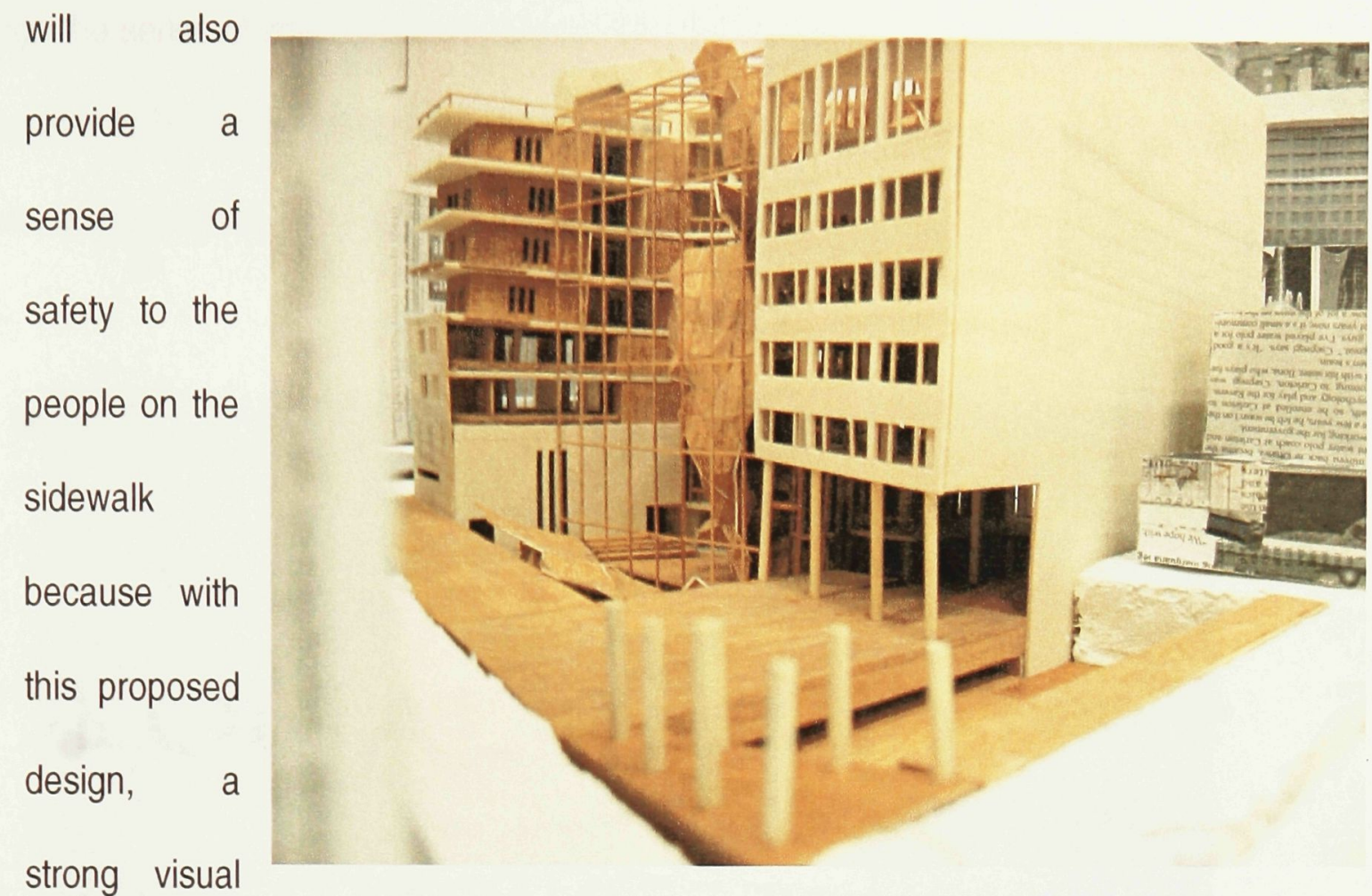

Figure 38. People in the atrium overlook the open space will provide a sense relationship is of safety to the users in the outdoor area.

Photo by author, 2004.

established

between inside and out. The more drastic changes to the building exteriors are also found at the façades that are oriented towards the existing parking lot for similar reason. These building elevations currently do not enable easy communication with the existing environment, so new exterior walls are proposed to incorporate the new atrium space and the climbing wall, and to relate better with the exterior courtyard and the surrounding area. Re-introducing glass panels along the exterior facades might be seen as a provocation to the neighbourhood. In this rough area of the city, where the current scene is filled with broken glass and fenced windows, a glazed atrium and new windows pose a challenge to the area but equally appear as an initial act of trust in the neighbourhood during the rehabilitative period. 
Through the series of interventions proposed above, this vocational school is intended to provide an opportunity for different social groups to interact. The building interventions proposed are part of an on-going process, allowing the building to adapt to different needs at different times.

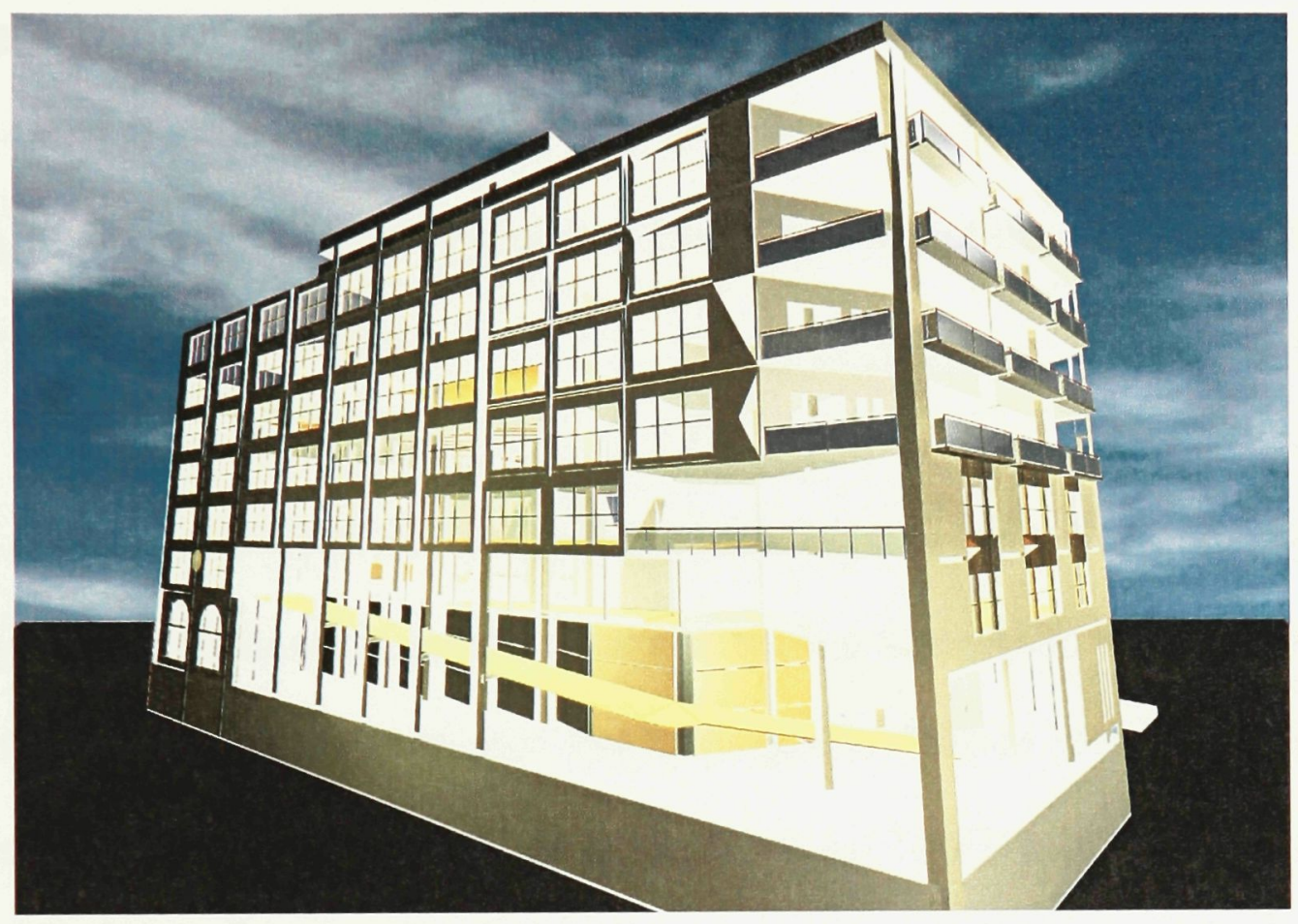

Figure 39. View from northeast.

Image by author, 2004. 


\section{Conclusions}

The primary focus of this thesis was to explore the possibilities and test the effectiveness of appropriating existing drug rehabilitation treatment strategies as a design methodology for the design component of the thesis. Given the hypothetical nature of the design proposal, it is not possible to comment on the actual possibilities of such an approach in a real life situation (the determination of client groups, financing, etc. was considered to be outside the bounds of the thesis), however it is possible to comment on the effectiveness of this methodology in the urban and architectural design process.

The drug rehabilitation model was selected partly because it is an activity that is already associated with the area of Vancouver in question, and also because it accurately represents the author's attitude towards a dysfunctional situation: look for the good in someone/something before giving up on it entirely. The author feels that as architects we can benefit from the knowledge gained through the lengthy and intense research that has been done in the area of drug and alcohol addiction, and its conclusions regarding effectiveness of various treatment strategies when applied to dysfunctional or troubled people.

During the initial stages of this thesis when background information was collected, the rehabilitation model directed the research to consider a number of factors related to the specific history and pathology of the site. Changes over time to the social structure, population structure and economic structure were studied and the reasons for certain present conditions of the site became apparent after in-depth research into the history of the area was conducted. In the case of the Hastings Street area in Vancouver Downtown Eastside, the use of alcohol and drugs has always existed; 
however, never in such an extreme situation as today. It is now understood that the lack of family relationships, the displacement between the local population and the labour industries, and the changes in the requirements of labour skills has increased the population's vulnerabilities to alcohol and drug consumption. With this background information, a rehabilitative treatment was tailored for this site in response to its specific needs.

At the urban scale, the rehabilitation model also directed the general design approach to the site. It established a framework for urban and building interventions. Beginning with a detoxification of the entire site, the interpretation of an acupuncture treatment model led to focus being placed on a few specific sites. An effective rehabilitative treatment is one that takes a holistic approach to the subject; in other words, one that considers a person's physical qualities, non-physical qualities (including psychological and spiritual qualities), and the person's relationship with his/her community. The approach of the urban intervention followed a similar framework, the three specific "acupuncture points" being selected based on an evaluation of the structural integrity of the building, the current usage of the building if any, and the architectural significance in the City. These acupuncture points were selected for their potentially positive influence on the overall neighbourhood. The holistic strategy at each acupuncture point generated an overall program for three sites, each with an emphasis on a single component.

At the building scale, the main objective of rehabilitation established the design approach to the building intervention: to work with the existing building and to propose a series of interventions that would allow the building to adapt to the needs of the changing conditions rather than resorting to demolition. The rehabilitation model also helped to generate the precise programs for the proposed vocational school by aligning the objectives of certain drug treatment models with 
possible program objectives of the school. At a more general level, the larger architectural design intentions were also drawn from the rehabilitation treatment objectives: providing spaces that are democratic, that promote communication and exchange, and that are easy to approach, i.e. to avoid an institutional feel, both visually and experientially.

An enormous benefit to the use of rehabilitation treatment strategies in the recovery of a dysfunctional urban fabric is that they can be applied to both urban and building scales. This contributes to a strong coherence and connection between the buildings and the urban environment. Each site has a unique identity, yet there is fluid consistency throughout the neighbourhood.

Based on the author's experience, the rehabilitation treatment model offered an enormously effective design structure for the thesis project; so much so, that the author feels that it would be worthwhile to consider the implications of applying a similar analogy when considering the real life implementation of such a project. In all cases, the focus is on enabling communication and exchange between people and spaces over time with an emphasis on maintaining and enhancing that which is essentially good. 


\section{Bibliography}

Addiction Information Center, "Detox," Alcohol and Drug Abuse Informational Website. $<$ http://www.addictioncareoptions.com/detox.htm>.

Alexander, Bruce K. The Roots of Addiction in Free Market Society. Ottawa: Canadian Centre for Policy Alternatives, 2001.

Allen, Isabel. "Getting Their Act Together." The Architect's Journalvol.207, no.19 (May 1998) 3336.

Berelowitz, Lance. "Yaletown on the Edge." The Canadian Architect vol.40, no.3 (Mar 1995) 2021.

Canadian Press. "City of Vancouver Buys Old Woodward's Building." CTV Website. 2003.

<http://www.ctv.ca/servlet/ArticleNews/story/CTVNews/1043888475689_34?hub=Canada>.

Carnegie Centre Community Association. On Hastings Street: 30 Years of Retail History in Vancouver's Downtown Eastside 1970-2000. 2001. $<$ www. downtowneastside.ca/ccap $>$.

Carnegie Community Centre. DTES Community Play. Carnegie Community Centre Website. $<$ http://www.carnegie.vcn.bc.ca/index.pl/whoweare2>.

City of Vancouver. Community Services: Carnegie Centre: The Downtown Eastside's Livingroom. 2004. <http://www.city.vancouver.bc.ca/commsvcs/CARNEGIECENTRE/>.

City of Vancouver. Community Services: Walking Tour. 2003. <http://www.city.vancouver.bc.ca/commsvcs/planning/heritage/walks/index.htm>.

City of Vancouver. Community WEBpages: Community Statistics. 2001. $<$ <ttp://www.city.vancouver.bc.ca/community_profiles/downtown_eastside/statistics.htm>.

City of Vancouver. DTES Revitalization Community History. 2003. $<h t t p: / / w w w . c i t y . v a n c o u v e r . b c . c a / c o m m s v c s /$ planning/dtes/communityhistory.htm>.

City of Vancouver. Downtown Eastside Revitalization. 2004. <http://www.city.vancouver.bc.ca/commsvcs/planning/dtes/index.htm>.

City of Vancouver. VanMap Public Version. 2004. <http://www.city.vancouver.bc.ca/vanmap/vanmappub.htm>.

Connors, Gerard J., Dennis M. Donovan, and Carlo C. DiClemente. Substance Abuse Treatment and the Stages of Change: Selecting and Planning Interventions. New York: The Guilford Press, 2001. 
Cossey, Keith M., Co-operative Strategies for Sustainable Communities: Community-Based Development Organizations. Sackville: Dept. of Geography, Mount Allison University, 1990.

Davis, Chuck, Marilyn Sacks, and Daniel Wood, ed. The Vancouver Book. North Vancouver: J.J. Douglas Ltd., 1976.

Detox 5 Website. 2002. <http://www.detox5.co.uk/d5/pages/101_intro.html>.

Duncan, William. "The Rebirth of Vancouver's Yaletown," History of Yaletown Webpage, 2004. http://www.mylocation.ca/articles2/yaletownhistory.htmls.

DuPont, Robert L., and John P. McGovern. A Bridge to Recovery: An introduction to 12-Step Programs. Washington, D.C.: American Psychiatric Press, Inc., 1994.

Footprint Community Art Project, Old Vancouver Townsite Waking Tour - Powell Street, Strathcona, Chinatown, and Victory Square. Ed. John Atkins. Vancouver, 2001.

Fosler, R. Scott and Renee A. Berger, ed. Public-Private Partnership in American Cities: Seven Case Studies. Lexington: D.C. Heath and Company, 1982.

Gastown Business Improvement Society. Gastown History. Gastown Website. 2004. $<$ http://www.gastown.org/history/index.html>.

Ghodse, Hamid. Drugs and Addictive Behaviour: A Guide to Treatment. $20023^{\text {rd }}$ Edition. Cambridge: Cambridge University Press, 1989.

Gibaldi, Joseph. MLA Handbook for Writers of Research Papers. New York: Modern Language Association of America, 1999.

Hardwick, Walter, Raymon Torchinsky, and Arthur Fallick. Shaping a Livable Vancouver Region: Public Opinion Surveys. Vancouver: Dept. of Geography, University of British Columbia, 1991.

Hester, Reid K., and William R. Miller, ed. Handbook of Alcoholism Treatment Approaches: Effective Approaches. $19952^{\text {nd }}$ Edition. Needham Heights: Simon \& Schuster Company, 1989.

Holcomb H. Briavel and Robert A. Beauregard. Revitalizing Cities. Washington D.C.: Association of American Geographers, 1981.

Hutton, Thomas A. The Transformation of Canada's Pacific Metropolis: A Study of Vancouver. Ed. France St. Hilaire. Montreal: Institute for Research on Public Policy, 1998.

Jacobs, Jane. The Death and Life of Great American Cities. New York: Random House, 1961.

Jung, John. Psychology of Alcohol and Other Drugs: A Research Perspective. Thousand Oaks: Sage Publications, Inc., 2001. 
Kalman, Harold. Exploring Vancouver 2: Ten Tours of the City and Its Buildings. 1978 Revised Edition. Vancouver: University of British Columbia Press, 1974.

Kamin, Blair. "The Latest Chapter in the CabriniGreen Saga: Can Public Housing be Reinvented." Architectural Record. vol.185, no.2 (Feb 1997) 84-89.

Kasl, Charlotte Davis. Many Roads, One Journey: Moving Beyond the Twelve Steps. New York: HarperCollins Publishers, Inc., 1992.

Knight, Rolf. Along the No. 20 Line: Reminiscences of the Vancouver Waterfront. Vancouver: New Star Books Ltd., 1980.

Krestan, Jo-Ann. Bridges to Recovery: Addiction, Family Therapy, and Multicultural Treatment. New York: The Free Press, 2000.

Landry, Mim J. Understanding Drugs of Abuse: The Processes of Addiction, Treatment, and Recovery. Washington D.C.: American Psychiatric Press, Inc., 1994.

MacLeod, Greg. New Age Business: Community Corporations That Work. Ottawa: Canadian Council on Social Development, 1986.

Mitchell, Jr., Richard G., Mountain Experience: The Psychology and Sociology of Adventure. Chicago: The University of Chicago Press, 1983.

Narcotics Anonymous. Narcotics Anonymous. $19885^{\text {th }}$ Edition. Van Nuys: World Service Office, Inc., 1982.

Morley, Alan. Vancouver: From Milltown to Metropolis. $19743^{\text {rd }}$ Edition. Vancouver: Mitchell Press, 1961.

Payne, Peter. Martial Arts: The Spiritual Dimension. Ed. Jill Purce. New York: Crossroad Publishing Company, 1981.

Perry Stewart E. Communities on the Way: Rebuilding Local Economies in the United States and Canada. Albany: State University of New York Press, 1987.

Perry Stewart E., and Mike Lewis. Reinventing the Local Economy: What 10 Canadian Initiatives Can Teach Us about Building Creative, Inclusive, and Sustainable Communities. Vernon: Centre for Community Enterprise, 1994.

Perry Stewart E., Mike Lewis, and Jean-Marc Fontan. Revitalizing Canada's Neighbourhoods: A Research Report on Urban Community Economic Development. Vernon: Centre for Community Enterprise, 1993.

Ratcliff, Richard U. Private Investment in Urban Redevelopment: A Study of the Disposal Phase in Urban Renewal. Berkeley: University of California, 1961. 
Seivewright, Nicholas. Community Treatment of Drug Misuse: More Than Methadone. Cambridge: Cambridge University Press, 2000.

Shier, Reid, ed., Stan Douglas: Every Building on 100 West Hastings. Vancouver: Contemporary Art Gallery, 2002.

Stimmel, Barry. Alcoholism, Drug Addiction, and the Road to Recovery: Life on the Edge. New York: Haworth Medical Press, 2002.

Storyeum Website. 2004. <http://www.storyeum.com/bk4.html>.

Tomalty, Ray. The Compact Metropolis: Growth Management and Intensification in Vancouver, Toronto, and Montreal. Toronto: ICURR Publications, 1997.

Turrell, James. James Turrell: First Light and Catso White, contributors Josef Helfenstein and Christoph Schenker. Stuttgart : Edition Cantz, 1991.

Van Wormer, Katherine. Alcoholism Treatment: A Social Work Perspective. Chicago: Nelson-Hall Publishers, 1995.

Vancouver Community College Website. 2004. <http://www.vcc.bc.cal>.

Waldern, Barbara, and Todd Keller. Private Security Guards Patrolling Public Areas: Just What Are They Doing and Do They Have Any Legal Right Being There at All? Vancouver: Main \& Hastings Community Development Society, 1999.

Walk Vancouver Website. 2001. <http://www.walkvancouver.com/yaletown/>.

Wallace, Barbara C., ed. The Chemically Dependent: Phases of Treatment and Recovery. New York: Brunner/Mazel, Inc., 1992.

What is Massage Therapy. Massage Network Website. $<$ <ttp://massagenetwork.com/massage_therapy.html>.

Wismer, Susan, and David Pell. Community Profit: Community-Based Economic Development in Canada. Ed. Maureen Hollingworth. Toronto: Is Five Press, 1981.

The Working Lives Collectives, Working Lives - Vancouver 1886-1986. Vancouver: New Star, 1985. 


\section{Appendix A: Drawings and Images}

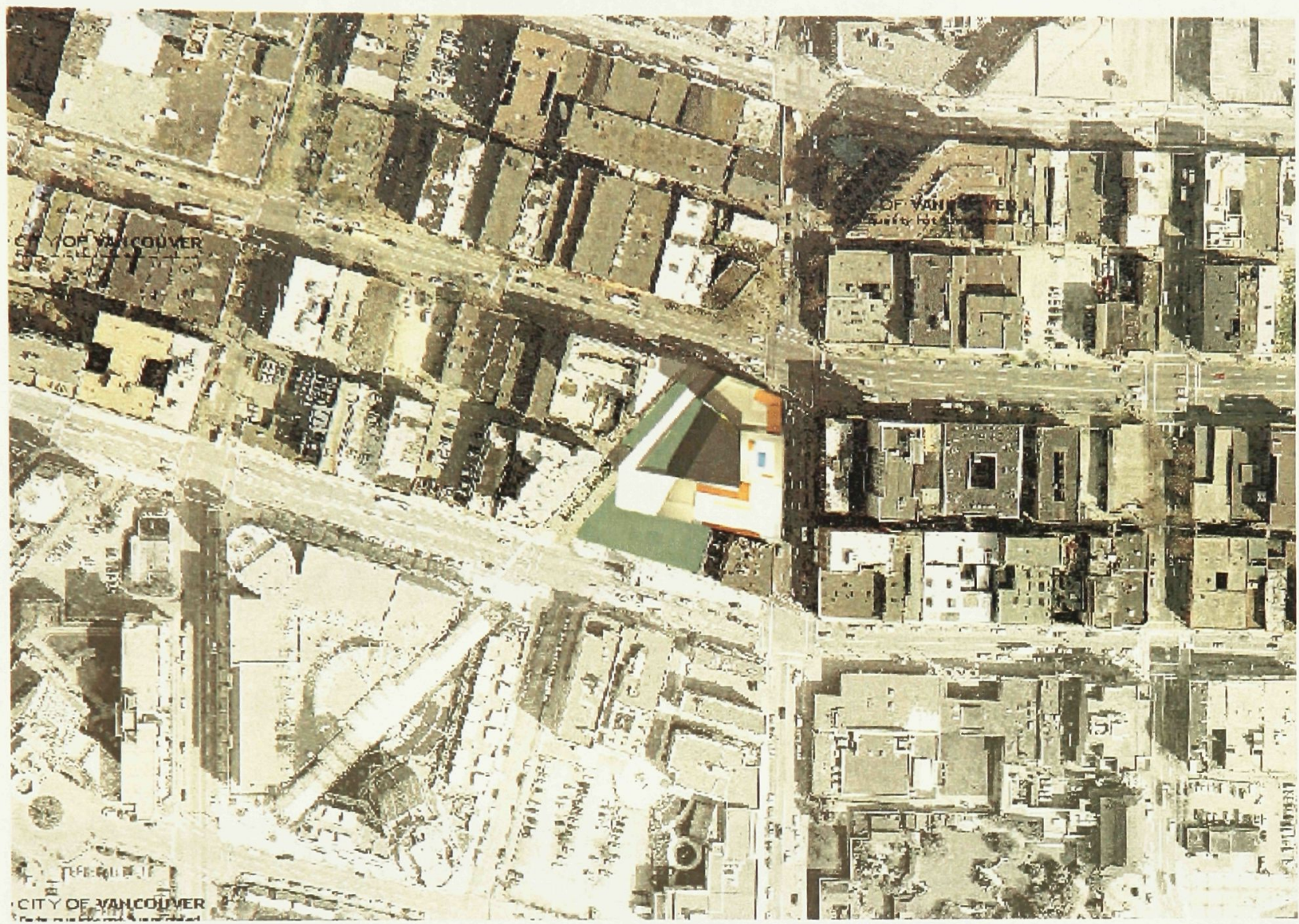

Drawing 1. Site plan.

Image by author, 2004. 


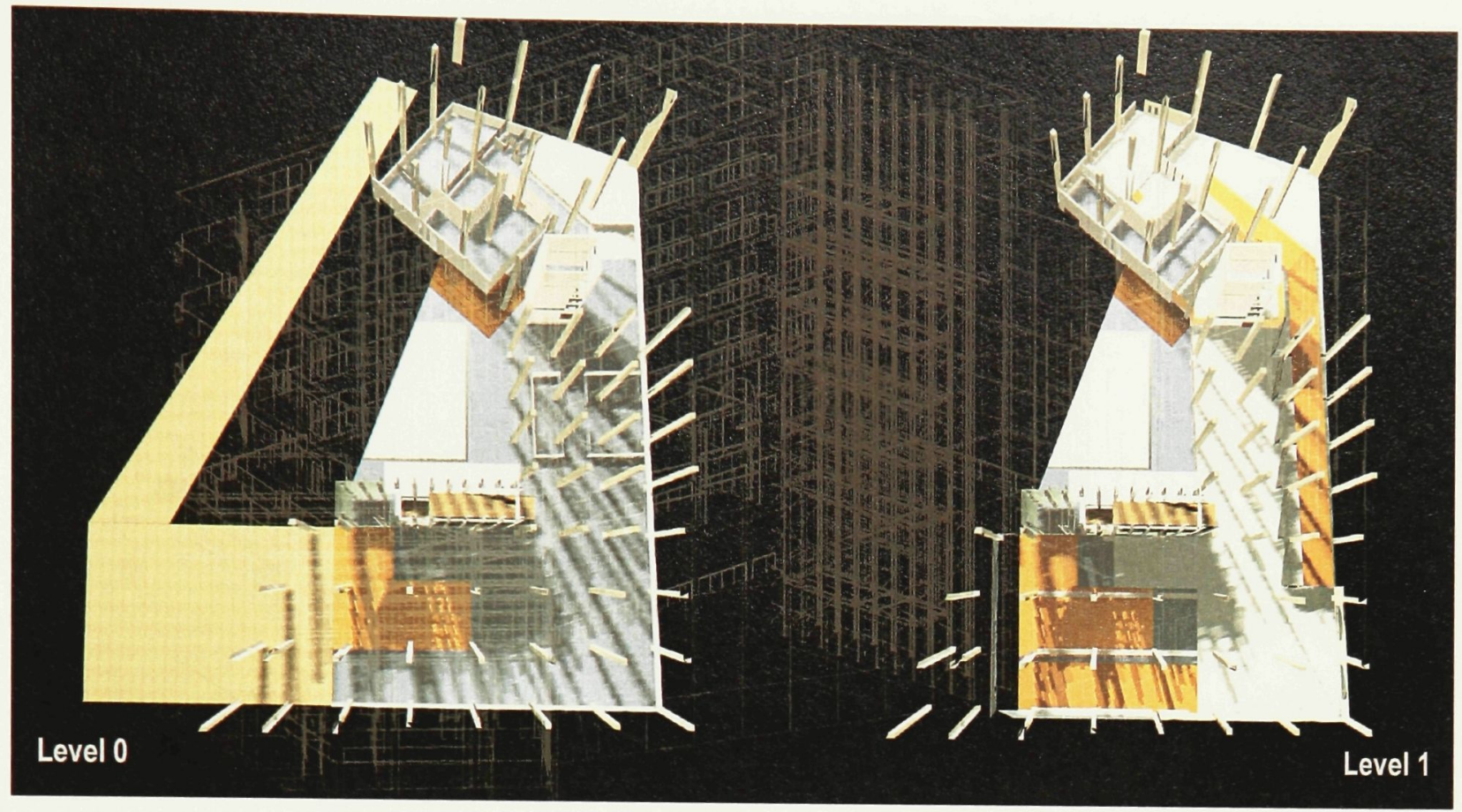

Drawing 3. Building plans.

Image by author, 2004.

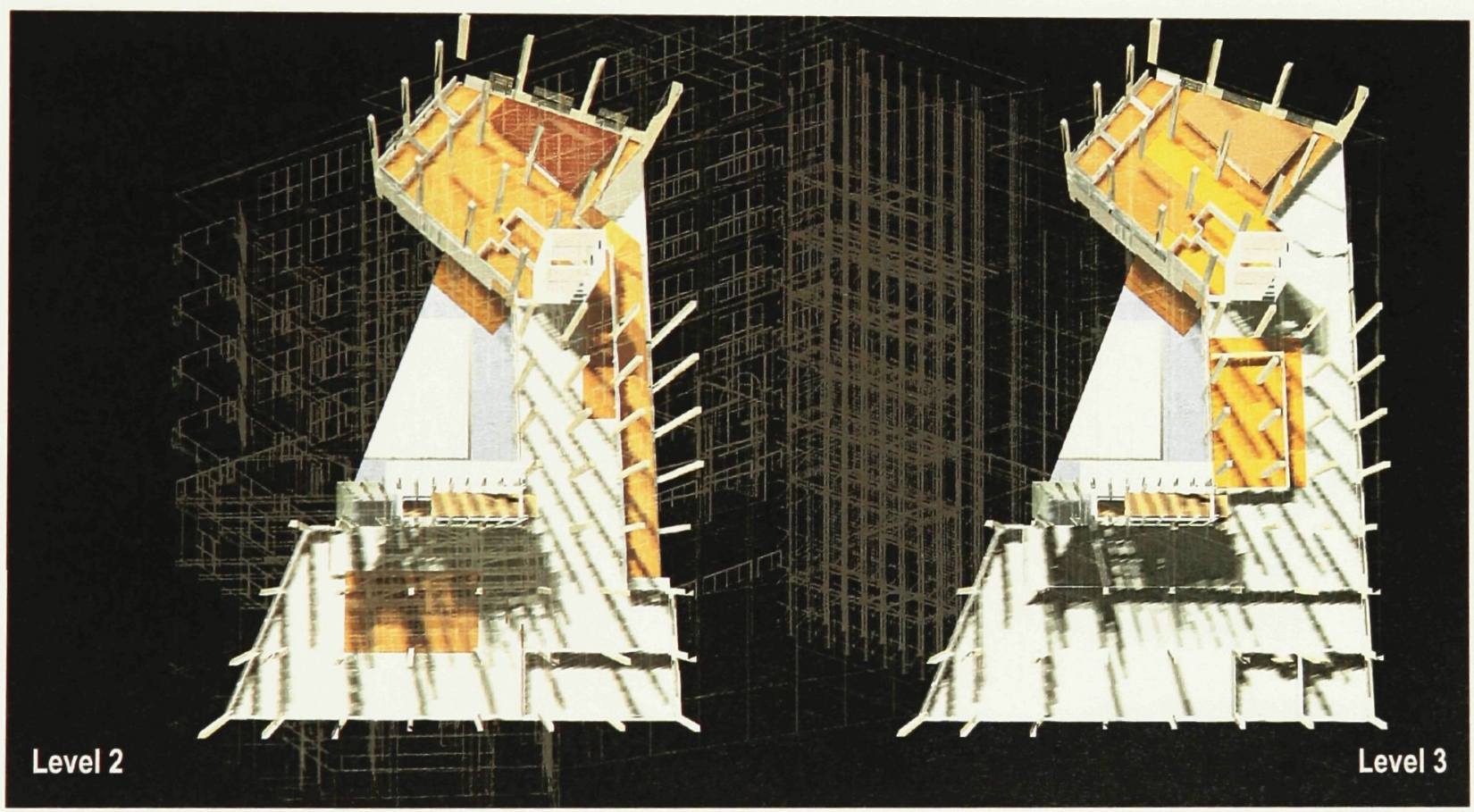

Drawing 2. Building plans.

Image by author, 2004. 


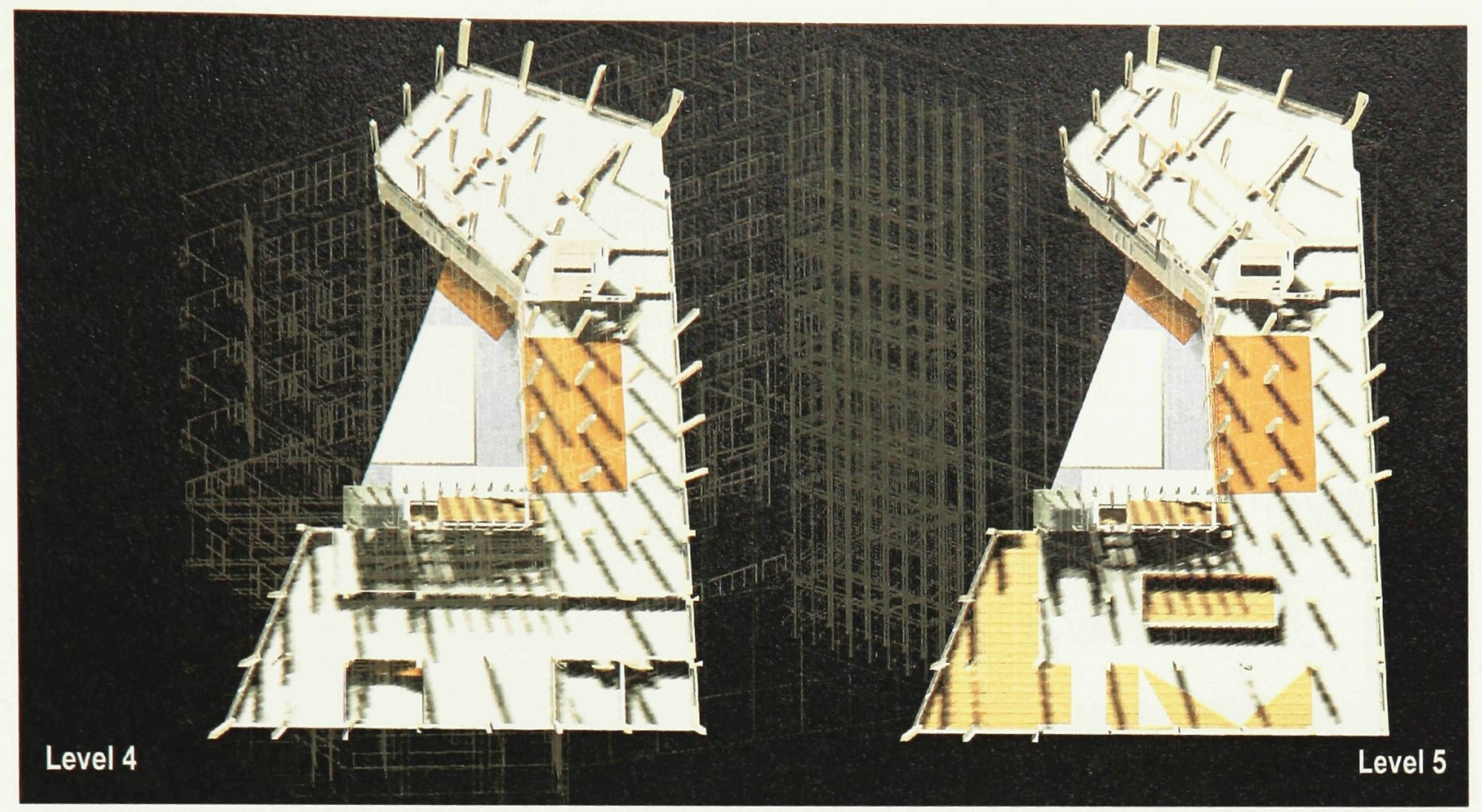

Drawing 5. Building plans.

Image by author, 2004.

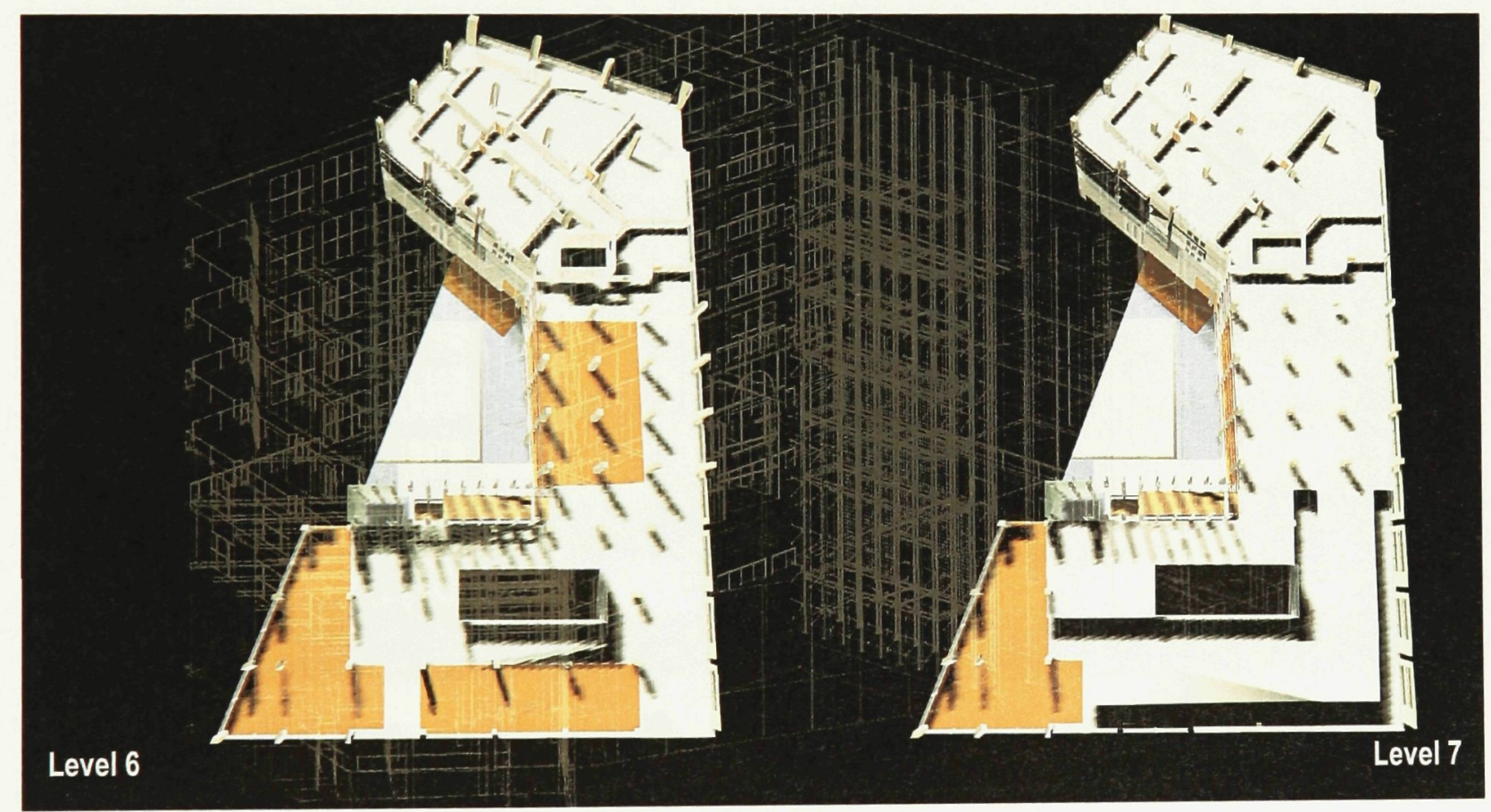

Drawing 4. Building plans.

Image by author, 2004. 


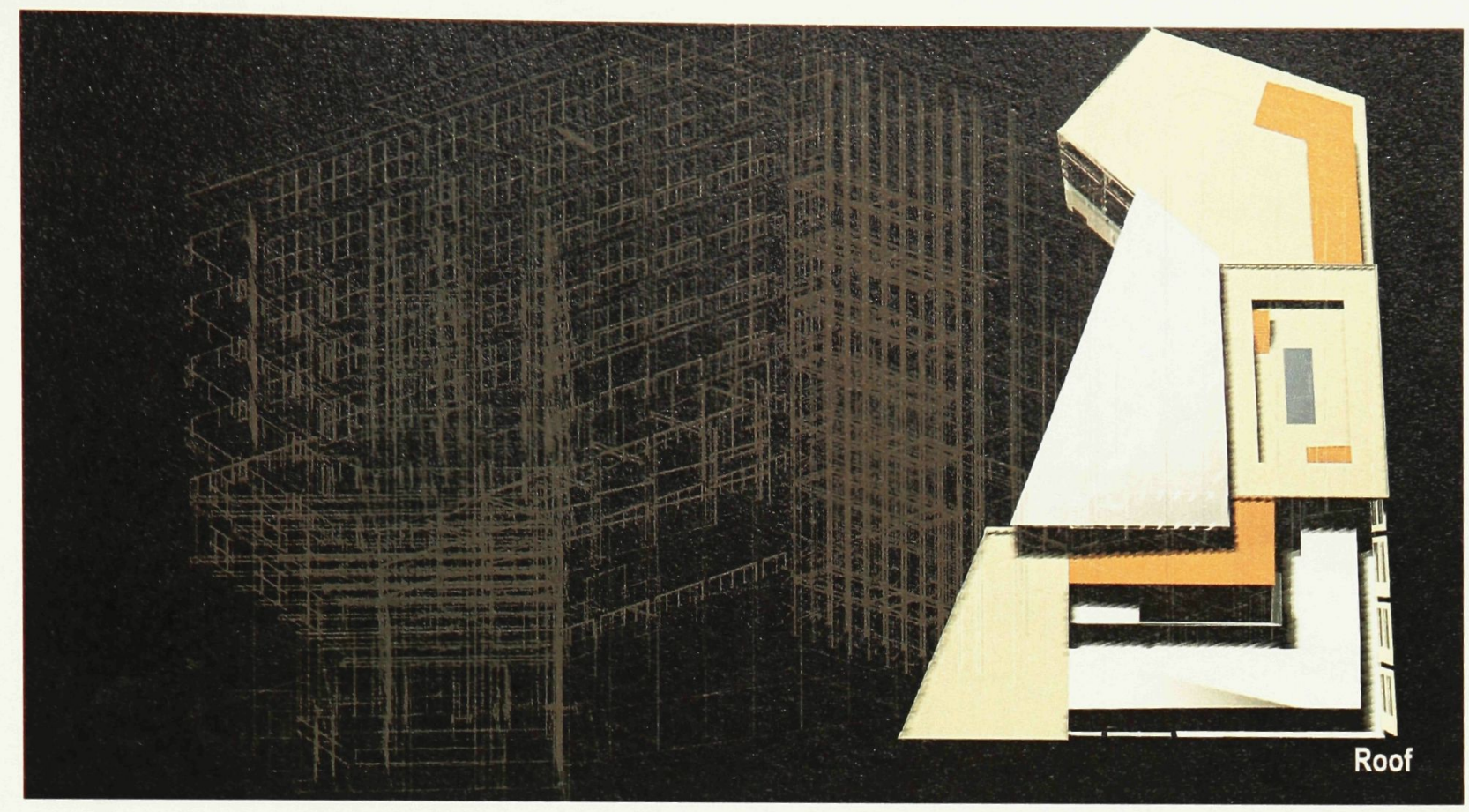

Drawing 6. Building plan.

Image by author, 2004.

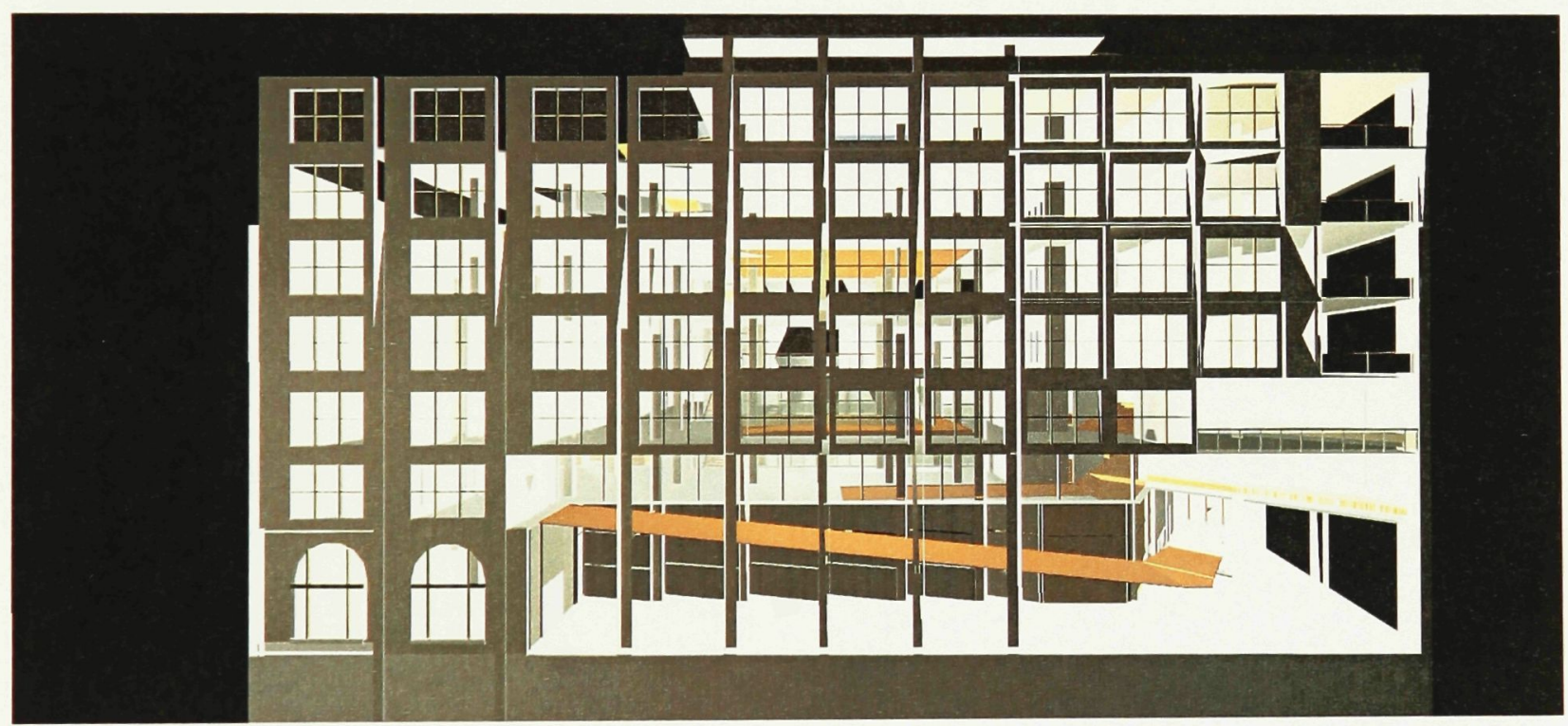

Drawing 7. East elevation.

Image by author, 2004. 


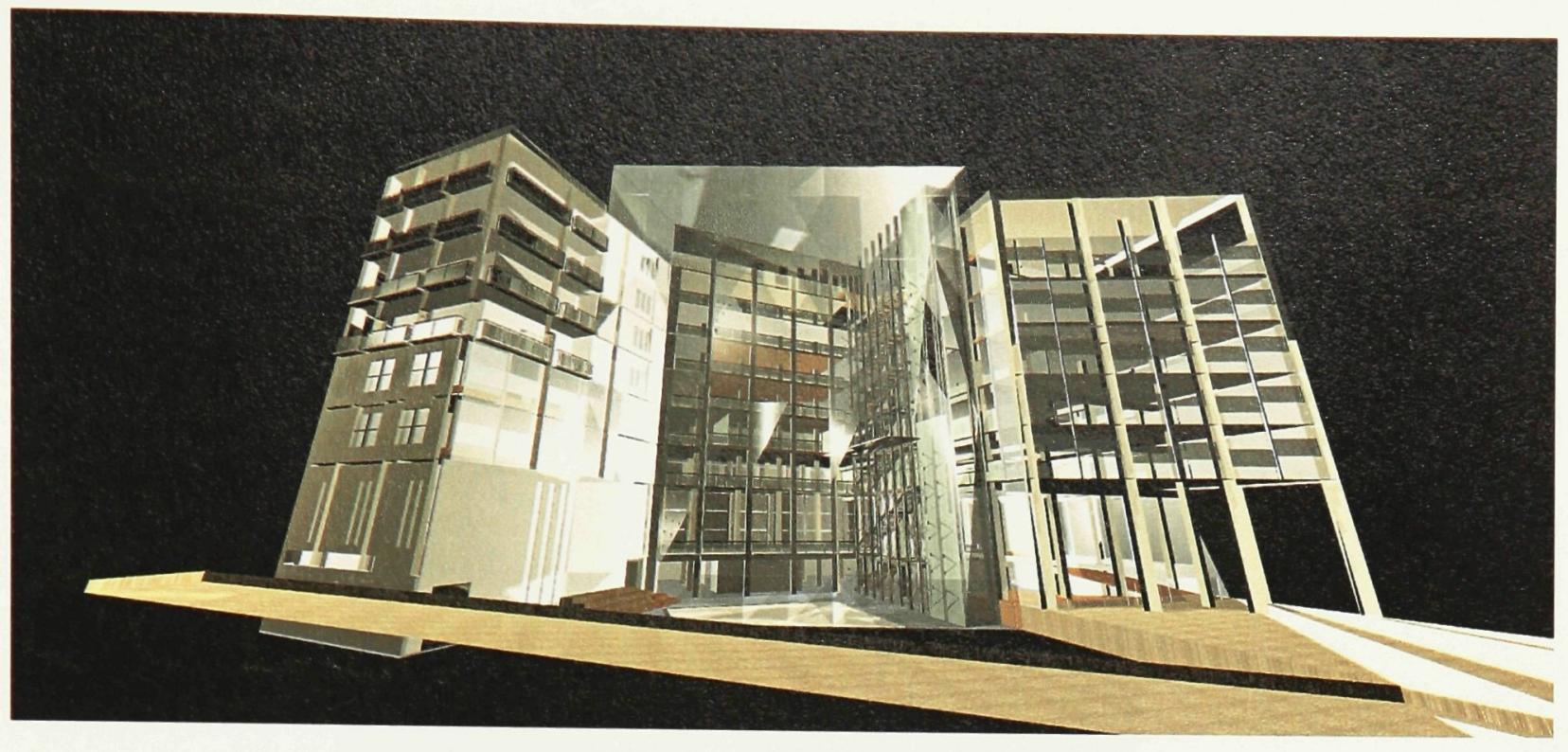

Drawing 8. West elevation.

Image by author, 2004.

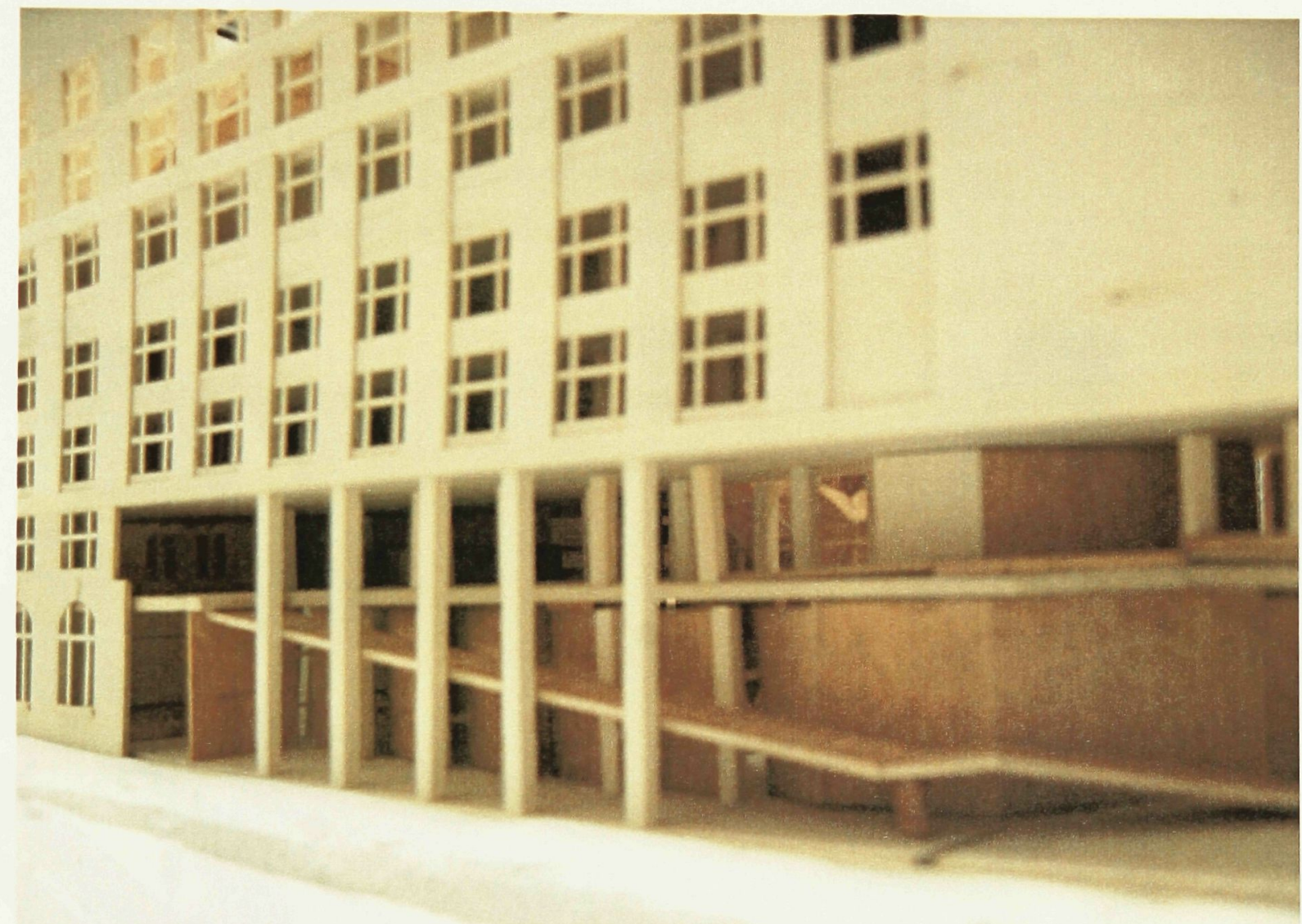

Image 1. Interventions proposed for the Carrall Street facade.

Image by author, 2004 


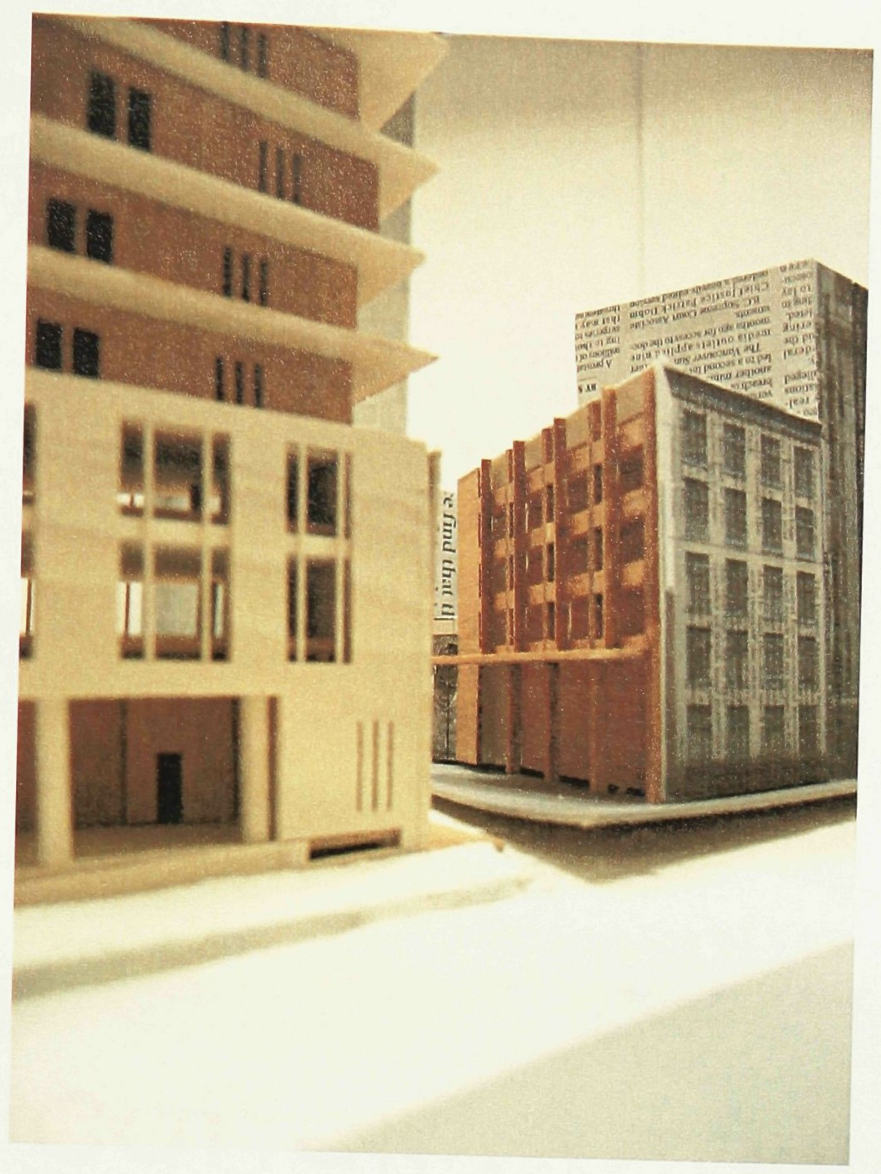

Image 2. A view from Hastings Street.

Image by author, 2004.

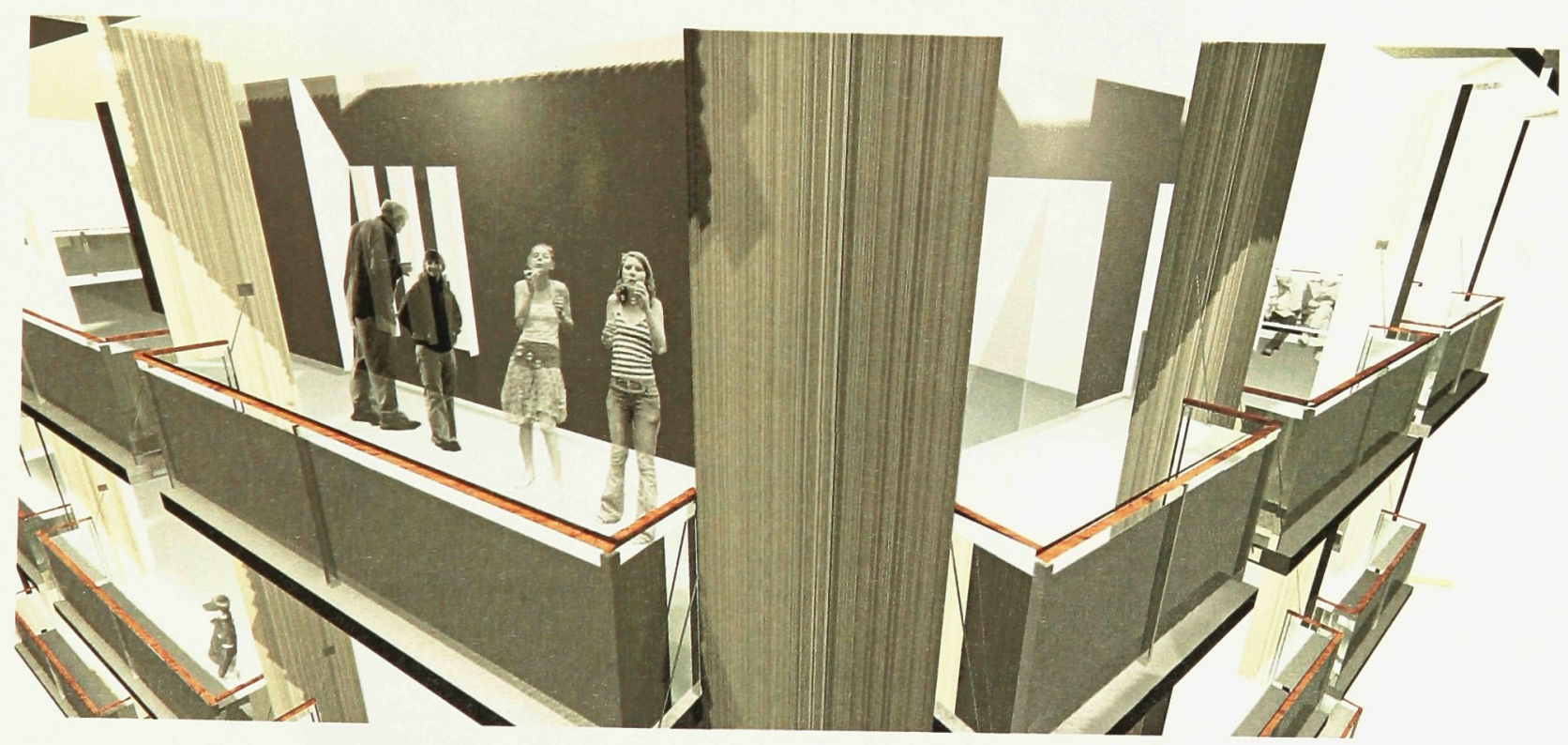

Image 3. Common balconies of the residential units.

Image by author, 2004. 


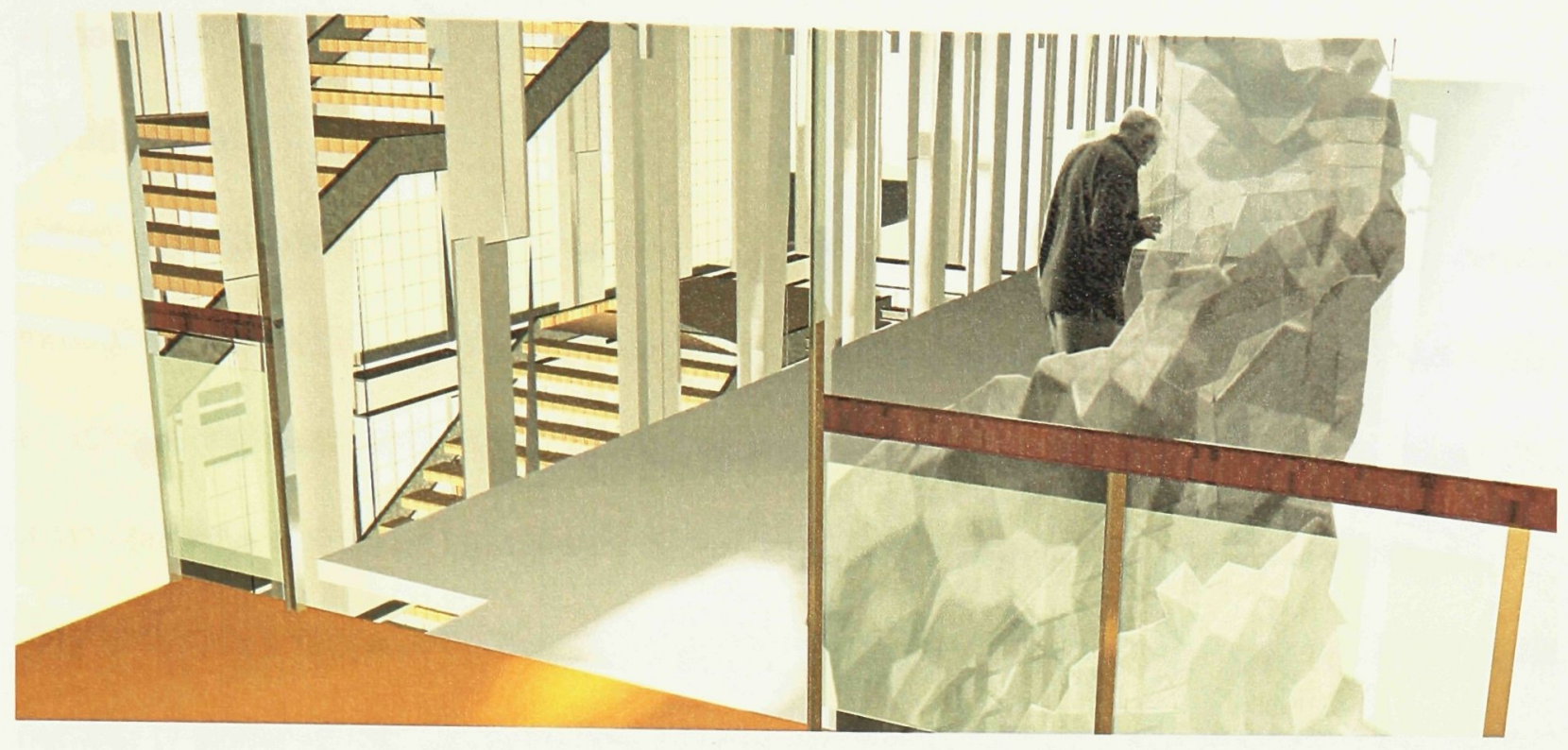

Image 4. A rest spot of the rock climbing wall. .

Image by author, 2004.

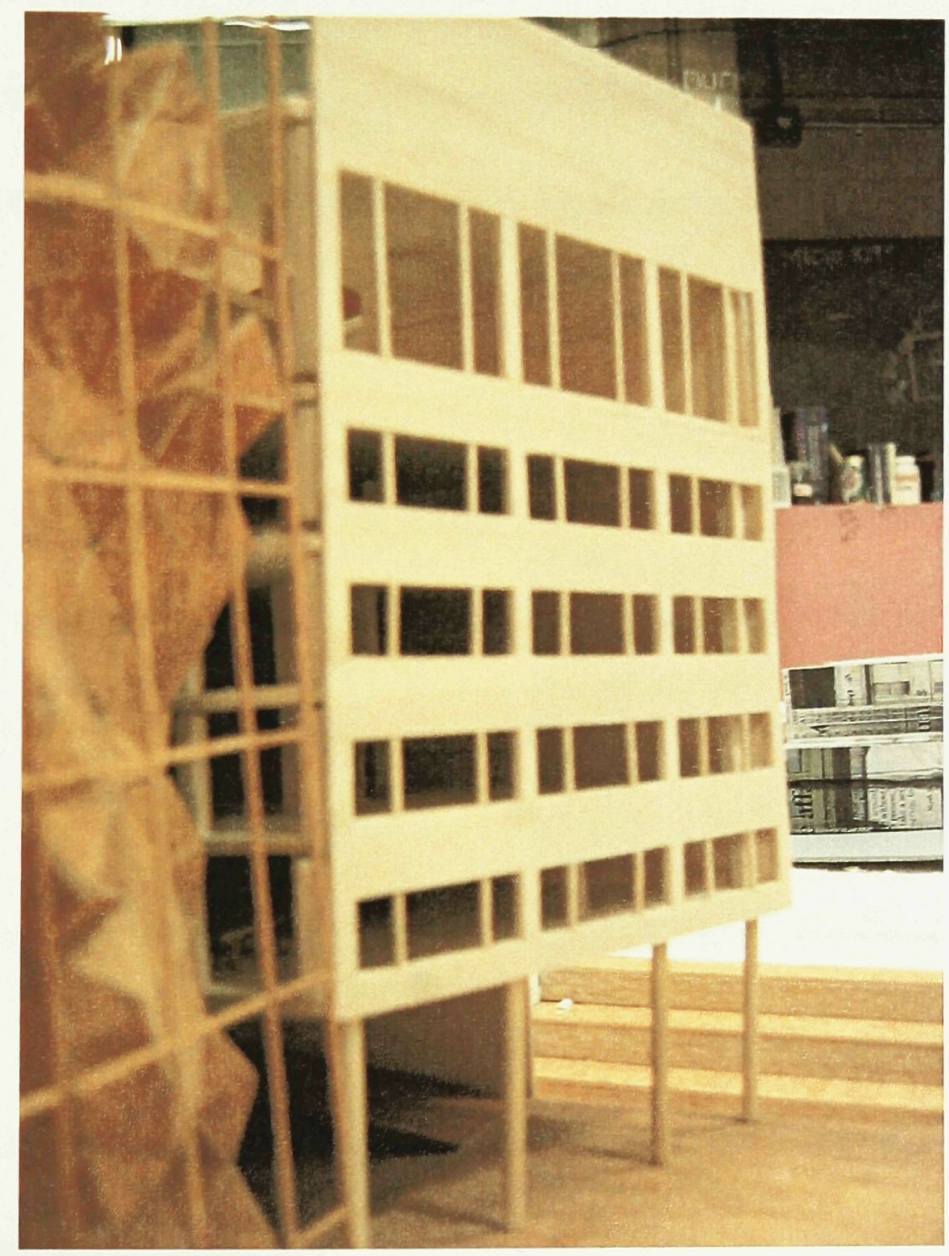

Image 5. New windows and glazing proposed for the facades facing the open space.

Image by author, 2004. 


\section{Appendix B: Economic Models for Urban Redevelopment Introduction}

Urban redevelopments are complex projects not only because they involve many parties throughout the process but also because there are many strategies that one can adopt and modify to achieve the desirable results. In projects like these, the economic issues are not always the main concerns, but rather the focus is on sustainability of communities because ultimately it is the long term health of the individual communities that dictates the well-being of a city. There are a number of elements that can determine the well-being of city. The obvious indicator is the physical aspect of the built environment. One of the most important elements that determine the scale and the success of an urban redevelopment is the economic model. In many cases, investments from different sectors are critical in transforming a proposal into an actual project. Each urban renewal project takes a specific strategy of the economic model in response to the unique condition of a city and community.

In all redevelopment projects, at least one of three sectors will be involved as the main "developer" or investor of the project; in many cases, projects will involve different combinations of these three in which participation of each may not necessarily have to equal. These three sectors are the private sector, the public sector, and the third sector (MacLeod 1986). All of the organizations or private companies responsible for urban renewal projects belong to one of these sectors, and often a hybrid of them. The main objective of this appendix is to identify the three main sectors in the economic models of urban redevelopment that are common in North America and demonstrate their strategies through case studies. 


\section{Private Sector}

In the realm of private sector, there are private corporations whose interests are land developments. Many of them are involved in urban renewal projectsbecause of their own interests and the economic benefits, fulfilling their private objectives (Radcliff 1961). The structure of the development team is solely determined by the corporation itself, and the projects can be developed by a single land developer or a collaboration of several. The issues of social sustainability, such as the health of community or poverty problems of the residents, are often less influential in a project. However, this does not mean that these social objectives will be jeopardized; this only suggests that the determinants or the driving forces in determining the final outcome of the project may not be the same between the community and the private developer. "The public objective is fully consistent with the objectives of private redevelopers whether they operate independently or in collaboration. It is true that the public objectives may go beyond those of the independent private developer. The public agency may put greater weight on aesthetic values, higher standards, longer-range objectives, and related social goals, but these extensions usually involve no major modifications to the basic land use plan and do not necessarily lead to a program abhorrent to private capital." 45 Proposals for these developments must be approved by different governmental departments such as the planning office and the city; however, they may not need support from the public. This strategy of development relies primarily on the government to express and give direction to the developments, such as providing public space and low-cost housing units in the project that responds to the needs of the community. Public involvement and influence are often indirect in this type of model because the public has no actual participation in the decision-making process; their voices can only be heard through the government agencies. These demands can be

${ }^{45}$ Richard U. Ratcliff, Private Investment in Urban Redevelopment (Berkeley, California: University of California, 1961) 6. 
negotiated and achieved with the land developer by giving them tax incentives, more allowance on building areas and other economic benefits in the project (Holcomb \& Beauregard 1981). The advantage of a private development in urban renewal project is efficiency. Once a proposal is approved by the government, the actual construction time is usually within the proposed schedule.

The type of redevelopment a land developer proposes depends on his/her private commitments. Some investors are "primarily interested in a long-term investment which will yield a regular return; others are primarily interested in the potential for capital gain. Individuals may shift from one to the other as circumstances change. The chance of capital gain is not overlooked by the long-term investors, and those who hope for a capital gain are aware of the advantages of a regular and substantial return as they await the strategic time to liquidate the investment." ${ }^{46}$ Again, this type of redevelopment project relies on the government to negotiate with the land developers if they share a common goal for the project. There are different approaches in site transformation that the private land developers may adopt; but gentrification is a common practice by private developers in recent years because this method of site transformation has proven to be quite successful in generating revenue for the developers in previous projects.

A private investor will evaluate a number of issues before commencing a project proposal; these evaluations are productivity analysis, risk and uncertainty, and entrepreneurial calculations. Productivity analysis is a forecast of what net income the prospective property will produce. The prediction will be used to estimate the return on the equity capital after income tax, of cash flow, and the probability of gain and loss. This analysis is conducted by an expert in real estate by

${ }^{46}$ Richard U. Ratcliff, Private Investment in Urban Redevelopment (Berkeley, California: University of California, 1961) 11. 
evaluating the dynamic aspect of the community and future predictions. ${ }^{47}$ Evaluation of risk and uncertainty is a forecast on the probable level of income. Evaluations of the project are made by calculating the differences between the certainty (from existing site information) and the uncetainty (predictions made from the existing information) of the project (Ratcliff 1961). Entrepreneurial calculation is an estimate of maximum return and minimum cash investment in minimum time. This will determine the type of project an investor will propose for a site, in order for maximum return and the least money and time involved. This calculation is extremely important to an entrepreneur because, in determining the total sum of the project that will be involved, it will influence issues such as the amount of cash flow needed during the project, the rate of interest of a loan with the bank and the amount of depreciation of the building materials. ${ }^{48}$

\section{Private Sector Investment - Case Study}

The former site of Expo 86 was partially sold for redevelopment to a private land development company, Concord Pacific. The first phase of the redevelopment, known as Yaletown Edge, began as a five acre site north of False Creek along Pacific Boulevard. It was completed in 1995. The project consists of eight towers, a street wall, and a public park. There are a total of 726 residential units of which 20 percent are non-profit housing, in line with Vancouver's planning and housing development policy. ${ }^{49}$ The project also took into consideration the existing urban fabric by keeping the new residential towers to an acceptable scale relative to the old warehouses in the area. Though the entire project development is intended to span over 20 years, the efficiency in construction time of this first stage is known locally (Berelowitz 1995). However, there are a few

${ }^{47}$ Richard U. Ratcliff, Private Investment in Urban Redevelopment (Berkeley, California: University of California, 1961) 11.

${ }^{48}$ Richard U. Ratcliff, Private Investment in Urban Redevelopment (Berkeley, California: University of California, 1961) 11.

49 Lance Berelowitz, "Yaletown on the Edge" The Canadian Architect 40 (1995): 21. 
issues regarding the sustainability of this community that this project has overlooked. First, the developer was inconsistent in responding to the local housing and community needs. Although this development has satisfied the government's requirement of non-profit housing, the type of community that the developer is promoting is rather selective to social groups, mainly for the affluent. There is a strong sense that the developer is transforming this area into a similar setting of Manhattan's SoHo (Berelowitz 1995) where one will find some of the most expensive restaurants in town, or shops that sell "lifestyle" objects such as designer furniture and other home ware. Second, the lack of government involvementin this project has jeopardized the sustainability of the community. "Given the declining federal and provincial levels of financial support, nonmarket housing sites within larger developments such as this will increasingly be left un-built, missing teeth awaiting expensive bridgework with no-one willing to pick up the tab."50 Within this site of development there is a block dedicated to a senior and family normarket housing that is still undeveloped. Third, the developer has chosen to market a majority of these residential units outside Canada. Although responses in the sales to this development were at times quite positive, the area is vulnerable to the issues of sustainability due to the lack of residents in the areas at the beginning (Berelowitz 1995).

\section{Public Sector}

Public sector includes governmental agencies and government-sponsored (non-profit) organizations. Although the amount of investment is still one of the primary concerns of the public sector, they also put greater weight on the longer-range objectives, the sustainability of the community, and provisions of facilities in the redevelopment. Projects are usually inclusive of all social classes. Since urban redevelopment requires large sums of investment, government-direct

50 Lance Berelowitz, "Yaletown on the Edge" The Canadian Architect 40 (1995): 21. 
involvement in these projects is diminishing. Usually the government is involved in the development of infrastructure and public buildings components of such projects. Infrastructure and public buildings include, but are not limited to, road work, highway-building, public transportation, schools, hospitals, cultural buildings, and civic facilities (Perry \& Lewis 1994). The disadvantage of this type of investment in redevelopment is the time and cost required. Since the various governmental agencies involved in such projects are usually many, and their organizational structures often complex, then when the public organizations, especially governmental agencies, become the sole investor of a project, the process of carrying out such projects can be inefficient; causing the project to fall behind schedule and increasing the cost of the entire redevelopment (Fosler \& Berger 1982).

\section{Public Sector Investment - Case Study}

The Cabrini-Green district is one of the most problematic public housing complexes in Chicago. Along Lake Michigan, the area spans over three-quarters of a mile, adjacent to some of the most affluent areas in Chicago including a district known as the Gold Coast, as well as the boutiques of Oak Street, which cater to talk-show hosts, the billionaire Pritzker family, and those who are merely millionaires. ${ }^{51}$ Despite living in such proximity, the typical Cabrini-Green family of four has an annual income of just $\$ 4,000$; they are often referred as the "poorest of the poor. 52 Public housing in this area began during the $19^{\text {th }}$ century when numerous immigrants from Europe came to this city; since the 1940's, this area has been mostly occupied by AfricantAmericans. The development also evolved from barracks-like row-houses built during the 1940's to high-rises built during the

\footnotetext{
51 Blair Kamin, "The Latest Chapter in the Cabrini-Green Saga: Can Public Housing Be Reinvented?" Architectural Record 185 (1997): 85.

52 Blair Kamin, "The Latest Chapter in the Cabrini-Green Saga: Can Public Housing Be Reinvented?" Architectural Record 185 (1997): 84.
} 
1950's and the1960's. Inspired from modernist thinking, the intention of this housing complex was create a notion of "tower in the park" where light, air, and green spaces were the focus of the project. There are 65 to 144 units in each residential tower, a density that is only desirable when the majority of the residents are in the work force; unfortunately, many of the residents are jobless, staying at home, and there have been ongoing incidents that worsen the situation (Kamin 1997).

In 1993, the Chicago Housing Authority (CHA) began a proposal to revitalize the area, but because $\mathrm{CHA}$ was involved in a series of scandalous incidents, the project did not start until the Federal government became involved in 1995. The redevelopment of Cabrini-Green was fully supported by the Mayor of Chicago in 1996. The total sum of the project has been estimated to be $\$ 700$ million, all funded by the government. The revised proposal submitted by the Mayor includes a series of low-rise townhouses and flats, in which public housing units will be indistinguishable from those selling at market rates, as well as public schools, parks, a police station, and stores..$^{53}$ The objectives of the redevelopment are not only to revitalize the area, but also to keep it a sustainable area and to reconnect to the rest of the city.

Although the government began the redevelopment project with good intentions, there are other social issues that this project did not fulfill. The most serious issue is the relocation of the residents. The public residential units in the new development are not affordable for most of the (word choice - 'previous' or 'original' assuming you are speaking of something already done in the past) residents. The units are "marketed" for families that make less than 50 percent of the median family income $(\$ 51300)$, a price that is still too high for many of the (original or previous) residents.

53 Blair Kamin, "The Latest Chapter in the Cabrini-Green Saga: Can Public Housing Be Reinvented?" Architectural Record 185 (1997): 88. 
The relocation of these residents was not guaranteed. The other concern of this project is the large amount of investment the government has to commit in order to be involved; jeopardizing the quality of the project. "Money represents another obstacle. If the Midwest economy weakens, so will the now-robust housing markets, affecting the redevelopment's ability to attract middle-income tenants. A lack of capital could hinder the city's ability to carry out the charrette's mandate of reintroducing the street grid and building other infrastructure." 54 Lastly, there is a possibility that the project could be at risk if there are any political changes - an underlying dread - politics could easily scuttle the entire initiative. 55

\section{Third Sector}

The last type of investor in an urban redevelopment project is known as the third sector. While both the public and private sectors are concerned with the formal activities in a redevelopment project, the third sector is more interested in the informal activities (Wismer \& Pell 1981). Formal activities involve an exchange of money, and informal activities are productive and have value but do not require an exchange of money. The third sector is neither private enterprise nor government-sponsored: it includes elements of both. It is also based on an interdependent mixture of social, economic, and cultural goals. ${ }^{56}$ The primary concern of the third sector in redevelopment projects is to respond and fulfill the needs of the community as their priority. Organizations that belong to the third sector do not necessarily have to be non-profit; rather, it is very much their intention to make profits in order to keep their organizations at a healthy financial status. They will invest most of the profit made from the redevelopment project back into the

\footnotetext{
${ }^{54}$ Blair Kamin, "The Latest Chapter in the Cabrini-Green Saga: Can Public Housing Be Reinvented?" Architectural Record 185 (1997): 89.

55 Blair Kamin, "The Latest Chapter in the Cabrini-Green Saga: Can Public Housing Be Reinvented?" Architectural Record 185 (1997): 89.

56 Susan Wismer and David Pell, Community Profit: Community-based Economic Development in Canada (Toronto: Is Five, 1981) 2.
} 
community (Wismer \& Pell 1981) by providing job training programs, continuing education, and career counselling for community members to develop or enhance their career opportunities in the local community. It is common practice for the third sector to hire an independent, non-profit organization to provide the training and manage these economic developments (CHF BC). This strategy of development is an effective technique in maintaining the sustainability of a community because it can keep viable a wide range of economic activities within a community. Also, these local community economic developments can create a stronger sense of community because the people have more control in determining their goals and the future paths of their neighbourhood, as well as establish a stronger sense of self-reliance (Wismer \& Pell 1981). The decision-making committee of the third sector is elected by all members of the community including everyone who can participate and be involved. This new sector is a relatively new concept when compared to the other two sectors; nonetheless, this strategy of development is becoming more and more widely adopted. An example of an organization that falls in this category of a third sector is a business ce op.

\section{Third Sector Investment - Case Study}

The Pinecrest-Queensway district in Ottawa has a population of 55,000 which can be divided roughly into two categories: one is the original middle-class residents who have long used the area as a bedroom community to commute to the offices in downtown Ottawa, the other group is mainly immigrants and low-income families. ${ }^{57}$ This neighbourhood had been struggling with a lack of community sense until 1986 when the West End Community Ventures (WECV) was founded. The organization's objective was to develop a local economy that would eventually revitalize the

57 Stewart E. Perry and Mike Lewis, Reinventing the Local Economy: What 10 Canadian Initiatives Can Teach Us About Building Creative, Inclusive, \& Sustainable Communities (Vernon: Centre for Community Enterprise, 1994) 44. 
community socially, keeping the neighbourhood more sustainable. WECV started with a grant from the government. A portion of the grant was invested in the residents by providing training programs in language (since the community had a diverse group of immigrants, all speaking different languages), workshops on self-employment, and skills development. All the training was targeted to encourage the residents to return to the workforce or to start in a small-scale local business. WECV experienced many difficulties throughout the revitalization process, but in about five years and with the support from many individuals and organizations, WECV was able to establish two local businesses that generated a stable income for the organization. One of the businesses is a "production line" of crafted objects. Since there were a few residents who had the expertise in arts and crafts, they set up training programs for those who were interested and willing to be part of the business development. The other business is a recycling program. They collected and sold un-used office products from private firms and government offices. ${ }^{58}$ Coincidentally, this was when the government no longer supported the organization financially. A stronger sense of community was developed through the process because not only did the residents care for their local economic development but the relationships between each other and the neighbourhood were also enhanced. They had stronger feelings about the sustainability of the community.

One should note that although this strategy of development has been considered as the more successful model, positive results are usually not immediate; they often take a long time to have an effect on the community. In this case, the organization took five years to establish their "profitmaking" businesses. Within this period, they experienced many difficulties or even crises, and

${ }_{58}$ Stewart E. Perry and Mike Lewis, Reinventing the Local Economy: What 10 Canadian Initiatives Can Teach Us About Building Creative, Inclusive, \& Sustainable Communities (Vernon: Centre for Community Enterprise, 1994) 55. 
worried that their businesses would terminate. A community as a whole must be patient with their investment because this model of redevelopment does not give immediate results.

\section{Conclusions}

Urban redevelopments are extremely complicated and require expertise from different disciplines. The economic strategy, being one of the most important elements in a redevelopment project can be generally divided into three main types: private development, public development, and development by the third sector. There are successful stories from each of the sectors individually; in many cases, urban redevelopments are a collaboration of these three main sectors, in response to the different needs of the community. In order to carry out a successful urban redevelopment project, one should examine the existing conditions of the community to determine their needs and then form or organize the most appropriate economic redevelopment model to maintain a sustainable environment. 
Appendix C: Street Front Land Use of 100 block West Hastings to 100 block East Hastings from 1970's to 2001

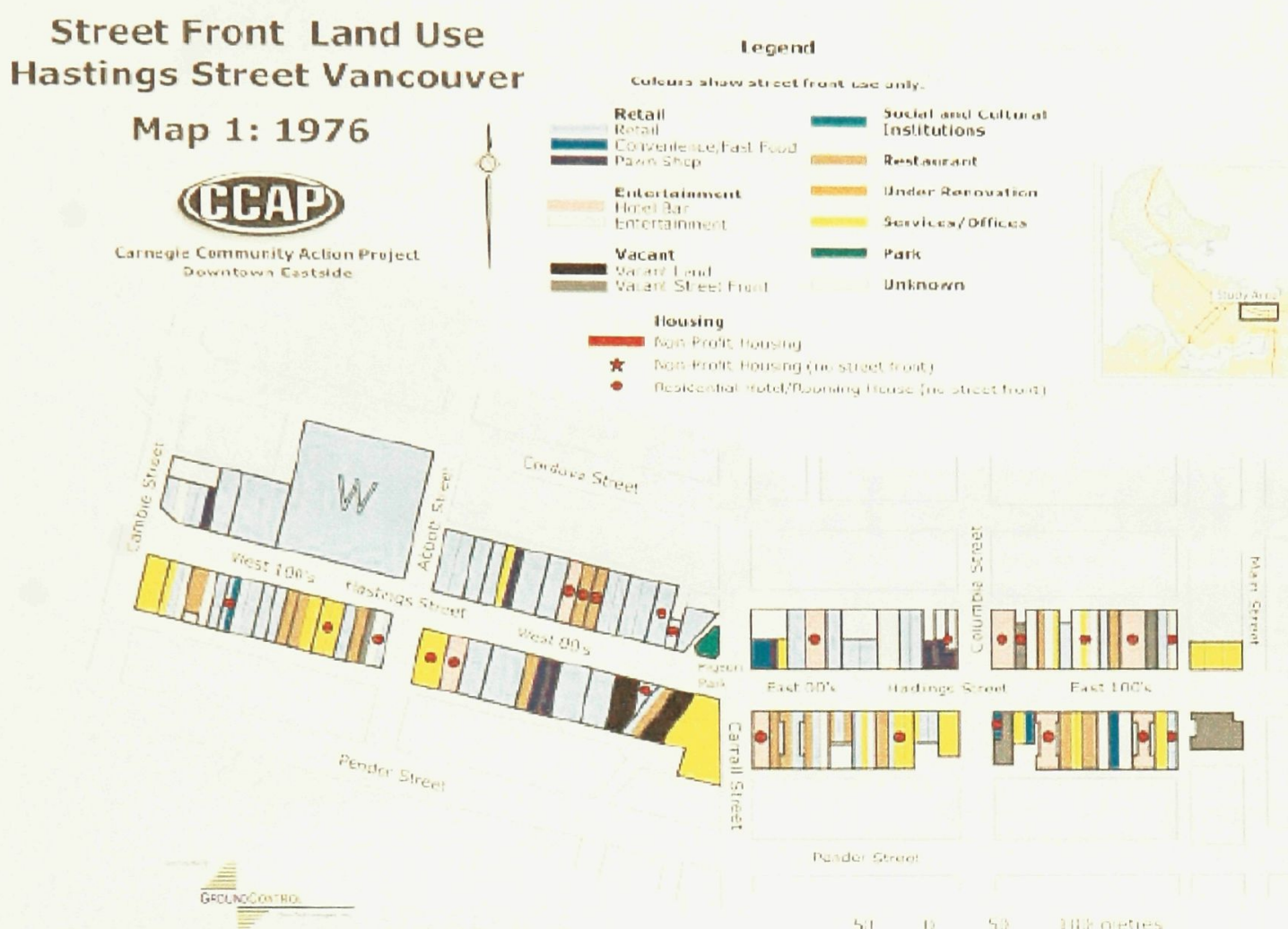

Street Front Land Use Hastings Street Vancouver Map 2: 1986
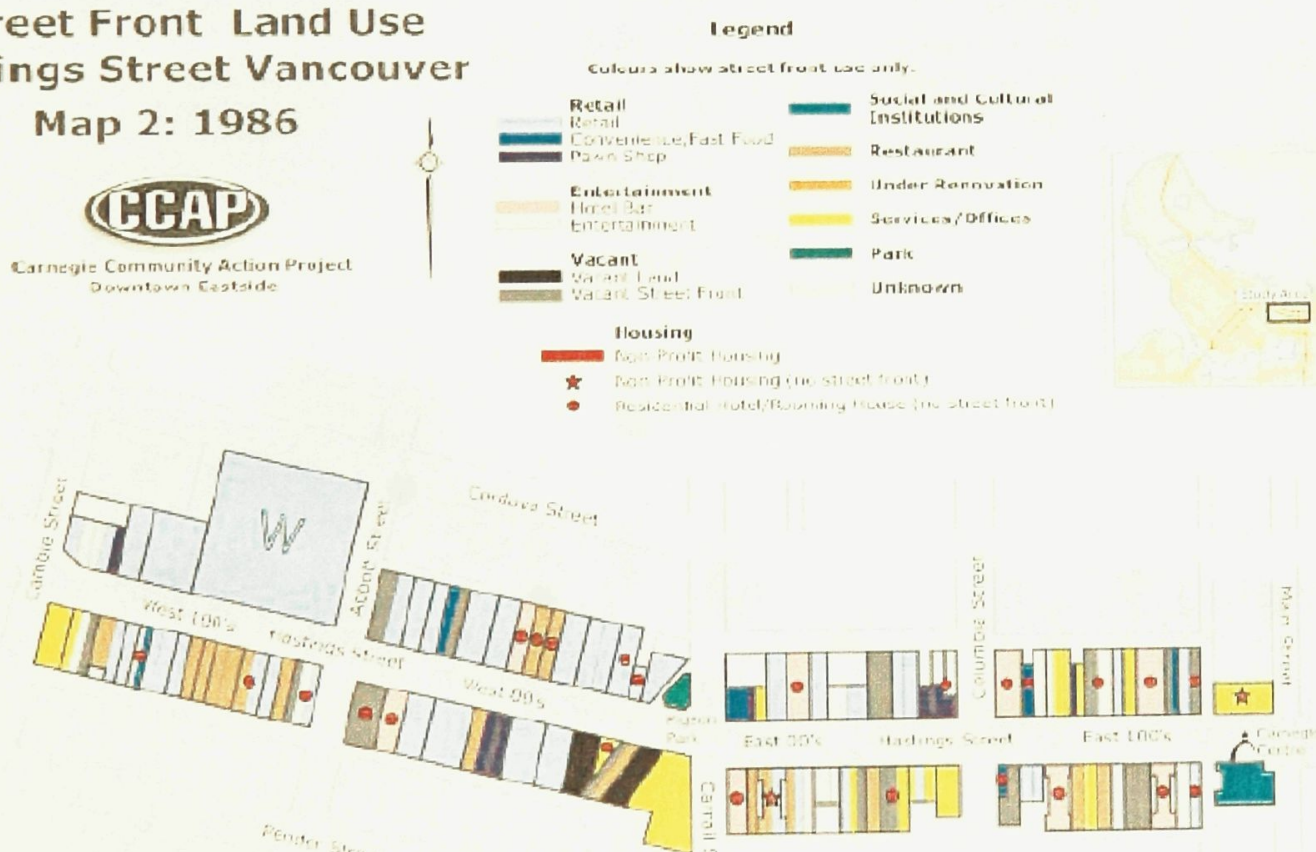


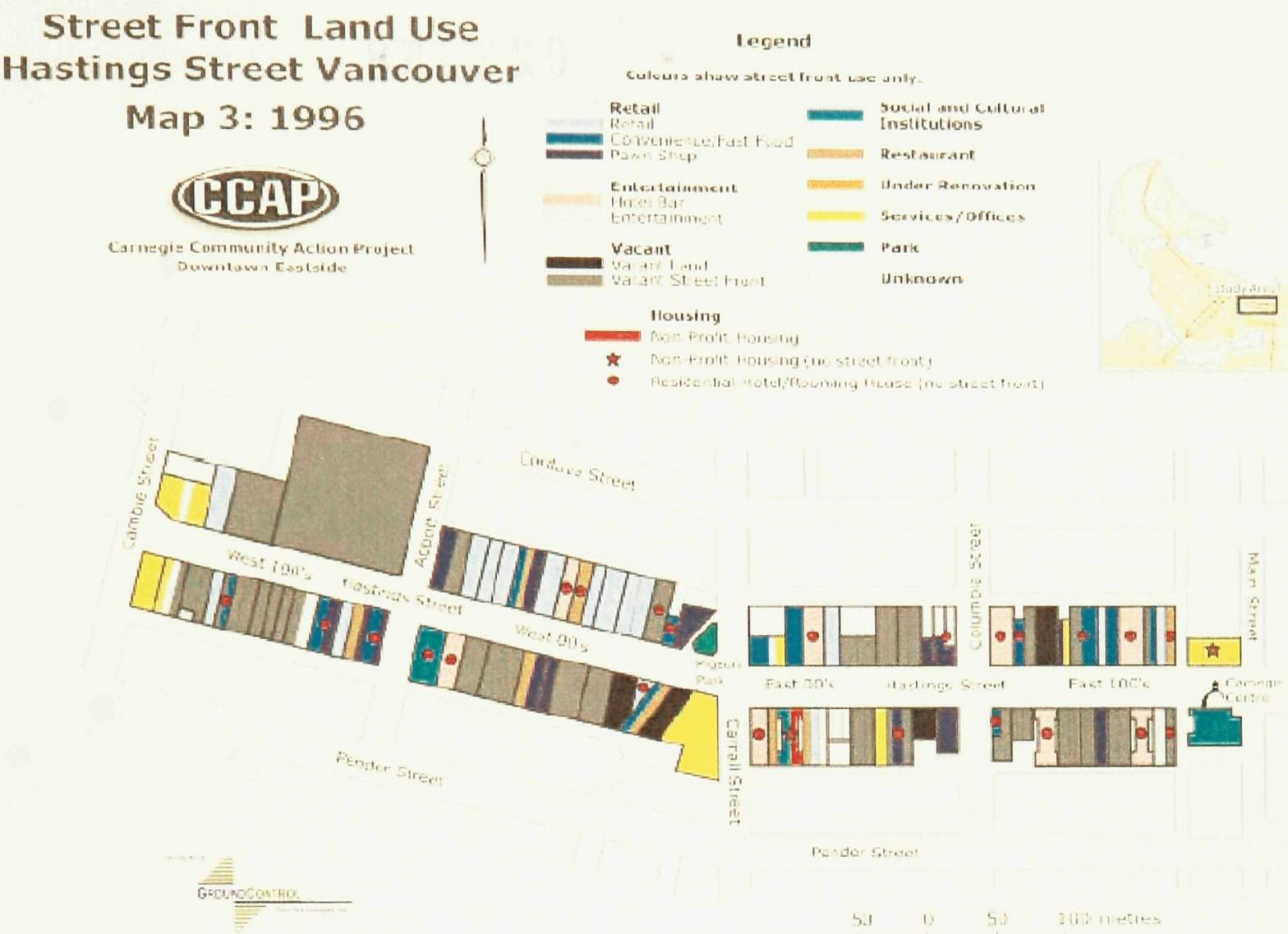

Street Front Land Use Hastings Street Vancouver
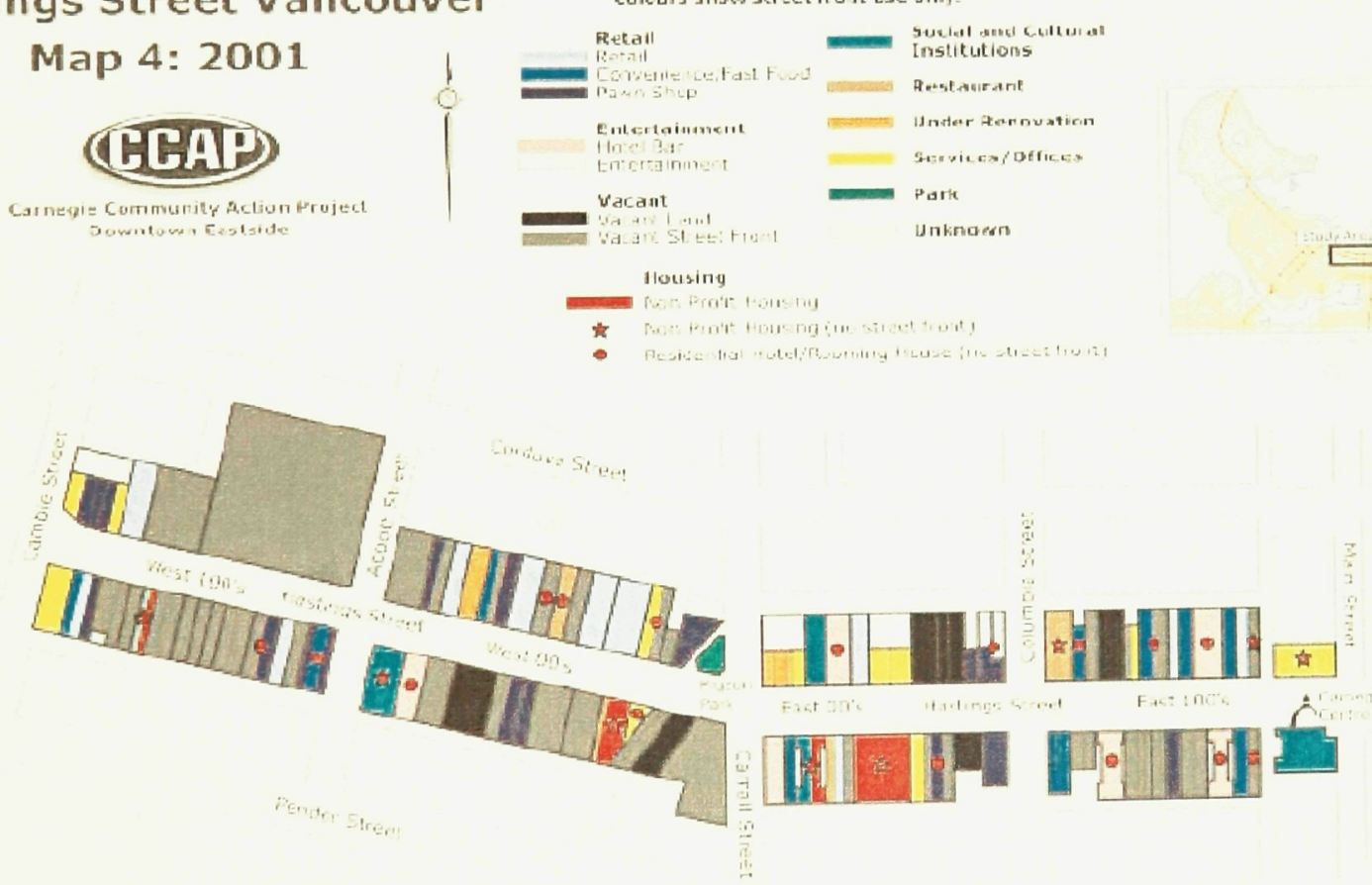